\title{
Electrical Performance Tests for True-RMS Voltmeters
}

R. S. Turgel

O. B. Laug

T. E. Leedy

U.S. DEPARTMENT OF COMMERCE

National Bureau of Standards

National Engineering Laboratory

Center for Electronics and Electrical Engineering

Electrosystems Division

Gaithersburg, MD 20899

March 1988

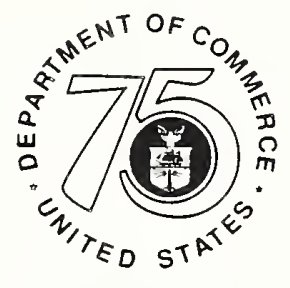

Strmulatıng America's Progress

Prepared for:

U.S. Army Communications Electronics Command

Fort Monmouth, New Jersey 07703 


\section{ELECTRICAL PERFORMANCE TESTS FOR TRUE-RMS VOLTMETERS}
R. S. Turgel
O. B. Laug
T. E. Leedy

U.S. DEPARTMENT OF COMMERCE

National Bureau of Standards

National Engineering Laboratory

Center for Electronics and Electrical Engineering

Electrosystems Division

Gaithersburg, MD 20899

March 1988

Prepared for:

U.S. Army Communications Electronics Command

Fort Monmouth, New Jersey 07703

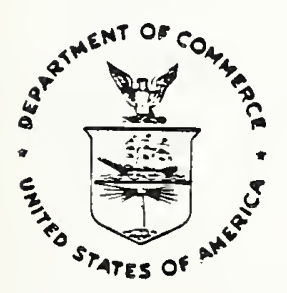

U.S. DEPARTMENT OF COMMERCE, C. William Verity, Secretary 


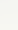


ELECTRICAL PERFORMANCE TESTS FOR TRUE-RMS VOLTMETERS

Table of Contents

Abstract . . . . . . . . . . . . . . . . . . . . . . . 1

1. INTRODUCTION . . . . . . . . . . . . . . . . . . . . . . . . 1

2. BACKGROUND . . . . . . . . . . . . . . . . . . . . . . . . . . . 2

3. AC VOLTMETER PRINCIPLES . . . . . . . . . . . . . . . . . . . . . . . 4

3.1. General Considerations . . . . . . . . . . . . . . . 4

3.2. Principles of Operation . . . . . . . . . . . . . . . . 5

3.2.1. AC to DC Conversion... . . . . . . . . . . . 5

3.2.2. Analog-to-Digital Conversion . . . . . . . . . . . . 6

4. VOLTMETER PERFORMANCE MEASUREMENTS . . . . . . . . . . . . . . . . . . 7

4.1. Input Characteristics . . . . . . . . . . . . . . . . . . . 7

4.1.1. Input Impedance . . . . . . . . . . . . . . . . 7

4.1.2. Common Mode Rejection . . . . . . . . . . . . 8

4.1.3. Input Protection . . . . . . . . . . . . . . . 9

4.2. AC Voltage Performance Tests... . . . . . . . . . . . 10

4.2.1. Range and Accuracy . . . . . . . . . . . . . . . 10

4.2.2. Frequency Range . . . . . . . . . . . . . . . . 13

4.2.3. True-RMS Detection ................ . . 13

4.2.4. Crest Factor . . . . . . . . . . . . . . . 15

4.2.5. Response Time... . . . . . . . . . . . . . 17

5. REFERENCES . . . . . . . . . . . . . . . . . . . . . . 18

APPENDIX A, True-RMS Voltmeter Specifications. . . . . . . . . . . . A-1

APPENDIX B, Test Procedures. . . . . . . . . . . . . . . . . . B-1

APPENDIX C, Computer Test Program. . . . . . . . . . . . . . . . . C-1

APPENDIX D, List of Special Parts. . . . . . . . . . . . . . . . . D-1

APPENDIX E, Equipment List for RMS Voltmeter Tests . . . . . . . . . . . E-1 
ELECTRICAL PERFORMANCE TESTS FOR TRUE-RMS VOLTMETERS

\section{List of Figures}

Page

Fig. 1. Concept of dual-slope integration shown for . . . . . . . . . . 7 Fig. 2 Test setup for measuring ac common mode rejection ratio. . . . . 9 Fig. 3 Set-up to check for true-rms response . . . . . . . . . . . . . . 14

Fig. 4. Crest-factor test waveform . . . . . . . . . . . . . . . . 16 


\title{
Electrical Performance Tests for True-RMS Voltmeters
}

\author{
R. S. Turgel, O. B. Laug, T. E. Leedy \\ Electrosystem Division \\ Center for Electrical and Electronic Engineering
}

\begin{abstract}
Electrical performance test procedures for true-rms voltmeters were developed by the National Bureau of Standards for the U. S. Army Communications-Electronics Command. The report provides detailed, step-by-step test procedures that are based on the specifications supplied by the Army for the purpose of evaluating the bid samples of this type of instrument. Examples of the data sheets and tables for recording of interim data and the final results are given.

This report discusses the philosophy underlying each of the measurement procedures with from a point of view of the basic metrology required to perform the measurements. In addition, the sources of measurement error are discussed.
\end{abstract}

Key Words: test procedures; true-rms voltmeter; rf voltmeter; and voltmeter.

\section{INTRODUCTION}

This report describes test procedures that were developed by the National Bureau of Standards (NBS) for the U.S. Army Communications-Electronics Command (CECOM), Ft. Monmouth, N.J., for testing the electrical performance of truerms responding voltmeters. The test procedures are based on meter performance specifications supplied by CECOM, and will be used by the Army in their Test Measurement and Diagnostic Equipment (TMDE) Modernization Program to evaluate bid samples for this type of instrument. The report focuses only on the test procedures for electrical performance that can be carried out without access to the interior of the instruments under test. The Army performance specifications, for the most part, represent performance levels attainable by modern state-of-the-art commercial wide-band, true-rms ac voltmeters.

The main objective in developing the test procedures has been to provide measurement techniques which are accurate, repeatable, and simple to perform. Most importantly, the procedures must be technically sound so as to provide an unbiased and objective evaluation of competitive instruments. The test equipment chosen has been selected not only to satisfy the requirements of 


\section{ELECTRICAL PERFORMANCE TESTS FOR TRUE-RMS VOLTMETERS}

each individual test, but within the broader context of building a laboratory at CECOM with an inventory of modern general-purpose test equipment that will serve a wide range of bid sample testing needs. Thus, most of the test equipment specified by make and model represent equipment that is a part, or will become a part, of the CECOM laboratory.

This report is divided into three sections: The first section gives a brief overview of the Army's TMDE Modernization Program. The second section contains general information on the principles of commercial wide-band, truerms voltmeters. The third section discusses, in depth, the primary performance measurements with emphasis on a preferred method and a consideration of error sources. The information in this last section is intended to provide the theory and analysis to support the actual test procedures given in Appendix B. The detailed step-by-step procedures in Appendix $B$ are intended for evaluation tests of bid samples by the Army to assure conformance with the set of Army specifications given in Appendix A. Also, included in Appendix B are samples of appropriate data sheets and tables for recording interim and final results.

As part of the test procedures, a computer program for testing the voltmeter efficiently is provided in Appendix C. Appendix D shows the design and characteristics of specialized fixtures that are used in some of the procedures, and Appendix E lists all the test equipment and accessories required for the test procedures. Although the test procedures described in this report were specifically developed for use by the Army TMDE Modernization Program, many of the tests can be considered generic in nature and perhaps could serve as the basis of an industry rest standard for commercial, wideband, true-rms voltmeters.

\section{BACKGROUND}

The Department of the Army has undertaken a Test, Measurement, and Diagnostic Equipment (TMDE) Modernization Program. The general goal of this program is to provide TMDE for the Army, eliminate the proliferation of numerous types and models of such equipment, and thus reduce the logistical burden. Specifically, the intent of the TMDE Modernization Program is to:

1. Introduce a minimum ensemble of different types and models of up-to-date TMDE into the Army inventory,

2. Replace multiple generic types of TMDE with a single new item, where feasible.

3. Periodically assess the Army TMDE inventory to identify individual or families of TMDE that require replacement. 
The acquisition of new TMDE items progresses through a two-step invitation-for-bid procedure. The first step begins with letter requests that are released to potential offerors for bid samples. The offeror has a period of 60 days to analyze the solicitation requirement and send bid sample equipment to the Communications-Electronic Command (CECOM), Ft. Monmouth, NJ for testing. Equipment is evaluated for performance, useability, maintainability, workmanship, ease of calibration, military suitability, safety, and environmental capability. After the bid sample testing, only the offerors with test equipment that meets the solicitation requirements are invited to submit bids.

The second step occurs when the bids are received, evaluated, and the lowest responsive bidder is awarded the contract. This procedure is believed by the Army to provide reliable and maintainable test equipment with superior performance characteristics for support of weapons systems. Bid sample equipment evaluation requires an established set of test procedures which can objectively determine conformance to specifications. Unlike some evaluations, such as safety and workmanship which are more general and widely applicable, test procedures for electrical performance are by necessity specific for each requirement. That is, for each particular electrical performance specification there must be a procedure. Although some equipment manufacturers provide performance check procedures for purposes of incoming inspection, or readjustment to specifications, there is a lack of generic test methods applicable to various classes of equipment that can be directly and objectively used by the Army. Therefore, before bid sample testing can proceed, appropriate test procedures must be developed and validated. This report describes the test procedures specifically developed by NBS for the Army to perform bid sample testing of commercial high-frequency, true-rms voltmeters. 


\section{ELECTRICAL PERFORMANCE TESTS FOR TRUE-RMS VOLTMETERS}

\section{AC VOLTMETER PRINCIPLES}

\subsection{General Considerations}

Voltmeters are one of the commonest tools of the electronic engineer and technician. A decade ago, voltmeters for frequencies up to the order of kilohertz were predominantly analog in nature and essentially consisted of an analog meter movement together with a manual switching network to implement the various range capabilities of the meter. Generally, most analog voltmeters were limited to the measurement of ac voltages with accuracies on the order of 0.5 to 10 percent. The analog meters depended, generally, on the measurand to provide the power necessary for the movement of a meter pointer. Thus, older meters had relatively low input impedance, typically $1000 \Omega / \mathrm{V}$, or less, for operation at the lower audio frequencies. Consequently, in some applications, the input impedance could affect the accuracy of the voltage readings obtained, since at least $500 \mu \mathrm{A}$ was needed to provide a full-scale deflection of the meter. Most of the ac voltmeters, especially for higher frequencies, including high-impedance input vacuum-tube voltmeters were rectifier instruments responding to average or peak voltage, but calibrated to read rms voltage for sinusoidal signals. If distortion was present, large errors could be incurred with these instruments. With the development of complex, miniaturized, low-power electronic circuitry, more sensitive and accurate meters could be constructed, and, in turn, these meters filled the need to service the newer electronic circuits being designed [1].

The digital voltmeter has largely replaced analog instruments and is generally more accurate and more versatile. It can perform many additional functions such as automatic ranging, data averaging, unit conversions (e.g., dB), and others. The basic functional blocks of the digital ac voltmeter include an ac-to-dc conversion stage followed by a form of analog-to-digital converter. To measure the $d c$ voltage resulting from the first stage, an integrating analog-to-digital converter is generally used. This can be either a dualslope or voltage-to-frequency type. The integrating period is usually chosen to minimize line-frequency interference.

The digital part of the circuitry in the voltmeter provides a means for making logical decisions, such as automatic ranging (auto-ranging). With autoranging, the range setting is automatically or electronically selected to give the best resolution possible, except that hysteresis is provided between the up-range and down-range transitions to prevent hunting between ranges at the transition points. Most ac voltmeters also automatically display the decimal point and indicate the units of measurement as well. Many of the newer ac voltmeters make use of embedded microprocessors to provide features such as linearization of the response characteristic, correction for frequency response, capability for making relative measurements between the present reading and a previously stored value, or special displays such as "analog" bar-graph readouts. Also, some voltmeters are able to store calibration data in an internal memory and automatically correct the readings, making the 
customary screwdriver adjustments of trimmers unnecessary. The elimination of physical circuit adjustments tends to improve long-term stability.

Although the digital processing power embedded in modern ac voltmeters distinguishes them from their older analog counterparts, the analog circuitry which amplifies and conditions the input signals is still an important factor in the overall measurement accuracy. With typical input impedances of $10 \mathrm{M} \Omega$ made possible by high-performance amplifiers, careful design of the range changing attenuator is required to keep a flat frequency response over a wide band. The high input impedance reduces source loading and makes possible overload protection that was previously impractical. The input protection typically consists of a metal-oxide varistor or zener diode circuit, possibly in combination with fuses, which provides a voltage clamping action to prevent high voltages or voltage transients from reaching the voltmeter's solid-state circuitry. The major attribute of such clamping circuitry is speed of operation and the ability to withstand high voltages without impairing the accuracy of the instrument. In addition, the commercial ac voltmeter is also designed to withstand vibration and mechanical shocks that are encountered in field applications.

\subsection{Principles of Operation}

\subsubsection{AC to DC Conversion}

The specific principle of operation of an ac voltmeter is highly dependent on the manufacturer's choice of technology and design decisions. In general, ac signals are measured by scaling and converting the ac voltage present at the input of the ac voltmeter to a dc voltage level intended to be proportional to the root-mean-square (rms) of the ac signal. The dc voltage is then digitized and displayed as an ac-voltage amplitude.

The ac(rms)-to-dc conversion can be accomplished by several techniques. Most voltmeters obtain the root-mean-square value either by squaring and averaging of the input signal using an analog multiplier and averaging circuit, or by using thermal converters which compare the heat dissipated by the ac signal to that of an equivalent dc quantity.

The analog multipliers/dividers can employ either direct multiplication and division using variations of the Gilbert (transconductance cell) multiplying circuit [2], or can be based on logarithmic amplifiers. In either case, by connecting the same ac signal to both "multiply" inputs and feeding the averaged output back to the "divide" input, the arithmetic operation can compute the root-mean-square (rms) value of the input.

Both the transconductance type and the logarithmic amplifier type multiplier are available as integrated circuits; some manufacturers also supply specialized rms-computing integrated circuits. 


\section{ELECTRICAL PERFORMANCE TESTS FOR TRUE-RMS VOLTMETERS}

An alternative means of rms-to-dc conversion is provided by thermal converters. These devices employ a voltage-ranging resistor in series with a low-resistance heating element to which a temperature sensor (thermocouple) is attached. The heating effect, and thus the dc voltage produced by the thermocouple, is approximately proportional to the square of the input signal current. To linearize the transfer characteristic, two similar thermoelements are used, one energized with the unknown ac signal and the other with a dc voltage which is adjusted in a servo loop until the thermoelement outputs are equal. The advantage of the thermal technique is that the instrument has a relatively wide bandwidth, is insensitive to waveform distortion, and can tolerate large crest factors. The big disadvantage is a relatively slow response time.

\subsubsection{Analog-to-Digital Conversion}

After the ac-to-dc conversion stage, most modern ac voltmeters use improved integrating dual-slope (sometimes called 'quad-slope') analog-to-digital converters that correct for zero offset errors and operate on the charge balance principle [3] [4] [5] [6], or the voltmeters use voltage to frequency converters. The dual-slope technique is based on a linear charge-discharge characteristic of a capacitor and arranged so that the discharge time, which is proportional to the input voltage, is measured by counting a train of clock pulses. In its simplest version, the input voltage is integrated by charging a capacitor for a predetermined time. Then, a reference voltage is switched to the integrating circuit and discharges the capacitor at a known rate until a level corresponding to "zero" input is reached. Figure 1 shows the voltage output of an idealized integrator for a typical measurement cycle. The time for the second integration process (discharge time) is proportional the average of the unknown signal over the predetermined integration period. The intergration time is measured by counting pulses generated with a constant clock frequency which is adjusted so that the count displayed on a readout provides a value in the appropriate measurement units.

Dual-slope techniques are widely used since the method does not require highaccuracy resistor networks to achieve high-accuracy measurements. The basis for accuracy resides in the precision reference source which is used during the reference integration time. The components, other than the reference source, are required to be stable only over the integration time in order for the ac voltmeter to hold the specified accuracy. There are many variations to the basic, dual-slope conversion technique. For example, additional circuitry may be added to provide compensation for zero offset during each measurement cycle. [7] [8] This zero compensation is accomplished by effectively shorting the input to the analog-to-digital converter, measuring the offset voltage and then subtracting it (in either an analog or digital manner) from the amplitude of the input signal being measured. Additional techniques may also be used to compensate for calibration errors, temperature errors, and frequency errors of ac measurements. 


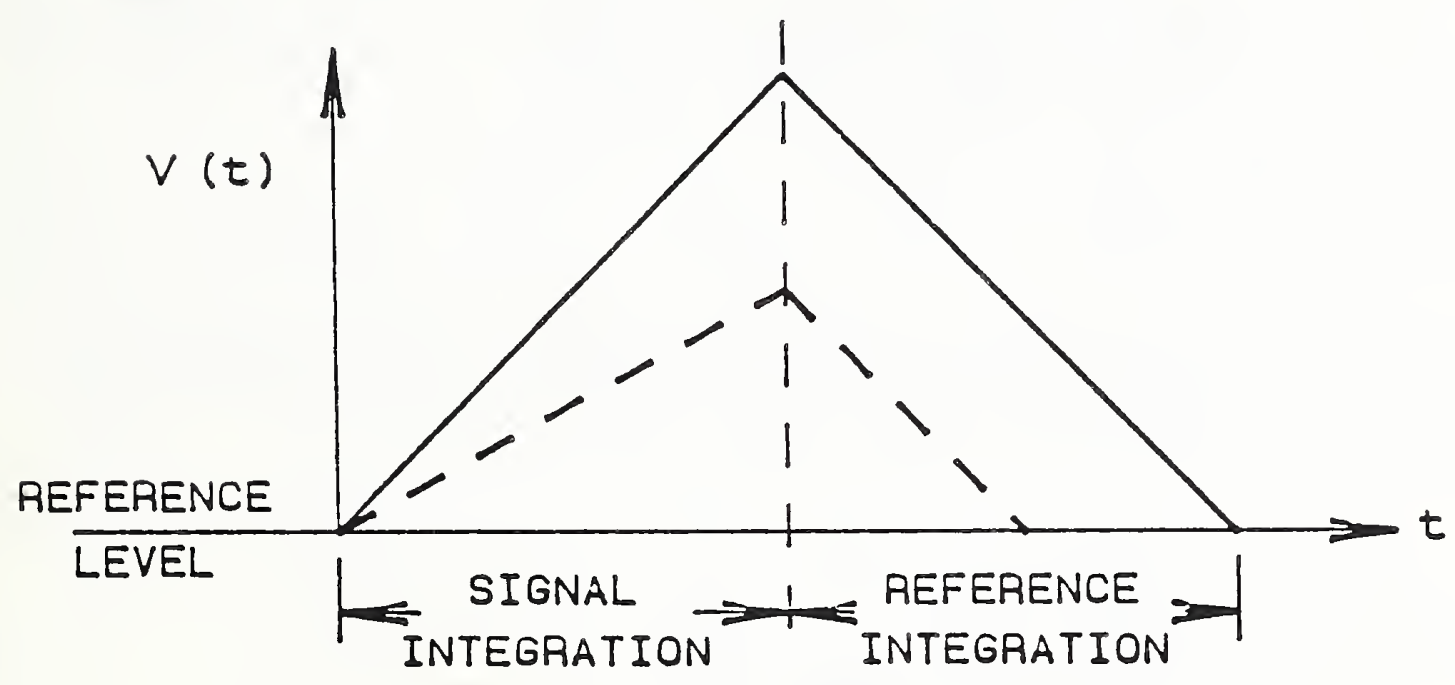

Fig. 1. Concept of dual-slope integration shown for two different input voltages. (The slope of each signal integration curve is proportional to the average of the corresponding input voltage.)

\section{VOLTMETER PERFORMANCE MEASUREMENTS}

\subsection{Input Characteristics}

The following sections describe the characteristics of the ac voltmeter input and how to measure them. The characteristics generally specified are: the input impedance, the common-mode rejection, the maximum input voltage and the input over-voltage protection.

\subsubsection{Input Impedance}

The input characteristics of wideband, ac voltmeters are designed to minimize disturbing the external circuit connected to the input terminals. Ideally, the voltmeter input should have an infinite impedance (zero loading) for ac and dc voltage measurements. In actual practice, the input impedance of the voltage measuring circuitry is typically a resistance of tens of megohms shunted by a capacitance of tens of picofarads. Since the capacitive reactance decreases with frequency, the effect of source loading by the input impedance increases with frequency. At low frequencies the effect of the input capacitance is usually negligible. 


\section{ELECTRICAL PERFORMANCE TESTS FOR TRUE-RMS VOLTMETERS}

\section{Measurement Technique}

The input impedance is determined using a commercial digital LCR meter to measure the input resistance and capacitance directly. This instrument is generally a self-balancing bridge which can determine the resistance and capacitance of an impedance across the input terminals. These quantities can be determined without additional equipment or calculations.

\section{Sources of Measurement Error}

The errors associated with using a direct-reading LCR meter are attributable to uncertainties associated with the accuracy of the of the LCR meter and the stray capacitance of the leads connecting the LCR meter to the voltmeter under test. The basic calibration accuracy of the LCR meter used in the procedure is specified by the manufacturer to be

$$
0.2 \text { of reading }+1 \text { digit }
$$

for capacitance measurements, and

$$
0.3 \text { of reading }+2 \text { digits }
$$

for resistance measurements. The total errors associated with the LCR meter, considering the ranges used and the number of digits displayed, are $\pm 2.1 \mathrm{pF}$ and $50 \mathrm{k} \Omega$ for the measurement of parallel capacitance and resistance, respectively.

\subsubsection{Common Mode Rejection}

Common-mode rejection is the degree to which the ac voltmeter measurement of the voltage drop across the input terminals remains unaffected by the presence of a "common" ac voltage at both terminals with respect to ground. This characteristic is particularly important for meters that are grounded by connection to the power line.

\section{Measurement Technique}

For the line-operated true-rms voltmeter, the calibrator is connected to the shorted input terminals and to chassis ground on the unit-under-test (UUT) as shown in Figure 2. Two measurements are made to determine the common-mode rejection (CMR); the first reading, $V_{2}$, on the unit-under-test is taken with the calibrator voltage set at or neax zero, and the second reading, $V_{2}$, is taken with the calibrator set to the specified common-mode voltage, $V_{C M}$. The $V$ is necessary to establish the reading of the voltmeter under conditions of "zero" input. Because of the wide-band response of the meter, noise and other stray signals will result in a non-zero reading even though there is no intended input voltage. The common-mode rejection, in units of decibels, is then calculated using the following equation: 
ELECTRICAL PERFORMANCE TESTS FOR TRUE-RMS VOLTMETERS

$$
C M R=20 \log _{10} \frac{\left(v_{2}^{2}-V_{1}^{2}\right)^{\frac{1}{2}}}{v_{C M}} .
$$

This procedure can be carried out at the specified frequencies and repeated at other frequencies. (The most commonly encountered power-line frequencies are 50,60 , and $400 \mathrm{~Hz}$.)

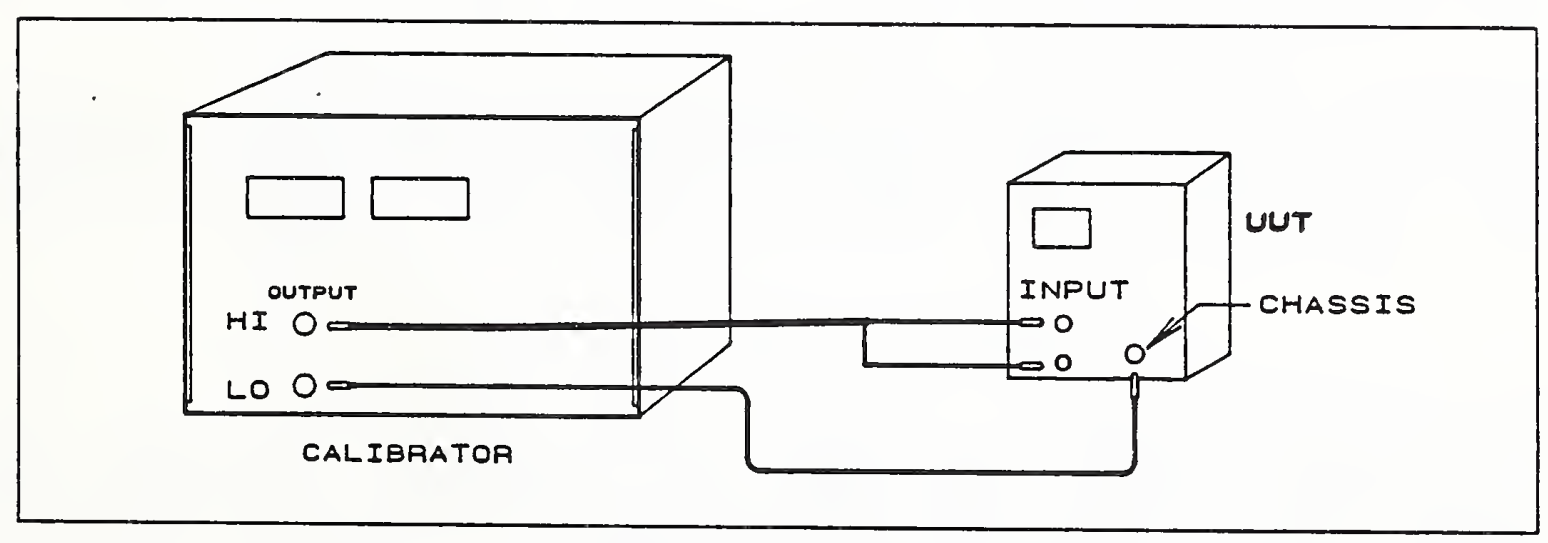

Fig. 2 Test setup for measuring ac common mode rejection ratio.

\section{Sources of Measurement Error}

The predominant source of measurement error is the voltmeter-under-test. If the common-mode voltage is small, the meter may not have sufficient resolution to provide more than a two-digit reading. Another, though usually negligible source of error, is the small but finite output voltage of the calibrator when its nominal output is assumed to be "zero." Since this voltage term, $V$, is squared in the calculation, its effect is normally small. (If $V_{1}$ is equal to 108 of $\mathrm{V}_{2}$, it will produce only a 18 error $\left.[0.09 \mathrm{~dB}]\right)$.

\subsubsection{Input Protection}

The input protection circuitry of the ac voltmeter permits the unit to survive voltage overloads without damage. This characteristic is important since the ac voltmeter may accidentally be subjected to high voltages when the range switch is set to a low-voltage range. 


\section{Measurement Technique}

The ability of the input circuity to withstand an overload condition is tested by applying to the voltmeter-under-test the specified overload voltage on all ranges. The overload protection tests are based on the tests for a maximum nondestructive input signal specified by the manufacturer as described in ANSI C39.6.1983 (paragraph 6.13) ${ }^{1}$. The meter passes the test if, after application of the specified voltage for the specified time (five minutes, if the specification is for continuous application), the meter still meets is rated accuracy requirements.

\section{Sources of Measurement Error}

The input protection tests are designed as pass/fail tests. As such, there is no source of meaningful measurement error. The uncertainty of the applied voltage, supplied by a high-accuracy meter calibrator, is negligible for this test.

\subsection{AC Voltage Performance Tests}

As pointed out in Section 3., measurement of ac quantities is usually a twostage process. In the first stage, the ac voltage is converted to an equivalent dc voltage, and in the second stage the dc voltage is digitized and displayed. In the first stage of the process, the accuracy of the ac-dc conversion circuitry is frequency dependent, and the range resistor network may be both frequency and amplitude dependent. In the second stage, the dc voltage-to-digital-output circuitry is independent of the frequency, but can introduce amplitude errors due to the non-linearities and incorrect reference voltages in the converter. Therefore, it is necessary to determine the performance of the ac meter at various combinations of frequencies and voltage levels.

\subsubsection{Range and Accuracy}

Using the accuracy specifications as a guide, test points are selected over the frequency and amplitude ranges of the unit-under-test. Generally, test points are chosen along the upper or lower limits, or both, associated with a specified accuracy on a frequency-amplitude plot. Additionally, intermediate points may also be chosen so that at least one point is checked on each amplitude range of the unit-under-test at one or more frequencies.

1 American National Standard for Electrical Instrumentation - Digital Measuring Instruments, ANSI C39.6-1983, published by the American National Standards Institute, 1430 Broadway, New York, NY 10018. 
ELECTRICAL PERFORMANCE TESTS FOR TRUE-RMS VOLTMETERS

\section{Measurement Technique}

No single measurement technique is adequate to check the accuracy over the entire frequency band of the true rms-voltmeter at all voltage levels. Three different methods are recommended for voltage measurement:

1. Over the frequency range from $10 \mathrm{~Hz}$ to $1 \mathrm{MHz}$, and for amplitudes from $1 \mathrm{mV}$ to $1000 \mathrm{~V}$, a meter calibrator (with an associated high-voltage amplifier) can check the voltmeter directly.

2. Above $1 \mathrm{MHz}$, and for voltages from $1 \mathrm{~V}$ to $100 \mathrm{~V}$, an uncalibrated test signal source is used, and a calibrated thermal converter is connected in parallel with the voltmeter input. The voltage source is then adjusted until the output of the calibrated thermal converter indicates that the desired voltage level has been reached. The voltage source is then effectively calibrated and the actual meter reading can be compared against the calibration voltage.

3. For voltages below $1 \mathrm{~V}$, at all frequencies, the calibration voltage is obtained from a micropotentiometer. A micropotentiometer is essentially a thermoelement used as an rms current measuring device. The current passes through a special shunt resistor that has a very low ac-dc difference and the voltage drop across the shunt becomes a calibrated output voltage. Typically, the current is $10 \mathrm{~mA}$ and shunts are in the range from 0.01 to $10.0 \Omega$ so that output voltages from $100 \mu \mathrm{V}$ to $100 \mathrm{mV}$ can be obtained.

Note: Thermal converters or micropotentiometers are assigned an ac-dc difference by the manufacturer or an independent calibration laboratory based on intercomparisons with similar devices with known or computable ac-dc difference. The value of this ac-dc difference is usually stable over long periods of time. However, the operating characteristic that links the current through a thermoelement with the output voltage of the temperature sensing device (thermocouple) is subject to drift. Therefore, before use in either method 2 or method 3 above, a preliminary calibration against a known dc or low-frequency ac reference standard is necessary.

\section{Sources of Measurement Error}

A source of error with electrical and electronic measuring instruments of any kind are currents that bypass the measuring circuit through ground loops or other stray paths. While it is relatively simple to avoid such stray currents 
with proper insulation when measuring $\mathrm{dc}$, for ac the problem is more complex because of capacitive and inductive coupling. This is especially true for the true-rms voltmeter. Careful circuit design, grounding, and shielding are necessary to avoid this type of exror. Each set-up has to be considered individually, and general rules can serve only as broad guidelines.

At low audio frequencies inductive coupling predominates, while capacitive coupling becomes more important with increasing frequencies. Any measuring circuit that produces a change in the reading when the operator comes near or touches part of the case or outside of a connecting cable is liable to give an incorrect measurement result. This is true even if care is taken not to touch or approach the equipment. A rearrangement of the measuring circuit, and in particular of the ground connections and shielding, is then advisable.

For performance tests on the true-rms ac voltmeter for signals above $10 \mathrm{MHz}$, the characteristic impedance of the connecting cables and connectors becomes important because of reflections at connectors and all other cable junctions. Careful placement of critical circuit components is necessary to be sure that the set-up measures the desired quantity. For instance, for a broad-band ac voltmeter at frequencies as low as $20 \mathrm{MHz}$, a few inches of coaxial cable between the high-impedance voltmeter input and the $50 \Omega$ terminating resistor can make an appreciable difference in the voltmeter reading. Keeping leads as short as possible is desirable.

When calibrating thermoelements with dc, errors can arise if the dc reversal difference in the thermoelement response is not taken into account. Measurements should always be made with both polarities of dc applied, and the average of the two readings should be used as a reference for subsequent ac measurements. Also, devices containing thermoelements (thermal converters and micropotentiometers) tend to drift with changes in ambient temperature and should, therefore, be protected from such temperature changes during the measurement.

To compute the uncertainty in the calibration voltage or current using method 1 (calibrator) above, only the specified error limits of the calibrator have to be taken into consideration.

For method 2 (thermal converter), the following factors have to be considered:

i. Uncertainty in the reference voltage $\left(u_{r}\right)$ (which can be dc or low-frequency ac).

i1. Uncertainty in the thermal converter ac-dc difference or frequency response correction $\left(u_{c}\right)$.

The total uncertainty in the calibrating voltage $u_{\mathrm{T}}$ is then computed as

$$
u_{T}=\sqrt{\left(\dot{u}_{r}^{2}+u_{c}^{2}\right)} .
$$




\section{ELECTRICAL PERFORMANCE TESTS FOR TRUE-RMS VOLTMETERS}

For method 3 (micropotentiometer) the same formula as that given in method 2 is used. The reference voltage in this case is the average of the two polarities of dc voltage across the shunt resistor of the micropotentiometer as measured by a calibrated dc microvoltmeter. The corresponding uncertainty, $u_{r}$, is the uncertainty in making this dc measurement. The uncertainty, $u_{c}$, in the frequency response is the uncertainty in the ac-dc difference of the micropotentiometer at the measurement frequency.

\subsubsection{Frequency Range}

Determination of the upper and lower limits of the frequency range of a truerms responding voltmeter can be combined with the accuracy check of the unitunder-test by selecting test points at the upper and lower specification limits of frequency and signal amplitude.

\section{Measurement Technique}

The test method is the same as for section 4.2.1, Range and Accuracy.

The tests for accuracy of the ac voltage ranges of the true-rms ac voltmeter are performed over the specified frequency range including the end points of the range. Instruments that do not exhibit the required accuracy at the endpoints are considered to possess insufficient frequency range. Consequently, no separate "frequency range" tests need to be performed.

\section{Sources of Measurement Error}

For a discussion of errors, see Range and Accuracy.

\subsubsection{True-RMS Detection}

The basis for this test is taken from IEC Publication 51 (which has superseded ANSI C39.1. [9]) The ability of the unit-under-test to measure waveforms using true-rms detection is tested with a nonsinusoidal waveform generated by adding approximately $30 \mathrm{~s}$ of third harmonic to a fundamental signal at $1 \mathrm{kHz}$. A true-rms responding meter will give an indication for this non-sinusoidal signal that is independent of the phase angle of the harmonic relative to the fundamental. (Note that an average or peak responding meter will give indications that will vary with the phase angle of the harmonic). To implement the test, a signal with a frequency that is somewhat greater than three times the fundamental by a small fraction of a hertz, is superimposed on the fundamental frequency. In this way the relative phase angle between the two signals increases slowly so that in a time interval of the order of half a minute, the phase angle has swept from $0^{\circ}$ to $360^{\circ}$. 
ELECTRICAL PERFORMANCE TESTS FOR TRUE-RMS VOLTMETERS

\section{Measurement Technique}

The test signal is generated by two independent signal generators, with stable frequencies, at least one of which should preferably be a synthesized waveform generator with a frequency adjustment in steps of fractional hertz. The choice of fundamental frequency for this test is arbitrary. For best results it is convenient to chose a frequency in a range where the specified meter error is smallest for both the fundamental and the third harmonic. The harmonic component is generated at about 3.0001 times the fundamental frequency so that the relative phase with respect to the fundamental sweeps through one cycle at a rate slowly enough so that the maximum and minimum meter response can be read. (With the ratio indicated, the phase of a $3-\mathrm{kHz}$ waveform will sweep through $360^{\circ}$ in 10 seconds.) The amplitude of the harmonic component should be set at about $20 \%$ ( $30 \%$ in the original ANSI standard) of that of the fundamental to conform to the IEC test specifications. To obtain good resolution on the readout of the meter, the amplitudes of the two signals should be chosen so that the meter indicates a value near full-scale on the range when relative phases are such that the combined signal is at a maximum. For instance, if the full-scale meter indication is $1.999 \mathrm{~V}$, then if the fundamental is $1.500 \mathrm{~V}$ and the harmonic component is 0.450 (308), the combined signal will not be greater than 1.950 volts; close to, but less than full-scale.

The simplest way to combine the two signals is to use a resistance network that acts as a summing junction for the inputs from the two generators as shown in the figure 3.

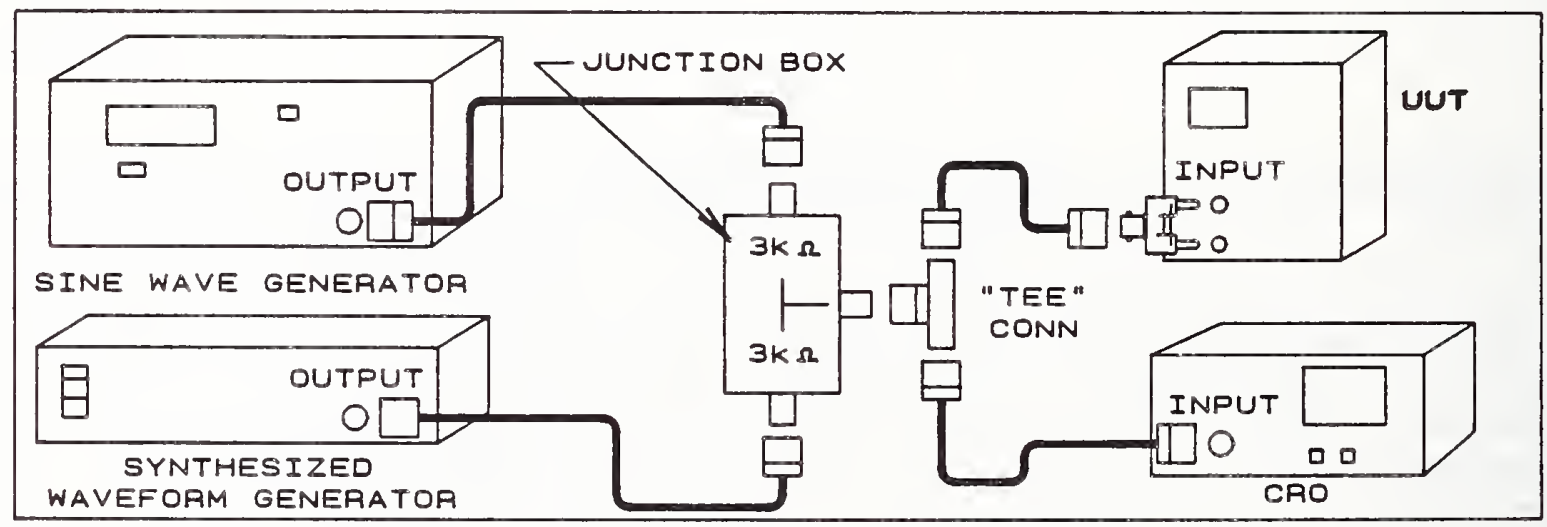

Fig. 3 Set-up to check for true-rms response 


\section{Sources of Measurement Error}

Since the measurement is concerned only with the constancy of the indicated value within the response tolerance for the range, a calibrated ac voltage source is not required. Even the signal frequencies need only be approximate for this test. Uncertainty statements are therefore not applicable.

\subsubsection{Crest Factor}

A crest-factor test is an important performance measure of voltmeters employing true-rms detection. The crest factor is the ratio of the maximum value of a voltage waveform (the peak) to the effective or rms value. Crestfactor limitations introduce an error when measuring non-sinusoidal signals.

Typical true-rms voltmeter systems can accept signals at full scale with crest factors of 4:1 or higher. When a crest factor specification does not contain an accuracy degradation statement, it must be assumed that all accuracy specifications are applicable for signals with the specified crest factor. High crest-factor signals inherently have a broad spectrum of harmonics, but for a given crest factor the spectral distribution depends on the waveshape of the signal. By careful choice of the waveshape of the test signal, it is therefore possible to set an upper frequency limit for significant harmonic components. For each given accuracy specification of the voltmeter response, there is an upper and lower frequency limit, and it is advantageous for the crest factor response determination to choose a test signal that has all of its significant frequency components within those frequency limits. If some significant harmonic components fall into another accuracy specification region, it becomes difficult to assess whether the voltmeter has passed or failed the test. Thus, unless the crest-factor test signal is carefully chosen, consistent test results will not be obtained.

\section{Measurement technique}

A crest-factor measurement is made by applying a test waveform with the specified crest factor to the voltmeter-under-test and comparing the voltmeter's indication with the true-rms value of the test waveform determined by independent means. A worst case condition is ensured by setting the rms value of the test waveform near the full-scale value of a range. For an autoranging voltmeter, an amplitude adjustment is required so that the test waveform amplitude is close to the upper end of a range.

The bipolar triangle waveform, shown in figure 4, offers a good compromise between ease of generation and mitigation of the higher order harmonics. In the absence of any specified waveform, it is the test waveform used for the procedure described in Appendix B. 


\section{ELECTRICAL PERFORMANCE TESTS FOR TRUE-RMS VOLTMETERS}

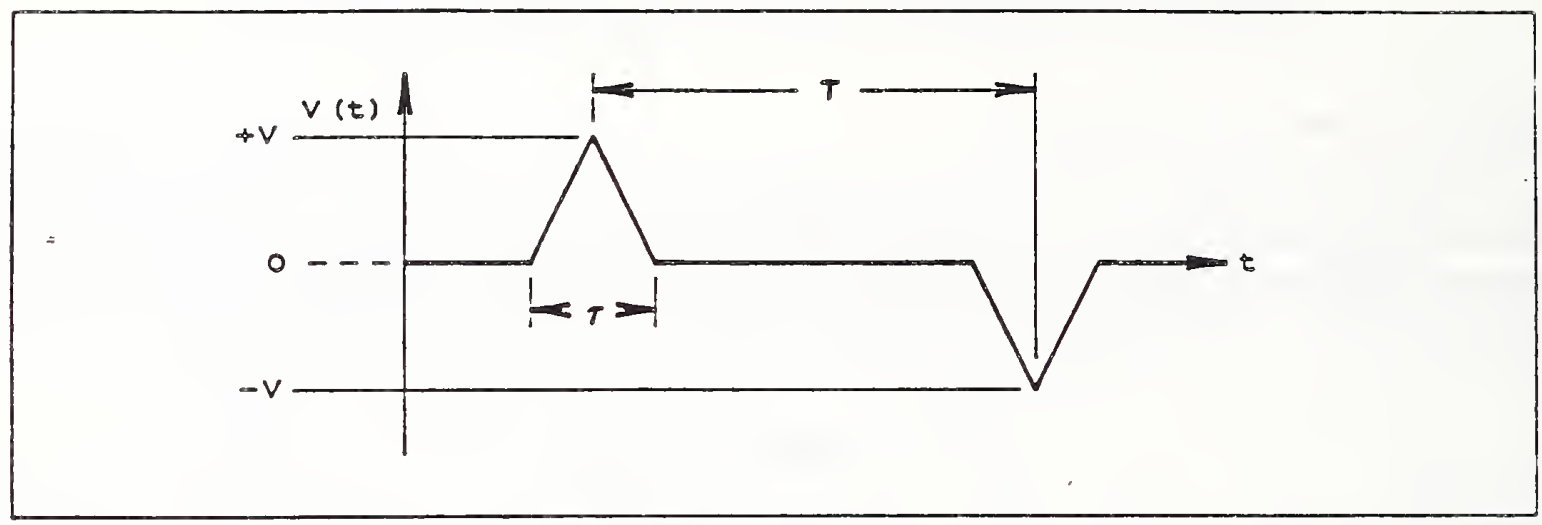

Fig. 4. Crest factor test waveform

The crest factor of this waveform is given by

$$
C F=(3 \mathrm{~T} / \tau)^{\frac{1}{2}} \text {. }
$$

For a 4:1 crest factor, the ratio of $T / \tau$ becomes $16 / 3$. The average of the test waveform is zero and therefore exercises the full peak-to-peak dynamic range of the voltmeter-under-test. The test waveform of figure 4 is most easily generated by an arbitrary waveform generator, but this method limits the fundamental to audio frequencies. A more meaningful test for the wideband, true-rms voltmeter should be performed at a fundamental test frequency near mid-band, and at a frequency which is low enough to insure that all the significant harmonics are within the specified frequency band. A test fixture, which generates the waveform shown in figure 4 with a $4: 1$ crest factor, has been specifically designed for the crest-factor test procedure. The design was implemented using a few logic gates and an operational amplifier. The details of the circuit can be found in Appendix D. The width of the triangle pulse $T$ is set to $3 \mu \mathrm{s}$ and the interval $T$ to $16 \mu \mathrm{s}$. The output amplitude of the waveform generator is set to a nominal 1-volt rms level. In the test procedure, a power amplifier boosts the output of the crest factor generator to a nominal level of 100 volts rms and applies it to the voltmeter-under-test at a full scale range setting of 100 volts. Performing the crest factor test at high amplitudes will emphasize any slewrate limitations existing in the voltmeter under test. The magnitude spectrum of the crest factor test waveform at the output of the power amplifier. Fig. $D-2$, Appendix $D$, shows that all significant harmonic energy is well within the bandwidth of the voltmeter.

\section{Sources of Measurement Error}

The main source of error for this measurement is the uncertainty with which the measurement of the rms value of the crest-factor signal can be made. Thermal converters offer the most accurate means of determining the rms value of high crest-factor waveforms. Thermal converters respond inherently to the rms value and have a flat frequency response over a wide range [10]. In the 
accuracy specification region on a frequency-amplitude plot, where the voltmeter accuracy is specified as $\pm 3 \%$, the measurement uncertainty of the crest-factor waveform using a thermal converter can be conservatively estimated to be better than $0.1 \%$. The sources of error and measurement uncertainty are generally the same as those discussed in Section 4.2.1.

\subsubsection{Response Time}

The response-time determination establishes whether a voltmeter reading within the specified accuracy limits can be obtained in the time interval specified.

\section{Measurement Technique}

The measurement of response time for instruments having only a visual readout is necessarily somewhat subjective and dependent on operator reaction time. The measurement is carried out with a bus controlled calibrator which applies a voltage to the unit-under-test, and, after a programmed time delay corresponding to the specified response time, the operator is signaled to read the meter. If the reading falls within the accuracy limits applicable for the range and frequency of the input, the test is deemed successful. Generally, it is beneficial to repeat the test several times to check the consistency of the result and to assure that the observer does not contribute excessive random errors to the outcome of the test.

\section{Sources of Measurement Error}

The predominant source of error is the reaction time of the observer. With practice, a skilled observer should be able to reduce the uncertainty in the time interval between application of the input signal and noting of the readout to \pm 0.2 seconds. Additional timing delays introduced by the bus controller, usually of the order of a few milliseconds, are negligible. 
ELECTRICAL PERFORMANCE TESTS FOR TRUE-RMS VOLTMETERS

\section{REFERENCES}

[1] For an interesting discussion of analog meters, see Soisson, Harold E., Electronic Measuring Systems, McGraw-Hill Book Company, Inc., New York, 1961 , pp. $182-188$.

[2] Gilbert, B., "A precise four-quadrant multiplier with subnanosecond response," IEEE J. Solid-State Circuits, Vol. SC-3, pp. 365-373. December 1968.

[3] Ammann, S. K., Integrating Analog-to-Digital Converter, U. S. Patent No. 3,316,547, April 25, 1967.

[4] Kime, Jr., R. C., The Charge-Balancing A-D Converter: An Alternative To Dual-Slope Integration, Electronics, May 24, 1973.

[5] Grandbois ,G., Pickerell, T., Quantized feedback takes its place in analog-to-digital conversion, Electronics, pp. 103-107, October 13, 1977.

[6] Hnatek, E. R., A User's Handbook of $D / A$ and $A / D$ Converters, John Wile \& Sons, New York, 1976.

[7] Mattera, L., Converter Stresses Stability, Electronics, p. 139-140, February 19, 1976.

[8] Jones, L. T., Ressmeyer, J. J., Clark, C. A., Precision DVM Has Wide Dynamic Range and High System Speed, Hewlett-Packard Journal, Vol. 32, No. 4, pp. 23-31, April 1981.

[9] Requirements for Electrical Analog Indicating Instruments, ANSI C39.11981; superceded by:

Direct Acting Indicating Analogue Electrical Measuring Instruments and their Accessories, IEC Publication $51-1984$

[10] Hermach, F. L., AC-DC Comparators for Audio-Frequency Current and Voltage Measurements of High Accuracy, IEEE Trans. on Instrum. \& Meas., Vol. IM-25, No. 4, pp.489-494, December 1976. 
ELECTRICAL PERFORMANCE TESTS FOR TRUE-RMS VOLTMETERS

\author{
APPENDIX A \\ PERFORMANCE SPECIFICATION FOR \\ THE ME-545()/G TRUE-RMS VOLTMETER ${ }^{2}$
}

Reprinted from the U. S. Army specifications for the TMDE modernization project.

A -1 


\subsection{Type of Response}

Meter AC voltage measurement capability shall be true rms responding over the entire voltage range, (para. 10.3).

\subsubsection{Coupling}

Meter shall have the capability of being dc coupled, for measuring AC signals with DC components.

\subsection{Frequency Range}

Frequency response shall be at least $10 \mathrm{~Hz}$ to $20 \mathrm{MHz}$.

\subsection{Voltage Range}

Shall be from 100 micro-volts rms or less, to 300 volts rms or greater except where limited by the volt-hertz product of para. 10.12.

\subsubsection{Selectable Ranges}

Meter shall provide no less than seven selectable ranges, with the lowest full scale range no greater than 2 millivolts rms, and the greatest full scale range at least 300 volts rms.

\subsubsection{Ranging}

Shall be auto-ranging, also shall have the capability of manually setting the range. Shall provide at least $10 \%$ over-range, or 108 under-range when manually auto-ranged.

\subsubsection{Voltage Resolution}

Display resolution in voltage mode shall be at least as specified herein:

\section{READING}

$$
\begin{aligned}
& \text { for readings below } 1.999 \mathrm{mV} \\
& 2.00 \mathrm{mV} \text { to } 19.99 \mathrm{mV} \\
& 20.00 \mathrm{mV} \text { to } 199.9 \mathrm{mV} \\
& 200 \mathrm{mV} \text { to } 1999 \mathrm{mV} \\
& 2.00 \mathrm{~V} \text { to } 19.99 \mathrm{~V} \\
& 20.0 \text { V to } 199.9 \mathrm{~V} \\
& 200 \quad V \text { to } 300 \quad \mathrm{~V}
\end{aligned}
$$

\section{RESOLUTION}

1 microvolt

10 microvolts

100 microvolts

1 millivolt

10 millivolts

100 millivoles

1 volt 
ELECTRICAL PERFORMANCE TESTS FOR TRUE-RMS VOLTMETERS

\subsection{Display Type and Units}

Shall have a digital display with $31 / 2$ digits, or more, in the voltage mode. Shall also have analog peak and null indicator. Analog peak and null indicator shall show changes in voltage equal to, or greater than 58 of full scale of range in use. The digital display shall have annunciators for volts, millivolts, decibels relative, dBm, and polarity.

\subsection{Decibel Measurements}

Meter shall have a minimum span of $130 \mathrm{~dB}$ and comply with the requirements herein.

\subsubsection{Decibel Display and Resolution}

Meter shall have at least 4-digit display with polarity indicator when in the decibel mode, decibel resolution shall be at least $0.01 \mathrm{~dB}$.

\subsection{2 dBm Reference Impedance}

In $\mathrm{dB}$ mode, reference impedance shall be selectable, with a minimum of five selection: 50 ohms, 75 ohms, 124 ohms, 135 ohms, and 600 ohms.

\subsection{Accuracy}

Shall be at least as specified below over the operating temperature range from 18 to 28 degrees Celsius, for ac-coupled measurements. AC + DC measurement accuracy shall be within twice the tolerance for ac measurements.

RF-DC transfer difference from dc to $100 \mathrm{MHz}$ at a voltage level of 100 microvolts

Shall be within $\pm 0.2 \%$ of dc input level.

Accuracy for frequencies from $10 \mathrm{~Hz}$ to $49.99 \mathrm{~Hz}$ for all input levels from 100 microvolts to 300 volts

Shall be within \pm 58 of true input level.

Accuracy for frequencies from $100 \mathrm{~Hz}$ to $99.9 \mathrm{kHz}$ for all input levels from 100 microvolts to 1 millivolt

Shall be within $\pm 5 \%$ of true input level. 
ELECTRICAL PERFORMANCE TESTS FOR TRUE-RMS VOLTMETERS

Accuracy for frequencies from $100 \mathrm{kHz}$ to $999.9 \mathrm{kHz}$ for all input levels from 100 microvolts to $1 \times 10^{8}$ volt-hertz.

Shall be within \pm 5 of true input level.

Accuracy for frequencies from $1 \mathrm{MHz}$ to $9.99 \mathrm{MHz}$ for all input levels from 100 microvolts to $1 \times 10^{8}$ volt-hertz.

Shall be within \pm 10 of of true input level.

Accuracy for frequencies from $10 \mathrm{MHz}$ to $19.99 \mathrm{MHz}$ for all input levels from 100 microvolts to $1 \times 10^{8}$ volt-hertz.

Shall be within $\pm 15 \%$ of true input level.

Accuracy for frequencies from $10 \mathrm{~Hz}$ to $49.99 \mathrm{~Hz}$ for all input levels from 100 microvolts to 300.0 volts and for frequencies from $50 \mathrm{~Hz}$ to $99.99 \mathrm{kHz}$; for all input levels from 1 millivolt to 300 volts (200 volts from $20 \mathrm{kHz}$ to $99.99 \mathrm{kHz}$ ).

Shall be within \pm 3 o of true input level.

Accuracy for frequencies from $100 \mathrm{kHz}$ to $999.9 \mathrm{kHz}$ for all input levels from 100 microvolts to $1 \times 10^{8}$ volt-hertz.

Shall be within \pm 5 of of true input level.

Accuracy for frequencies from $1 \mathrm{MHz}$ to $9.99 \mathrm{MHz}$ for all input levels from 100 microvolts to $1 \times 10^{8}$ volt-hertz.

Shall be within \pm 10 of true input level.

Accuracy for frequencies from $10 \mathrm{MHz}$ to $19.99 \mathrm{MHz}$ for all input levels from 100 microvolts to $1 \times 10^{8}$ volt-hertz.

Shall be within \pm 15 of true input level.

\subsection{Response Time}

Shall be 3 seconds or less to rated accuracy.

$$
\text { A }-4
$$


Shall be within \pm 38 of true input level.

10.8 Crest Factor

Meter shall handle crest factors of 4:1 for all input levels below 100 volts, increasing for downscale measurements.

\subsection{Input Connector}

Input connector of meter shall be selectable by a front panel switch, allowing the outer connector to be floating from chassis ground or to be connected to chassis ground. Connector type shall be BNC type female.

\subsection{AC Common Mode Rejection}

Shall be greater than $60 \mathrm{~dB}$ up to $400 \mathrm{~Hz}$.

\subsection{Maximum Input Protection}

Shall be at least 420 volts peak ( 300 volts rms) on all ranges, and shall be at least $1 \times 10^{8}$ volts-hertz on all ranges above 1 volt.

\subsection{Input Impedance}

Input impedance shall be 1 megohm or greater, shunted by 50 picofarads capacitance or less.

\subsection{Output}

The meter shall have rear panel dc output. Output connector shall be BNC type female or dual banana female. 

ELECTRICAL PERFORMANCE TESTS FOR TRUE-RMS VOLTMETERS

APPENDIX B

TEST PRODEDURES FOR

THE ME-545()/G TRUE-RMS VOLTMETER 
TEST PROCEDURES FOR ME-545()/G TRUE-RMS VOLTMETER

Note:

The material in this Appendix has been prepared for use by the Department of the Army, CECOM, Fort Monmouth, New Jersey. Certain commercial equipment is identified with each test procedure listed. This identification does not imply endorsement by the National Bureau of Standards, nor does it imply that the equipment identified is necessarily the best available for the purpose. 


\section{TEST PROCEDURES FOR ME-545()/G TRUE-RMS VOLTMETER}

\section{Table of Contents}

Page

List of Figures . . . . . . . . . . . . . . . . . . . . . . . 4

List of Tables . . . . . . . . . . . . . . . . . . . . . 5

10.1 Type of Response . . . . . . . . . . . . . B-6

10.1.1 DC Coupling . . . . . . . . . . . . . . . . B-10

10.2 Frequency Range ................. B-13

10.3 Voltage Range . . . . . . . . . . . . . . B-14

10.3.1 Selectable Ranges ................. . B-15

10.3.2 Ranging . . . . . . . . . . . . . . . . B-17

10.3.3 Voltage Resolution ............... . B-20

10.4 Display Type and Units . . . . . . . . . . . . . B-24

10.5 Decibel Measurements .. . . . . . . . . . . . B-26

10.5.1 Decibel Display and Resolution . . . . . . . . . B-28

10.5.2 $\mathrm{dBm}$ Reference Impedance . . . . . . . . . . . . . B-30

10.6 Accuracy . . . . . . . . . . . . . . B-32

10.7 Response Time................. B-65

10.8 Crest Factor .................. . B-68

10.9 Input Connector . . . . . . . . . . . . . . B-73

10.11 AC Common Mode Rejection . . . . . . . . . . . . B-75

10.12 Maximum Input Protection . . . . . . . . . . . B-78

10.13 Input Impedance . . . . . . . . . . . . . . B-81

10.14 DC Output . . . . . . . . . . . . . . . B-84 
TEST PROCEDURES FOR ME-545()/G TRUE-RMS VOLTMETER

\section{List of Figures}

Fig. 10.1a Set-Up for Type-of-Response Test

Fig. 10.1b

Waveforms for Type of Response Test.

Fig. 10.1.1 Set-Up for testing DC Coupling

Fig. $10 \cdot 3 \cdot 2 \mathrm{a}$

Set-Up for Voltage Range Test

Fig. $10 \cdot 3 \cdot 2 b$

Set-Up for Voltage Range Test for voltages above 100 volts.

Fig. $10 \cdot 3 \cdot 3 a$

Set-Up for Voltage Resolution Test

Fig. $10.3 .3 \mathrm{~b}$

Set-Up for the Resolution Test for voltages above 100

volts.

Fig. 10.5

Set-Up for the Decibel Test.

Fig. 10.5.1

Set-Up for Decibel Resolution Test

Fig. 10.6 .1

Set-Up for Micropotentiometer DC Calibration

Fig. 10.6 .2

Set-Up for $100 \mu \mathrm{V}$ AC Measurements.

Fig. 10.6 .3

Set-Up for the Accuracy Test with the Calibrator

Fig. $10 \cdot 6.4$

Set-Up for the Accuracy Test with the Calibrator and

Amplifier.

Fig. 10.6.5 Set-Up for the 100-Volt Accuracy Test

using a Thermal Converter.

Fig. 10.6.6 Set-Up for Low-Voltage Accuracy Test

using a Thermal Converter.

Fig. 10.7.1

Set-Up for Response Time Test.

Fig. 10.8

Set-Up for the Crest Factor Test

Fig. 10.11.1

Test setup

or measuring the common mode rejection.

Fig. 10.12

Test setup for measuring maximum input protection. 
TEST PROCEDURES FOR ME-545()/G TRUE-RMS VOLTMETER

List of Tables

Page

Table 10.1

Type-of-Response Test

Table 10.1.1

DC Coupling Test.

Table 10.3.1

Selectable Ranges 16

Table 10.3.2

Ranging

Table $10 \cdot 3 \cdot 3.1$

Voltage Resolution

Table $10 \cdot 3 \cdot 3 \cdot 2$

Voltage Resolution

Table 10.4

Display Type and Resolution . . . . . . . . . . . 25

Table 10.5

Decibel Measurement . . . . . . . . . . . 27

Table 10.5.1

Decibel Measurements . . . . . . . . . . . 29

Table 10.5.2

dBm Reference Impedance

Table $10.6 a$

Accuracy Test, Data Sheet, Micropotentiometer Measurements.

Table $10.6 \mathrm{~b}$

Accuracy Test, Data Sheet, Calibrator.

Table $10.6 \mathrm{c}$

Accuracy Test, Data Sheet, Thermal Converter. 64

Table 10.7

Response Time, Data Sheet, ( 3 Seconds)

Table 10.8

Crest Factor.

Table 10.9

Input Connector 74

Table 10.11

Common Mode Rejection 77

Table 10.12

Maximum Input Protection. 80

Table 10.13 Input Impedance 83

Table 10.14 DC Output 
TEST PROCEDURES FOR ME-545()/G TRUE-RMS VOLTMETER

\subsection{Type of Response}

\section{Specification:}

Meter AC voltage measurement capability shall be true rms responding over the entire voltage range, (para. 10.3).

The test checks whether the meter is true-rms responding. The basis for this test is taken from ANSI 39.1 and consists of adding approximately $30 \%$ third harmonic to a fundamental signal at $1 \mathrm{kHz}$. A true-rms responding meter will give the same indication for this non-sinusoidal signal independent of the phase angle of the harmonic relative to the fundamental. (Note: an average or peak responding meter will give indications that are dependent on the phase angle of the harmonic.) To implement the test, a signal with a frequency that is greater than three times the fundamental by a small fraction of a hertz, is superimposed on the fundamental frequency. In this way the relative phase angle between the two signals increases slowly so that in a time interval of about one minute the phase angle has increased from $0^{\circ}$ to $360^{\circ}$.

\section{Test Condition:}

The fundamental frequency $(1 \mathrm{kHz}$ ) is generated with the Waverek Model 275 Arbitrary Waveform Generator, and the harmonic component is produced using the Hewlett-Packard Model 3325A Function Generator.

\section{Equipment:}

Items

Function Generator

Arbitrary Waveform Generator

Oscilloscope

Cable with BNC connectors

BNC tee connector

Special Resistor Junction Box Special part (NBS) $\underline{\text { Model }}$

Hewlett-Packard $3325 \mathrm{~A}$ or equivalent

Wavetek 275 or equivalent

Tektronix 465 or equivalent

\section{Procedure:}

Set up the equipment as shown in figure 10.1a. Connect the output of the function generator and of the arbitrary waveform generator to the resistor terminations of the special resistor junction box. Attach a BNC tee to the third connector of the junction box, and connect one end of the tee to the UUT and the other to the oscilloscope. 


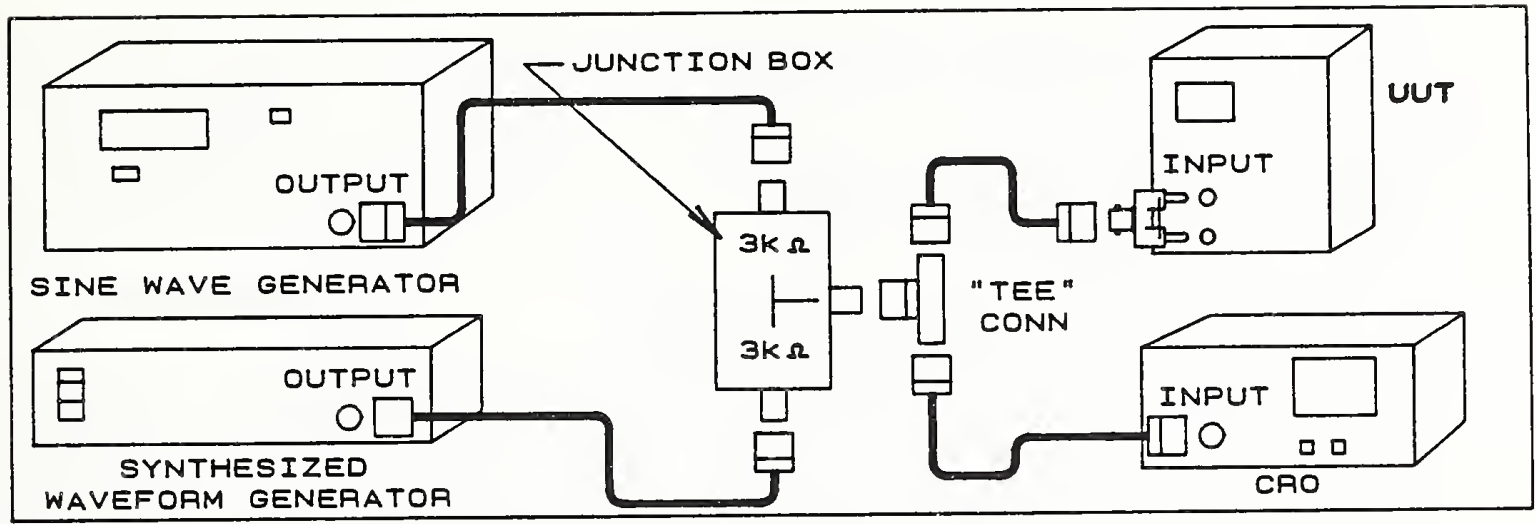

Fig. 10.1a Set-Up for Type-of-Response Test

To set up the Wavetek Model 275, push the front-panel controls in the following sequence:

1. Power

2. STAT Check Display as indicated in Wavetek Instruction Manual, page $2-4$.

3. OUT-ON, 1, EXEC Display reads "OUTPUT ON(1)"

(This command connects the signal to the output terminal)

Steps 1 to 3 set up the Wavetek Function Generator to its default values of $1 \mathrm{kHz}$ and $5 \mathrm{~V}$.

The next three steps will set up the Hewlett-Packard Model 3325A Synthesizer to approximately $3 \mathrm{kHz}$ and $1.5 \mathrm{~V}$ rms.

4. Turn on power switch

5. FREQ, 3, $\mathrm{kHz}$

6. AMPTD, 1.5, V rms .

This should produce an image of a distorted sine wave on the oscilloscope. Since the frequency setting of the Wavetek Model 275 may not be exactly $1 \mathrm{kHz}$, a fine adjustment of the frequency of the Hewlett-Packard Model $3325 \mathrm{~A}$ Synthesizer may be necessary. To adjust the frequency, proceed as follows:

7. FREQ, Left arrow in the "Modify" field. (This turns on additional digits on the display).

8. Push left arrow repeatedly until the zero to left of the decimal point is blinking. 
TEST PROCEDURES FOR ME-545()/G TRUE-RMS VOLTMETER

9. Push the "up" or the "down" arrow until the pattern on the oscilloscope is almost stationary.

If the adjustment is too fine, use the "left" arrow once more, then use the "up" or "down" arrows.

If the adjustment is too coarse, use the "right" arrow instead of the "left" arrow and proceed as before.

If the frequency fine adjustment has been done correctly, the image on the oscilloscope screen should vary slowly from one waveform, shown in figure $10.1 \mathrm{~b}$, to the other and back again. The time for the pattern to return to its original shape should take approximately 10 seconds.

10. While the waveform pattern is changing slowly, observe the output reading of the digital voltmeter-under-test (UUT), and enter into the data sheet the highest and lowest readings obtained. The difference between the two readings should be within \pm 38 .

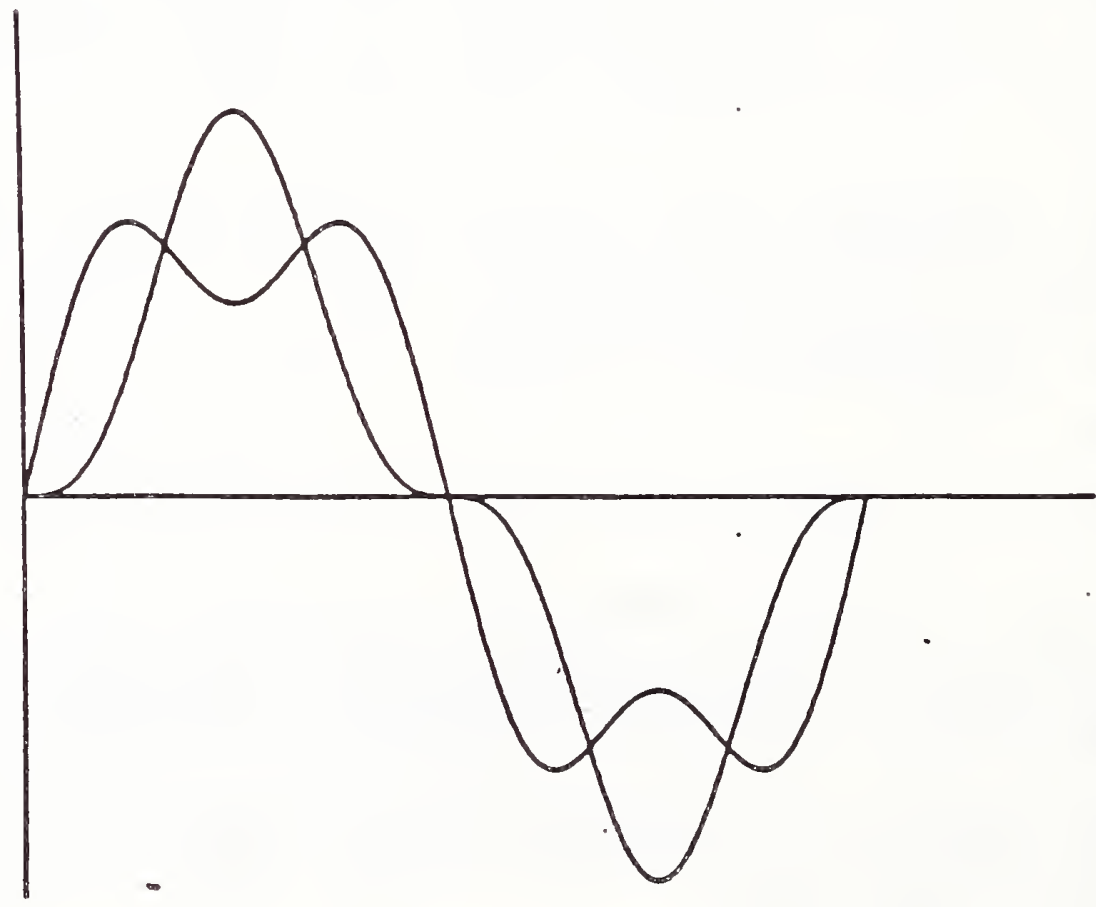

Fig. 10.1b Waveforms for Type of Response Test 
TEST PROCEDURES FOR ME-545()/G TRUE-RMS VOLTMETER

Table 10.1 Type-of-Response Test

\begin{tabular}{|c|c|c|c|c|}
\hline $\begin{array}{l}\text { High Reading } \\
\text { (Volts) }\end{array}$ & $\begin{array}{c}\text { Low Reading } \\
\text { (Volts) }\end{array}$ & $\begin{array}{c}\text { Difference } \\
\text { (Volts) }\end{array}$ & Uncertainty & $\begin{array}{l}\text { Specification } \\
\text { Limits }\end{array}$ \\
\hline & & & $\pm 1 \mathrm{lsd}^{*}$ & \pm 38 \\
\hline
\end{tabular}


10.1.1 DC Coupling

Specification:

Meter shall have the capability of being dc coupled, for measuring ac signals with dc components.

This test checks whether the digital voltmeter under test (UUT) correctly combines dc signals and ac signals. The Hewlett-Packard Model 3325A Function Generator (or equivalent) is used as signal source. This signal generator provides means for adding a dc offset (maximum $443 \mathrm{mV}$ ).

\section{Equipment:}

\section{Items}

Function Generator

DC millivoltmeter

Oscilloscope

Cable with BNC connectors

50-ohm BNC adapter

BNC tee connector

BNC to dual banana adaptex
Mode 1

Hewlett-Packard $3325 \mathrm{~A}$ or equivalent Fluke $8506 \mathrm{~A}$ or equivalent Tektronix 465 or equivalent

\section{Procedure:}

1. Connect the output of the Hewlett-Packard Model 3325A Function Generator to the digital voltmeter under test (UUT) using a 50-ohm BNC adapter at the voltmeter input terminal and also to the input of the dc millivoltmeter. Set the UUT to its "actdc" mode, and set the millivoltmeter to its 1 -volt dc range.

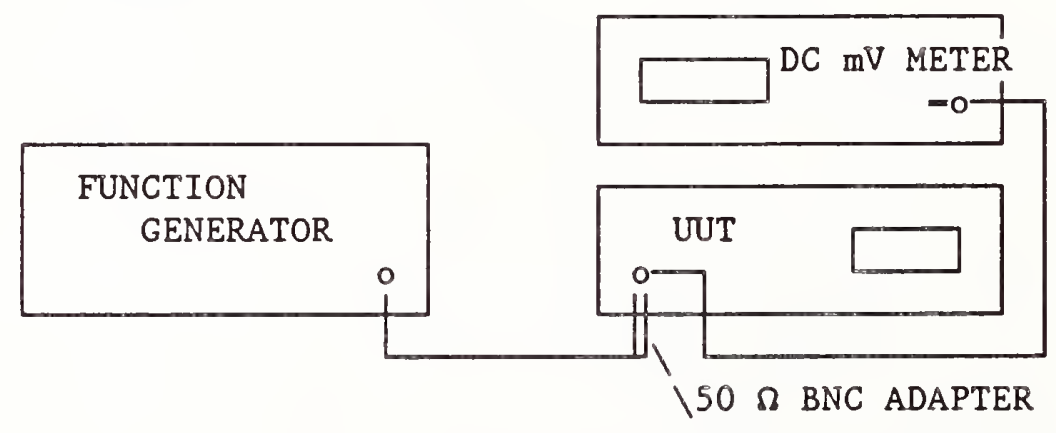

Fig. 10.1.1 Set-Up for testing DC Coupling

2. Set the frequency to $1 \mathrm{kHz}$.

3. Set the amplitude to $30 \mathrm{mV} \mathrm{rms}$. 
TEST PROCEDURES FOR ME-545()/G TRUE-RMS VOLTMETER

4. Set the dc offset to $0.00 \mathrm{~V}$.

6. Read the meter and record the ac reading on the data sheet.

7. Set the dc offset to $0.040 \mathrm{~V}$.

8. Read the UUT and record the actdc reading on the data sheet, Table 10.1.1.

9. Read the dc millivoltmeter and record the dc reading on the data sheet.

10. Compute what the meter should read using formula below:

$$
\text { reading }(\mathrm{ac}+\mathrm{dc})=\sqrt{\left\{(\mathrm{ac} \mathrm{rdg} \text { in } \mathrm{mV})^{2}+(\mathrm{dc} \text { reading })^{2}\right\}}
$$


TEST PROCEDURES FOR ME-545()/G TRUE-RMS VOLTMETER

Table 10.1.1 DC Coupling Test

\begin{tabular}{|c|c|c|c|c|c|}
\hline $\begin{array}{c}\mathrm{AC} \\
\text { Reading } \\
\text { (mV) } \\
{\left[\begin{array}{ll}\text { Step 6] }\end{array}\right.}\end{array}$ & $\begin{array}{l}\text { AC+DC } \\
\text { Reading } \\
(\mathrm{mV}) \\
{\left[\begin{array}{ll}\text { Step } & 8\end{array}\right]}\end{array}$ & $\begin{array}{c}\text { DC } \\
\text { Reading } \\
\text { (mV) } \\
\text { [Step 9] }\end{array}$ & $\begin{array}{l}\text { Computed } \\
\text { Reading } \\
\text { (mV) } \\
\text { [Step 10] }\end{array}$ & $\begin{array}{c}\text { Uncertainty } \\
\text { (mV) }\end{array}$ & Specification \\
\hline & & & & 0.08 & \pm 68 \\
\hline
\end{tabular}


TEST PROCEDURES FOR ME-545()/G TRUE-RMS VOLTMETER

\subsection{Frequency Range}

\section{Specification:}

Frequency response shall be at least $10 \mathrm{~Hz}$ to $20 \mathrm{MHz}$.

Compliance with the frequency range specifications is implicit if the digital voltmeter-under-test (UUT) passes the tests for accuracy (see 10.6). A special test is therefore not necessary. 
TEST PROCEDURES FOR ME-545()/G TRUE-RMS VOLTMETER

10.3 Voltage Range

\section{Specification:}

Shall be from 100 micro-volts rms or less, to 300 volts rms or greater except where limited by the volt-hertz product of para. 10.12 .

The limits of the voltage range of the digital voltmeter under test (UUT) are determined as part of the Accuracy test (see 10.6). 
TEST PROCEDURES FOR ME-545()/G TRUE-RMS VOLTMETER

10.3.1 Selectable Ranges

Specification:

Meter shall provide no less than seven selectable ranges, with the lowest full scale range no greater than 2 millivolts rms, and the greatest full scale range at least 300 volts rms.

\section{Procedure:}

1. Consult the manufacturer's literature concerning the number and upper limits of the selectable ranges available. 
TEST PROCEDURES FOR ME-545()/G TRUE-RMS VOLTMETER

Table 10.3.1 Selectable Ranges

\begin{tabular}{|c|c|c|c|c|c|}
\hline $\begin{array}{l}\text { Measurement } \\
\text { Description }\end{array}$ & $\begin{array}{c}\text { Measurement } \\
\text { Data }\end{array}$ & $\begin{array}{c}\text { Estimated } \\
\text { Measurement } \\
\text { Uncertainty }\end{array}$ & $\begin{array}{l}\text { Specificatio } \\
\text { Min. }\end{array}$ & $\begin{array}{l}\text { Limits } \\
\text { Max. }\end{array}$ & Units \\
\hline $\begin{array}{r}\text { Number of } \\
\text { ranges }\end{array}$ & & N/A & 7 & & \\
\hline $\begin{array}{l}\text { Lowest } \\
\text { range }\end{array}$ & & $\mathrm{N} / \mathrm{A}$ & & 2 & $\mathrm{mV}$ \\
\hline $\begin{array}{l}\text { Highest } \\
\text { range }\end{array}$ & & $\mathrm{N} / \mathrm{A}$ & 300 & & V \\
\hline
\end{tabular}




\subsubsection{Ranging}

\section{Specification:}

Shall be auto-ranging, also shall have the capability of manually setting the range. Shall provide at least 108 over-range, or 108 under-range when manuatly auto-ranged.

This test determines whether in the automatic mode sufficient hysteresis has been provided so that the instrument will not hunt between ranges when the input voltage is near the range transition voltage.

\section{Equipment:}

Items

\section{AC Calibrator}

Power amplifier

Cable with BNC connectors

Dual banana plug to BNC

adapter

\section{Mode1}

Fluke $5200 \mathrm{~A}$ or equivalent

Fluke $5205 \mathrm{~A}$ or equivalent

3 feet or less, each.

\section{Procedure:}

1. Connect the ac voltage calibrator (Fluke Model 5200) to the digital voltmeter under test (UUT) using a dual banana plug-to-BNC adapter and a cable with BNC connectors. Use the set-up shown in Fig. $10.3 .2 \mathrm{~b}$ for tests greater than 120 volts.

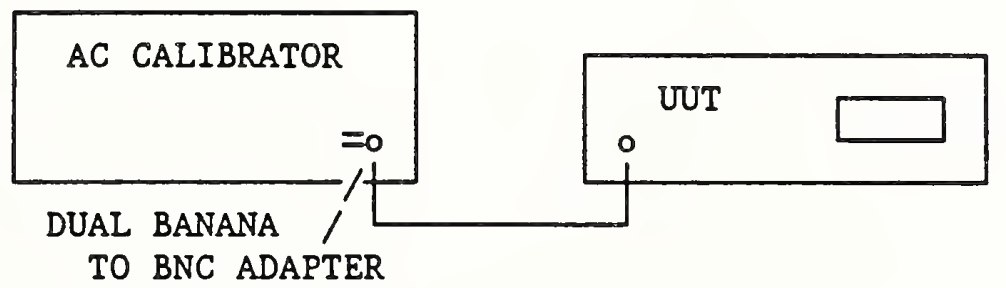

Fig. 10.3.2a Set-Up for Voltage Range Test

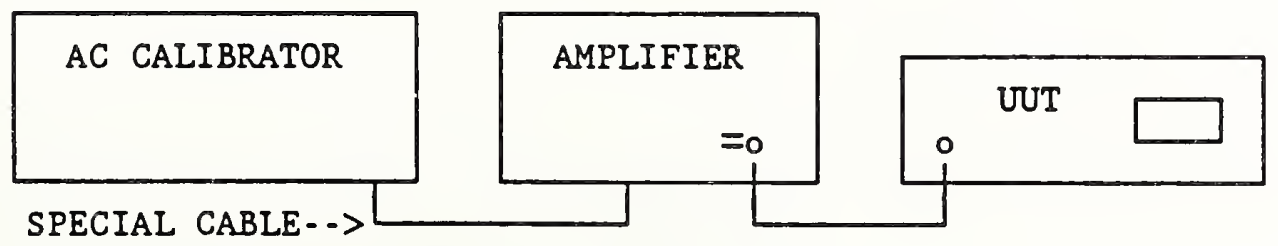

Fig. 10.3.2b Set-Up for Voltage Range Test for voltages above 100 volts 
2. Set the amplitude to zero, and set the frequency of the calibrator to $1 \mathrm{kHz}$.

3. Set the UUT to autoranging.

4. Increase the voltage of the calibrator so that a reading on the lowest range is obtained.

5. Slowly increase the voltage further until the UUT switches to the next higher range. Note, but do not record the approximate transition voltage.

6. Starting from somewhat below the approximate transition voltage, again increase the voltage, but more slowly than before, until the meter changes range. Observe the indicated voltage at each step and record the voltage on the data sheet corresponding to the step just before the meter changes to the next higher range. The changing of the range occurs when the analog voltage indicator changes from near full-scale deflection downscale to zero or near zero.

If the transition voltage cannot be determined exactly on the first txy, repeat step 6 , allowing the meter to settle a little longer after each step increase of the input voltage.

7. Starting from somewhat above the transition voltage, decrease the input voltage, using a procedure similar to that of step 6 , until the meter shifts to a lower range. Record on the data sheet the indicated voltage after the downshift has occurred.

8. Repeat steps 6 and 7 for each range of the meter. 
TEST PROCEDURES FOR ME-545()/G TRUE-RMS VOLTMETER

Table 10.3.2 Ranging

\begin{tabular}{|c|c|c|c|c|}
\hline \multirow[t]{2}{*}{$\begin{array}{c}\text { Transition } \\
\text { Up-Range }\end{array}$} & $\begin{array}{l}\text { Transition } \\
\text { Down-Range }\end{array}$ & Difference & Uncertainty & $\begin{array}{l}\text { Specification } \\
\text { Limits }\end{array}$ \\
\hline & & & $\mathrm{N} / \mathrm{A}$ & \pm 108 \\
\hline & & & N/A & \pm 108 \\
\hline & & & $\mathrm{N} / \mathrm{A}$ & $\pm 10 \%$ \\
\hline & & & N/A & \pm 108 \\
\hline & & & $\mathrm{N} / \mathrm{A}$ & \pm 108 \\
\hline & & & $\mathrm{N} / \mathrm{A}$ & \pm 108 \\
\hline & & & N/A & \pm 108 \\
\hline & & & $\mathrm{N} / \mathrm{A}$ & \pm 108 \\
\hline & & & $\mathrm{N} / \mathrm{A}$ & \pm 108 \\
\hline & & & N/A & $\pm 10 \%$ \\
\hline
\end{tabular}


10.3.3 Voltage Resolution

Specification:

Display resolution in voltage mode shall be at least as specified herein:

READING

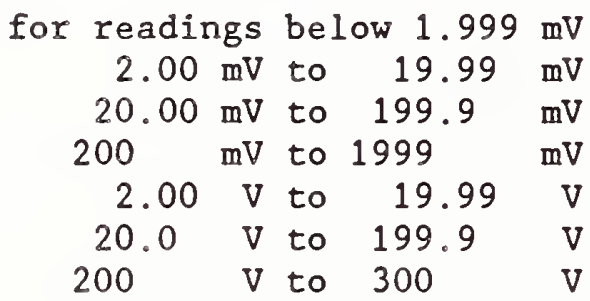

RESOLUTION

1 microvolt

10 microvolts

100 microvolts

1 millivolt

10 millivolts

100 millivolts

1 volt

\section{Test Points:}

Table 10.3.3.1

\begin{tabular}{|l|cc|cc|c|}
\hline T.P.No. & Test Voltage & Voltage Increment & Frequency \\
\hline \hline & & & & & \\
1. & 1.998 & $\mathrm{mV}$ rms & $0.001 \mathrm{mV} \mathrm{rms}$ & $10.00 \mathrm{kHz}$ \\
2. & 19.98 & $\mathrm{mV}$ rms & $0.010 \mathrm{mV} \mathrm{rms}$ & $10.00 \mathrm{kHz}$ \\
3. & 199.8 & $\mathrm{mV}$ rms & $0.100 \mathrm{mV}$ rms & $10.00 \mathrm{kHz}$ \\
4. & 1.998 & V rms & $0.001 \mathrm{~V}$ rms & $10.00 \mathrm{kHz}$ \\
5. & 19.98 & V rms & 0.010 & V rms & $10.00 \mathrm{kHz}$ \\
6. & 199.8 & V rms & 0.100 & V rms & $10.00 \mathrm{kHz}$ \\
7. & 298 & V rms & 1.000 & V rms & $10.00 \mathrm{kHz}$ \\
\hline
\end{tabular}




\section{Equipment:}

Items

AC Calibrator Power amplifier

Cable with BNC connectors

Dual banana plug to BNC

adapter

\section{Model}

Fluke $5200 \mathrm{~A}$ or equivalent Fluke 5205A or equivalent 3 feet or less, each.

\section{Procedure:}

It is important to read the entire procedure before beginning the test. All equipment should be warmed up following the manufacturers' specification before any measurements are made.

1. Connect the ac voltage calibrator (Fluke Model 5200) to the digital voltmeter under test (UUT) using a dual banana plug-to-BNC adapter and a cable with BNC connectors.

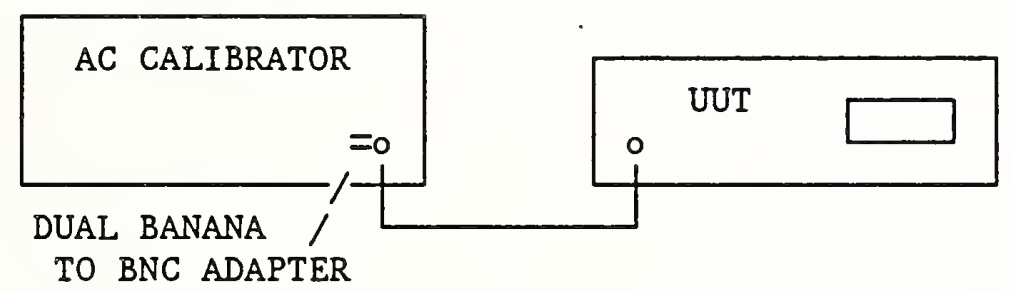

Fig. 10.3.3a Set-Up for Voltage Resolution Test

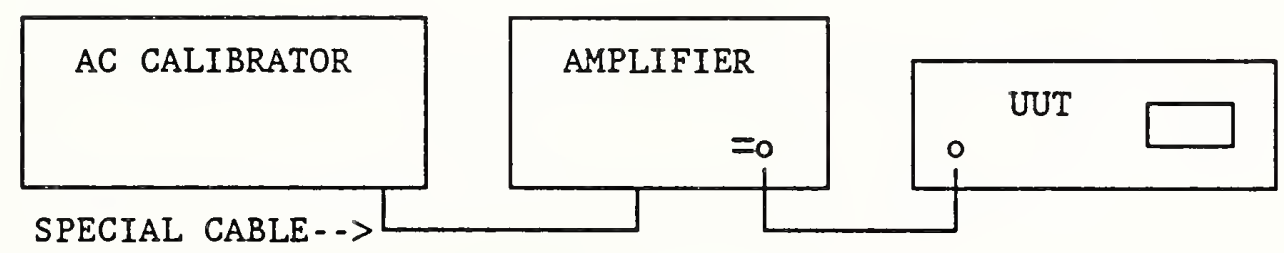

Fig. 10.3.3b Set-Up for the Resolution Test for voltages above 100 volts.

2. Set the output amplitude on the ac calibrator to approximately $1.99 \mathrm{mV}$.

3. Set the signal frequency to $10 \mathrm{kHz}$. 
4. Using the values given in Table 10.3.3.1, repeat the procedure in step 5 to step 9 below for Test Points 1. to 7.

5.

6.

7.

8.

9.

10. Calculate the differences between the value of the meter reading obtained in step 9 and the Test Point Voltage. (This establishes the resolution on the range selected). Note the units of the Test Point Voltage and the specification limits. 


\section{TEST PROCEDURES FOR ME-545()/G TRUE-RMS VOLTMETER}

Table 10.3.3.2 Voltage Resolution

\begin{tabular}{|c|c|c|c|c|}
\hline Test Point & Meter Rdg. & Difference & Uncertainty & Specification \\
\hline $1.998 \mathrm{~m}$ & & & $\pm 0.01 \mu \mathrm{V}$ & $1 \mu \mathrm{V}$ \\
\hline 19.98 & & & $\pm 0.1 \mu \mathrm{V}$ & $10 \mu \mathrm{V}$ \\
\hline 199.8 & & & $\pm 1.0 \quad \mu \mathrm{V}$ & $100 \mu \mathrm{V}$ \\
\hline 1.998 & & & $\pm 0.01 \mathrm{mV}$ & $1 \mathrm{mV}$ \\
\hline 19.98 & & & $\pm 0.1 \mathrm{mV}$ & $10 \mathrm{mV}$ \\
\hline 199.8 & & & $\pm 1.0 \mathrm{mV}$ & $100 \mathrm{mV}$ \\
\hline 298 & & & \pm 0.01 & 1 \\
\hline
\end{tabular}


TEST PROCEDURES FOR ME-545()/G TRUE-RMS VOLTMETER

10.4 Display Type and Units

Specification:

Shall have a digital display with $31 / 2$ digits, or more, in the voltage mode. Shall also have analog peak and null indicator. Analog peak and null indicator shall show changes in voltage equal to, or greater than 58 of full scale of range in use. The digital display shall have annunciacors for volts, millivolts, decibels relative, $d B m$, and polarity.

Procedure:

1. Check digital voltmeter under test (UUT) by visual inspection. 
TEST PROCEDURES FOR ME-545()/G TRUE-RMS VOLTMETER

Table 10.4 Display Type and Resolution

\begin{tabular}{|l|c|c|c|c|c|}
\hline $\begin{array}{c}\text { Measurement } \\
\text { Description }\end{array}$ & $\begin{array}{c}\text { Measurement } \\
\text { Data }\end{array}$ & $\begin{array}{c}\text { Estimated } \\
\text { Measurement } \\
\text { Uncertainty }\end{array}$ & $\begin{array}{c}\text { Specification Limits } \\
\text { Min. }\end{array}$ & Units \\
\hline $\begin{array}{c}\text { Number of } \\
\text { digits }\end{array}$ & & N/A & $31 / 2$ & & \\
\hline $\begin{array}{c}\text { Peak and } \\
\text { null indic. }\end{array}$ & & N/A & Yes & & \\
\hline $\begin{array}{l}\text { Show changes } \\
\geq 58 \text { of FS }\end{array}$ & & N/A & Yes & & \\
\hline $\begin{array}{l}\text { Proper } \\
\text { annunciators }\end{array}$ & & N/A & Yes & & \\
\hline
\end{tabular}


TEST PROCEDURES FOR ME-545()/G TRUE-RMS VOLTMETER

\subsection{Decibel Measurements}

\section{Specification:}

Meter shall have a minimum span of $130 \mathrm{~dB}$ and comply with the requirements herein.

\section{Equipment:}

\section{Items}

Mode 1

AC Calibrator

Power amplifier

Cable with BNC connectors

Dual banana plug to BNC adapter

\section{Procedure:}

The following test indicates the range of the voltage to decibel conversion capability of the digital voltmeter under test (UUT).

1. Short the input to the meter.

2. Set the meter into the decibel (dB) mode.

3. Set the meter to auto-ranging, note the decibel ( $d B$ ) reading, and enter the value into the data sheet, Table 10.5.

4. Remove the short from the input and connect the meter to the ac voltage standard and amplifier with the frequency set to $1 \mathrm{kHz}$, as shown in figure 10.5.

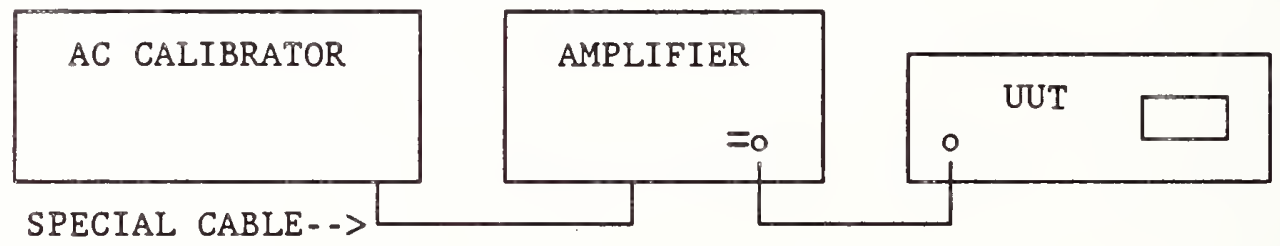

Fig. 10.5 Set-Up for the Decibel Test.

5. Set the output from the ac voltage standard to $300 \mathrm{~V}$.

6. Note the decibel reading with the voltage applied, and enter the value into the data sheet, Table 10.5.

7. Subtract the value obtained in step 3 from the value obtained in step 6 , and enter this difference on line 3 of the data sheet, Table 10.5 . 
TEST PROCEDURES FOR ME-545()/G TRUE-RMS VOLTMETER

Table 10.5 Decibel Measurement

\begin{tabular}{|l|c|c|c|c|c|}
\hline $\begin{array}{l}\text { Measurement } \\
\text { Description }\end{array}$ & $\begin{array}{c}\text { Measurement } \\
\text { Data }\end{array}$ & $\begin{array}{c}\text { Estimated } \\
\text { Measurement } \\
\text { Uncertainty }\end{array}$ & $\begin{array}{c}\text { Specification Limits } \\
\text { Min. }\end{array}$ & Units \\
\hline $\begin{array}{l}\text { Reading with } \\
\text { input shorted }\end{array}$ & & N/A & $* * * *$ & $* * * *$ & $\mathrm{~dB}$ \\
\hline $\begin{array}{l}\text { Reading with } \\
300 \text { V applied }\end{array}$ & & N/A & $* * * *$ & $* * * *$ & $\mathrm{~dB}$ \\
\hline $\mathrm{dB}$ range & & N/A & 130 & & \\
\hline
\end{tabular}




\subsubsection{Decibel Display and Resolution}

\section{Specification:}

Meter shall have at least 4-digit display with polarity indicator when in the decibel mode, decibel resolution shall be at least $0.01 \mathrm{~dB}$.

\section{Equipment:}

Items

AC Calibrator

Cable with BNC connectors

Dual banana plug to BNC adapter

\section{$\underline{\text { Mode } 1}$}

Fluke $5200 \mathrm{~A}$ or equivalent

3 feet or less, each.

\section{Procedure:}

The number of digits in the display of the digital voltmeter under test (UUT) are determined by inspection.

1. Set the meter to the auto-ranging mode and to the decibel display mode.

2. Connect the ac voltage standard to the meter as shown in figure 10.5 .1 , and set the voltage to 1.00 volt.

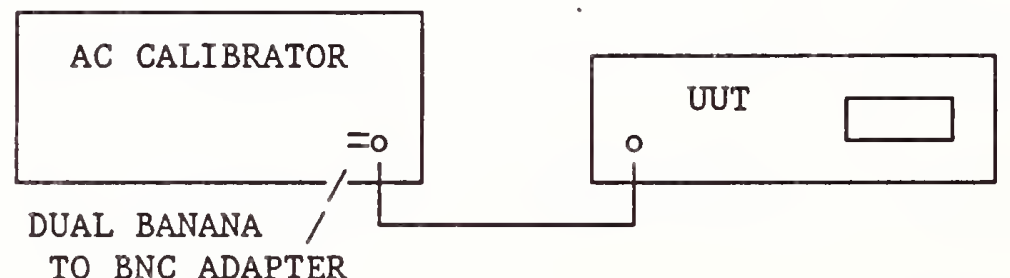

Fig. 10.5.1 Set-Up for Decibel Resolution Test

3. Adjust the voltage up or down until the maximum number of digits are displayed.

4. Check the number of digits and the presence of a polarity indicator and enter the appropriate answers in the data sheet, Table 10.5.1. 
TEST PROCEDURES FOR ME-545()/G TRUE-RMS VOLTMETER

Table 10.5.1 Decibel Measurements

\begin{tabular}{|l|c|c|c|c|c|}
\hline $\begin{array}{c}\text { Measurement } \\
\text { Description }\end{array}$ & $\begin{array}{c}\text { Measurement } \\
\text { Data }\end{array}$ & $\begin{array}{c}\text { Estimated } \\
\text { Measurement } \\
\text { Uncertainty }\end{array}$ & $\begin{array}{c}\text { Specification Limits } \\
\text { Min. }\end{array}$ & Units \\
\hline $\begin{array}{c}\text { Number of } \\
\text { digits }\end{array}$ & & N/A & 4 & & \\
\hline $\begin{array}{c}\text { Polarity } \\
\text { indicator }\end{array}$ & & N/A & Yes & & \\
\hline Resolution & & N/A & 0.01 & $\mathrm{~dB}$ \\
\hline
\end{tabular}


TEST PROCEDURES FOR ME-545()/G TRUE-RMS VOLTMETER

10.5.2 dBm Reference Impedance

\section{Specification:}

In $d B$ mode, reference impedance shall be selectable, with a minimum of five selection: 50 ohms, 75 ohms, 124 ohms, 135 ohms, and 600 ohms.

\section{Procedure:}

1. The number and values of the reference impedances are to be determined by inspection. 
TEST PROCEDURES FOR ME-545()/G TRUE-RMS VOLTMETER

Table 10.5.2 dBm Reference Impedance

\begin{tabular}{|c|c|c|c|c|c|}
\hline $\begin{array}{l}\text { Measurement } \\
\text { Description }\end{array}$ & $\begin{array}{c}\text { Measurement } \\
\text { Data }\end{array}$ & $\begin{array}{l}\text { Estimated } \\
\text { Measurement } \\
\text { Uncertainty }\end{array}$ & $\begin{array}{l}\text { Specificatio } \\
\text { Min. }\end{array}$ & $\begin{array}{l}\text { Limits } \\
\text { Max. }\end{array}$ & Units \\
\hline $\begin{array}{l}\text { Number of } \\
\text { ref. levels }\end{array}$ & & $\mathrm{N} / \mathrm{A}$ & 5 & & \\
\hline $\begin{array}{l}\text { Levels } \\
\text { comply }\end{array}$ & & $\mathrm{N} / \mathrm{A}$ & Yes & & \\
\hline
\end{tabular}


TEST PROCEDURES FOR ME-545()/G TRUE-RMS VOLTMETER

10.6 Accuracy

\section{Specification:}

Shall be at least as specified below over the operating temperature range from 18 to 28 degrees Celsius, for ac-coupled measurements. $A C+D C$ measurement accuracy shall be within twice the tolerance for ac measurements.

\section{Procedure:}

Note: Because of the wide frequency and voltage ranges covered by the digital voltmeter under test (UUT), accuracy tests are carried out using three different methods.

From $10 \mathrm{~Hz}$ to $99.9 \mathrm{kHz}$, for voltages above 1 millivolt, test signals are obtained from a calibrated ac voltage standard, while at frequencies from $100 \mathrm{kHz}$ to $20 \mathrm{MHz}$ an uncalibrated signal source is used, and the voltage applied to the meter is measured using thermal converters.

For measurements at a voltage level of 100 microvolts, regardless of the signal frequency, a micropotentiometer is used.

The procedures that make use of the ac voltage calibrator have been automated with a Hewlett-Packard Model 9836 computer as the controller for the calibrator. Readings of the digital voltmeter under test (UUT) are read visually and entered via the computer keyboard. The computer terminal provides the necessary prompts to carry out the calibration.

For tests at frequencies at or above $100 \mathrm{kHz}$, a Hewlett-Packard Model 3325A Function Generator and a power amplifier (ENI Model A300-40PA) are used as a signal source. For output voltages from 1.0 to 50.0 volts rms, the output of the amplifier is connected directly to the input of the meter, and for voltages above 50 volts a special step-up (output) transformer (ENI Model AM5-5B) is used. 
TEST PROCEDURES FOR ME-545()/G TRUE-RMS VOLTMETER

PRELIMINARY DC CALIBRATION OF THE MICROPOTENTIOMETER

RF-DC transfer difference from dc to $100 \mathrm{MHz}$ at a voltage level of 100 microvolts

Specification:

Shall be within 0.28 of dc input level.

Test Point: $\quad 100 \mu \mathrm{V}$ rms at dc

Equipment:

Items

DC calibrator

10-mA Micropotentiometer

$0.01 \mathrm{ohm}$ standard resistor

DC millivoltmeter

Thermal converter output

cable attached)
Model

Fluke $5440 B$ or equivalent

Ballantine 440-10

Ballantine 440-02

Fluke $8506 \mathrm{~A}$ or equivalent ( 2 required)

Special cable with dual Banana plug

\section{Procedure:}

It is important to read the entire procedure before beginning the test. All equipment should be warmed up following the manufacturers' specification before any measurements are made.

WARNING: Thermoelements are easily damaged

by even moderate over-voltage.

Do not leave connected except when

actually carrying out test.

1. Attach the 0.01 ohm standard resistor to the output port of the micropotentiometer housing.

2. Connect the equipment as shown in figure 10.6.1. Attach a BNC (female) to type $\mathrm{N}$ (male) adapter to the input connector of the micropotentiometer. Attach a dual banana plug (male) to type $\mathrm{N}$ (female) adapter to a type $N-N$ (male-male) adapter, and connect the adapters to the output connector (standard resistor) of the micropotentiometer. Connect the combination to the input of one of the millivoltmeters.

3. Connect the output of the thermal converter to the other dc 
millivoltmeter using the attached thermal converter output cable. Set the millivoltmeter to the l-volt range.

4. Set the de calibrator to an amplitude of approximately 0.15 volts, and then fine-adjust the calibrator voltage until the micropotentiometer output reads 100 microvolts. NOTE WARNING Wait for about one minute until the voltage reading settles, and then read and record on the data sheet the output voltage of the thermoelement of the micropotentiometer on the other millivoltmeter.

Note: To achieve the required accuracy, the dc millivoltmeter must be used in the averaging mode.

5. Reverse the polarity of the dc supplied by the calibrator and repeat step 4. Then proceed to step 6 .

6. Calculate the average of the two thermoelement output voltages by adding the two numerical values recorded on the data sheet, ignoring the sign, and dividing the sum by two.

7. Disconnect the dc voltage calibrator immediately after making the measurement to prevent possible damage to the thermoelement. Carefully disassemble the setup so that the micropotentiometer and its associated resistor can be used to make ac measurements. Note warning! 


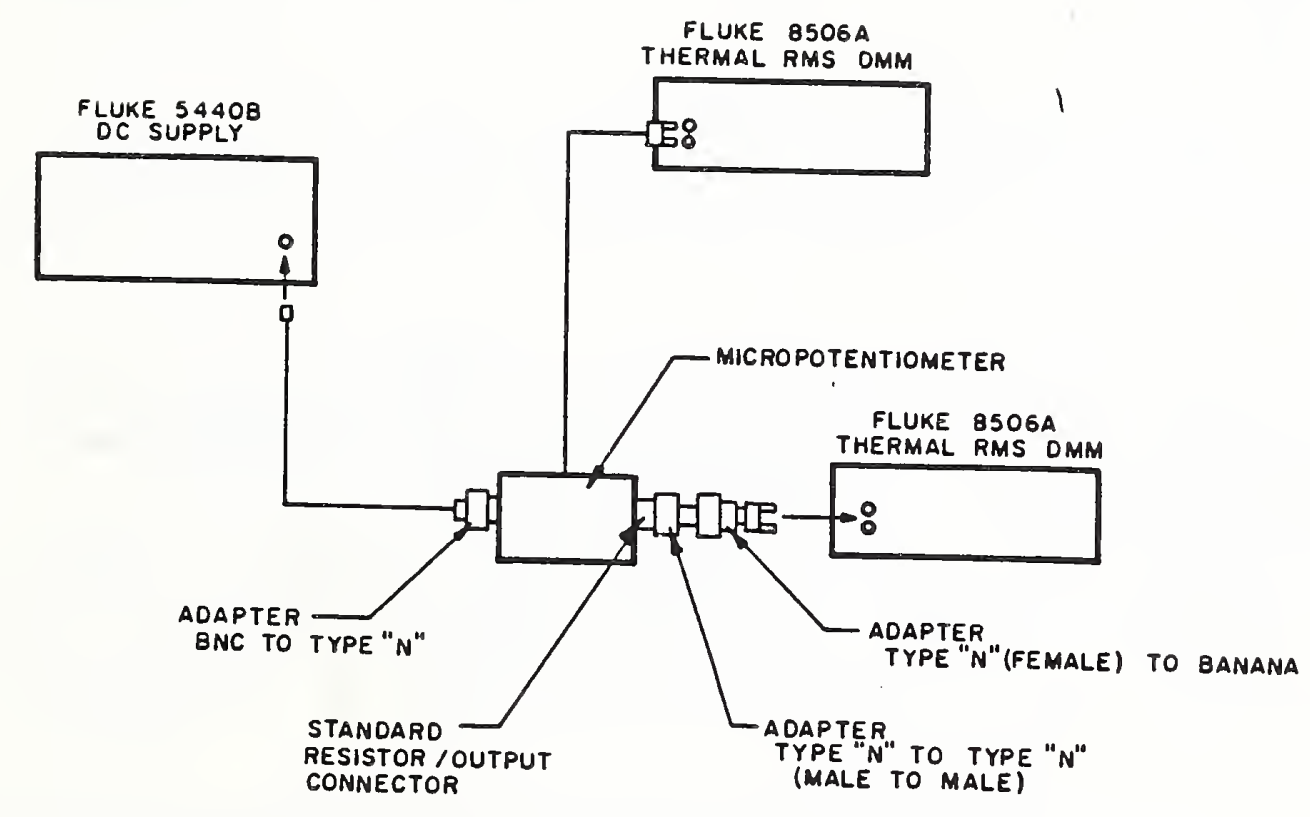

Fig. 10.6.1 Set-Up for Micropotentiometer DC Calibration 
Accuracy for frequencies from $10 \mathrm{~Hz}$ to $49.99 \mathrm{~Hz}$ for all input levels from 100 microvolts to 300 volts

\section{Specification:}

Shall be within $\pm 5 \%$ of true input level.

Test Point: $\quad 100 \mu \mathrm{V}$ rms at $10.0 \mathrm{~Hz}$

Equipment:

Items

Function generator

10-mA Micropotentiometer

$0.01 \mathrm{ohm}$ standard resistor

DC millivoltmeter

Thermal converter output

cable
Mode 1

Hewlett-Packard 3325A or equivalent

Ballantine 440-10

Ballantine 440.02

Fluke $8506 \mathrm{~A}$ or equivalent

Attached to micropotentiometer, free end dual Banana plug

\section{Procedure:}

It is important to read the entire procedure before beginning the test. All equipment should be warmed up following the manufacturers' specification before any measurements are made.

WARNING: Thermoelements are easily damaged

by even moderate over-voltage.

Do not leave connected except when

actually carrying out test.

1. Attach the 0.01 ohm standard resistor to the output port of the micropotentiometer housing.

2. Connect the equipment as shown in figure 10.6.2. Attach a BNC (female) to type $\mathrm{N}$ (male) adapter to the input connector of the micropotentiometer. Attach a BNC (male) to type $\mathrm{N}$ (female) adapter to a type $\mathrm{N}$ - N (male-male) adapter, and connect the adapters to the output connector (standard resistor) of the micropotentiometer. Connect the combination to the input of the UUT.

3. Connect the output of the thermal converter to the dc millivoltmeter using a thermal converter output cable. Set the millivoltmeter to the 1 -volt range. 
4. Set the function generator to a frequency of $10.0 \mathrm{~Hz}$, and set the

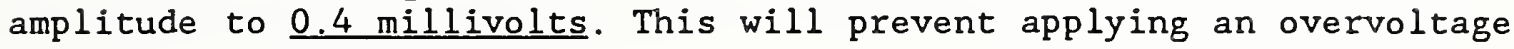
to the thermoelement.

5. Connect the output of the function generator to the input of the micropotentiometer using any shielded cable (e.g. RG 58-U) with BNC connectors.

6. Slowly increase the output voltage of the function generator, while watching the reading of the dc millivoltmeter, until the reading reaches the voltage determined during the dc calibration of the micropotentiometer. An ac voltage of $100 \mu \mathrm{V}$ is then being applied to the UUT.

7. Consult the manufacturer's instructions for operation of the UUT in the $100-\mu \mathrm{V}$ range, and make the prescribed adjustments such as setting the averaging time constant, switching a filter into the circuit, etc.

8. When the reading of the UUT has settled, note and record it on the data sheet.

9. Disconnect the function generator immediately after making the measurement to prevent possible damage to the thermoelement. Note warning! 
TEST PROCEDURES FOR ME-545()/G TRUE-RMS VOLTMETER

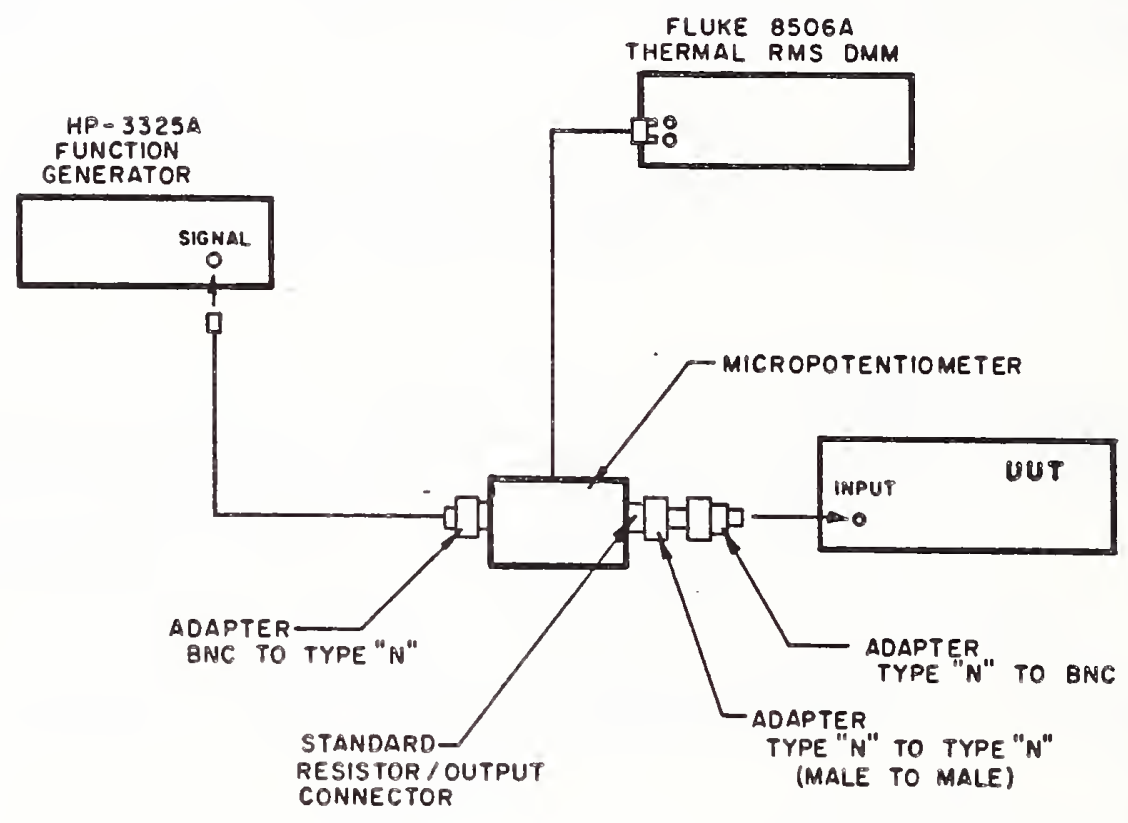

Fig. 10.6.2 Set-Up for $100 \mu \mathrm{V}$ AC Measurements 
Accuracy for frequencies from $100 \mathrm{~Hz}$ to $99.9 \mathrm{kHz}$ for all input levels from 100 microvolts to 1 millivolt

\section{Specification:}

Shall be within \pm 58 of true input level.

Test Point: $\quad \quad \quad \quad \quad \mu 0 \mathrm{\mu V}$ rms at $10.0 \mathrm{kHz}$

\section{Equipment:}

\section{Items}

Function generator 10-mA Micropotentiometer $0.01 \mathrm{ohm}$ standard resistor DC millivoltmeter Thermal converter output cable
Mode

Hewlett-Packard $3325 \mathrm{~A}$ or equivalent Ballantine 440-10

Ballantine 440-02

Fluke $8506 \mathrm{~A}$ or equivalent

Attached to micropotentiometer, free end dual Banana plug

\section{Procedure:}

It is important to read the entire procedure before beginning the test. All equipment should be warmed up following the manufacturers' specification before any measurements are made.

\begin{tabular}{|c|c|}
\hline WARNING : & $\begin{array}{l}\text { Thermoelements are easily damaged } \\
\text { by even moderate over-voltage. } \\
\text { Do not leave connected except when } \\
\text { actually carrying out test. }\end{array}$ \\
\hline
\end{tabular}

1. Attach the 0.01 ohm standard resistor to the output port of the micropotentiometer housing.

2. Connect the equipment as shown in figure 10.6.2. Attach a BNC (female) to type $\mathrm{N}$ (male) adapter to the input connector of the micropotentiometer. Attach a BNC (male) to type $N$ (female) adapter to a type $N$ - N (male-male) adapter, and connect the adapters to the output connector (standard resistor) of the micropotentiometer. Connect the combination to the input of the UUT.

3. Connect the output of the thermal converter to the dc millivoltmeter using a thermal converter output cable. Set the millivoltmeter to the 1 -volt range. 
4. Set the function generator to a frequency of $10.0 \mathrm{kHz}$, and set the amplitude to 0.4 millivolts. This will prevent applying an overvoltage to the thermoelement.

5. Connect the output of the function generator to the input of the micropotentiometer using any shielded cable (e.g. RG 58-U) with BNC connectors.

6. Slowly increase the output voltage of the function generator, while watching the reading of the dc millivoltmeter, until the reading reaches the voltage determined during the dc calibration of the micropotentiometer. An ac voltage of $100 \mu \mathrm{V}$ is then being applied to the UUT.

7. Consult the manufacturer's instructions for operation of the UUT in the $100-\mu \mathrm{V}$ range, and make the prescribed adjustments such as setting the averaging time constant, switching a filter into the circuit, etc.

8. When the reading of the UUT has settled, note and record it on the data sheet.

9. Disconnect the function generator immediately after making the measurement to prevent possible damage to the thermoelement. Note warning! 
Accuracy for frequencies from $100 \mathrm{kHz}$ to $999.9 \mathrm{kHz}$ for all input levels from 100 microvolts to $1 \times 10^{8}$ volt-hertz.

\section{Specification:}

Shall be within $\pm 5 \%$ of true input level.

Test Point: $\quad 100 \mu \mathrm{V}$ rms at $999.9 \mathrm{kHz}$

Equipment:

Items

AC calibrator

Function generator

10-mA Micropotentiometer

$0.01 \mathrm{ohm}$ standard resistor

DC millivoltmeter

Thermal converter output

cable
Model

Fluke $5200 \mathrm{~A}$ or equivalent

Hewlett-Packard $3325 \mathrm{~A}$ or equivalent

Ballantine 440-10

Ballantine 440-02

Fluke $8506 \mathrm{~A}$ or equivalent

Attached to micropotentiometer, free end dual Banana plug

\section{Procedure:}

It is important to read the entire procedure before beginning the test. All equipment should be warmed up following the manufacturers' specification before any measurements are made.

\begin{tabular}{|c|c|}
\hline WARNING: & $\begin{array}{l}\text { Thermoelements are easily damaged } \\
\text { by even moderate over-voltage. } \\
\text { Do not leave connected except when } \\
\text { actually carrying out test. }\end{array}$ \\
\hline
\end{tabular}

1. Attach the $0.01 \mathrm{ohm}$ standard resistor to the output port of the micropotentiometer housing.

2. Connect the equipment as shown in figure 10.6.2. Attach a BNC (female) to type $\mathrm{N}$ (male) adapter to the input connector of the micropotentiometer. Attach a BNC (male) to type $\mathrm{N}$ (female) adapter to a type $N$ - N (male-male) adapter, and connect the adapters to the output connector (standard resistor) of the micropotentiometer. Connect the combination to the input of the UUT.

3. Connect the output of the thermal converter to the dc millivoltmeter using a thermal converter output cable. Set the millivoltmeter to the 1 -volt range. 
4. Set the function generator to a frequency of $999.9 \mathrm{kHz}$, and set the amplitude to 0.4 millivolts. This will prevent applying an overvoltage to the thermoelement.

5. Connect the output of the function generator to the input of the micropotentiometer using any shielded cable (e.g. RG 58.U) with BNC connectors.

6. Slowly increase the output voltage of the function generator, while watching the reading of the dc millivoltmeter, uncil the reading reaches the voltage determined during the dc calibration of the micropotentiometer. An ac voltage of $100 \mu \mathrm{V}$ is then being applied to the UUT.

7. Consult the manufacturer's instructions for operation of the UUT in the $100-\mu V$ range, and make the prescribed adjustments such as setting the averaging time constant, switching a filter into the circuit, etc.

8. When the reading of the UUT has settled, note and record it on the data sheet.

9. Disconnect the function generator immediately after making the measurement to prevent possible damage to the thermoelement. Note warning! 
Accuracy for frequencies from $1 \mathrm{MHz}$ to $9.99 \mathrm{MHz}$ for all input levels from 100 microvolts to $1 \times 10^{8}$ volt-hertz.

\section{Specification:}

Shall be within $\pm 10 \%$ of true input level.

Test Point: $\quad 100 \mu \mathrm{V}$ rms at $9.99 \mathrm{MHz}$

Equipment:

Items

Function generator

10-mA Micropotentiometer

$0.01 \mathrm{ohm}$ standard resistor

DC millivoltmeter

Thermal converter output

cable
Model

Hewlett-Packard 3325A or equivalent

Ballantine 440-10

Ballantine 440-02

Fluke $8506 \mathrm{~A}$ or equivalent

Attached to micropotentiometer, free end dual Banana plug

\section{Procedure:}

It is important to read the entire procedure before beginning the test. All equipment should be warmed up following the manufacturers' specification before any measurements are made.

WARNING: Thermoelements are easily damaged

by even moderate over-voltage.

Do not leave connected except when

actually carrying out test.

1. Attach the 0.01 ohm standard resistor to the output port of the micropotentiometer housing.

2. Connect the equipment as shown in figure 10.6.2. Attach a BNC (female) to type $N$ (male) adapter to the input connector of the micropotentiometer. Attach a BNC (male) to type N (female) adapter to a type $N$ - N (male-male) adapter, and connect the adapters to the output connector (standard resistor) of the micropotentiometer. Connect the combination to the input of the UUT.

3. Connect the output of the thermal converter to the dc millivoltmeter using a thermal converter output cable. Set the millivoltmeter to the 1 -volt range. 
4. Set the function generator to a frequency of $9.99 \mathrm{MHz}$, and set the amplitude to 0.4 millivolts. This will prevent applying an overvoltage to the thermoelement.

5. Connect the output of the function generator to the input of the micropotentiometer using any shielded cable (e.g. RG 58-U) with BNC connectors.

6. Slowly increase the output voltage of the function generator, while watching the reading of the dc millivoltmeter, until the reading reaches the volrage determined during the dc calibration of the micropotentiometer. An ac voltage of $100 \mu \mathrm{V}$ is then being applied to the UUT.

7. Consult the manufacturer's instructions for operation of the UUT in the $100-\mu \mathrm{V}$ range, and make the prescribed adjustments such as setting the averaging time constant, switching a filter into the circuit, etc.

8. When the reading of the UUT has settled, note and record it on the data sheet.

9. Disconnect the function generator immediately after making the measurement to prevent possible damage to the thermoelement. Note warning! 
Accuracy for frequencies from $10 \mathrm{MHz}$ to $19.99 \mathrm{MHz}$ for all input levels from 100 microvolts to $1 \times 10^{8}$ volt-hertz.

\section{Specification:}

Shall be within \pm 158 of true input level.

Test Point: $\quad 100 \mu \mathrm{V}$ rms at $19.99 \mathrm{MHz}$

Equipment:

Items

\section{AC calibrator}

Function generator

10-mA Micropotentiometer

$0.01 \mathrm{ohm}$ standard resistor

DC millivoltmeter

Thermal converter output

cable

\section{Model}

Fluke $5200 \mathrm{~A}$ or equivalent

Hewlett-Packard 3325A or equivalent

Ballantine 440-10

Ballantine 440-02

Fluke $8506 \mathrm{~A}$ or equivalent

Attached to micropotentiometer, free end dual Banana plug

\section{Procedure:}

It is important to read the entire procedure before beginning the test. All equipment should be warmed up following the manufacturers' specification before any measurements are made.

WARNING: Thermoelements are easily damaged

by even moderate over-voltage.

Do not leave connected except when actually carrying out test.

1. Attach the 0.01 ohm standard resistor to the output port of the micropotentiometer housing.

2. Connect the equipment as shown in figure 10.6.2. Attach a BNC (female) to type $N$ (male) adapter to the input connector of the micropotentiometer. Attach a BNC (male) to type $\mathrm{N}$ (female) adapter to a type $N$ - N (male-male) adapter, and connect the adapters to the output connector (standard resistor) of the micropotentiometer. Connect the combination to the input of the UUT.

3. Connect the output of the thermal converter to the dc millivoltmeter using a thermal converter output cable. Set the millivoltmeter to the 1 -volt range. 
4. Set the function generator to a frequency of $19.99 \mathrm{MHz}$, and set the amplitude to 0.4 millivolts. This will prevent applying an overvoltage to the thermoelement.

5. Connect the output of the function generator to the input of the micropotentiometer using any shielded cable (e.g. RG 58/U) with BNC connectors.

6. Slowly increase the output voltage of the function generator, while watching the reading of the dc millivoltmeter, until the reading reaches the voltage determined during the dc calibration of the micropotentiometer. An ac voltage of $100 \mu \mathrm{V}$ is then being applied to the UUT.

7. Consult the manufacturer's instructions for operation of the UUT in the $100-\mu \mathrm{V}$ range, and make the prescribed adjustments such as setting the averaging time constant, switching a filter into the circuit, etc.

8. When the reading of the UUT has settled, note and record it on the data sheet.

9. Disconnect the function generator immediately after making the measurement to prevent possible damage to the thermoelement. Note warning! 
Accuracy for frequencies from $10 \mathrm{~Hz}$ to $49.99 \mathrm{~Hz}$ for all input levels from 100 microvolts to 300.0 volts and for frequencies from $50 \mathrm{~Hz}$ to $99.99 \mathrm{kHz}$ for all input levels from 1 millivolt to 300 volts (200 volts $20 \mathrm{kHz}$ to 99.99 $\mathrm{kHz}$ ).

\section{Specification:}

Shall be within $\pm 3 \%$ of true input level.

Test Points: $\quad 1.0 \mathrm{mV}$ rms at $10.00 \mathrm{~Hz}$ $300.0 \mathrm{~V}$ rms at $10.00 \mathrm{~Hz}$

$1.0 \mathrm{mV}$ rms at $50.00 \mathrm{~Hz}$

$300.0 \mathrm{~V}$ rms at $50.00 \mathrm{~Hz}$

$1.0 \mathrm{mV}$ rms at $10.0 \mathrm{kHz}$

$10.0 \mathrm{mV} \mathrm{rms}$ at $10.00 \mathrm{kHz}$

$100.0 \mathrm{mV}$ rms at $10.00 \mathrm{kHz}$

$1.0 \mathrm{~V}$ rms at $10.00 \mathrm{kHz}$

$10.0 \mathrm{~V}$ rms at $10.00 \mathrm{kHz}$

$300.0 \mathrm{~V}$ rms at $10.00 \mathrm{kHz}$

$1.0 \mathrm{mV}$ rms at $99.99 \mathrm{kHz}$

200.0 V rms at $99.99 \mathrm{kHz}$

Equipment:

\section{Items}

AC calibrator

Power amplifier

Instrument Controller

(IEEE-488 Bus)

IEEE-488 cable

Dual banana to BNC adapter

Cable with BNC connectors
Model

Fluke $5200 \mathrm{~A}$ or equivalent Fluke $5205 \mathrm{~A}$ or equivalent

Hewlett-Packard 9836 or equivalent

\section{Procedure:}

It is important to read the entire procedure before beginning the test. All equipment should be warmed up following the manufacturers' specification before any measurements are made. 
WARNING: This procedure uses lethal voltages during the test

Care should be taken to avold injury or shock.

1. Link the instrument controller (computer) to the calibrator and the power amplifier using the IEEE-488 cable. Also, connect the power amplifier to the calibrator with the special purpose cable supplied by the manufacturer.

For tests with voltages between 1 volt and 100 volts, use the equipment as shown in figure 10.6.3. Connect the calibrator to the to the input of the UUT directly using the cable with BNC connectors and the dual. banana adapter.

For tests with voltages above 100 volts, connect the UUT to the power amplifier using the cable attached to the power amplifier and an adapter to make the connection as shown in figure 10.6.4. (The program will provide the necessary prompts.)

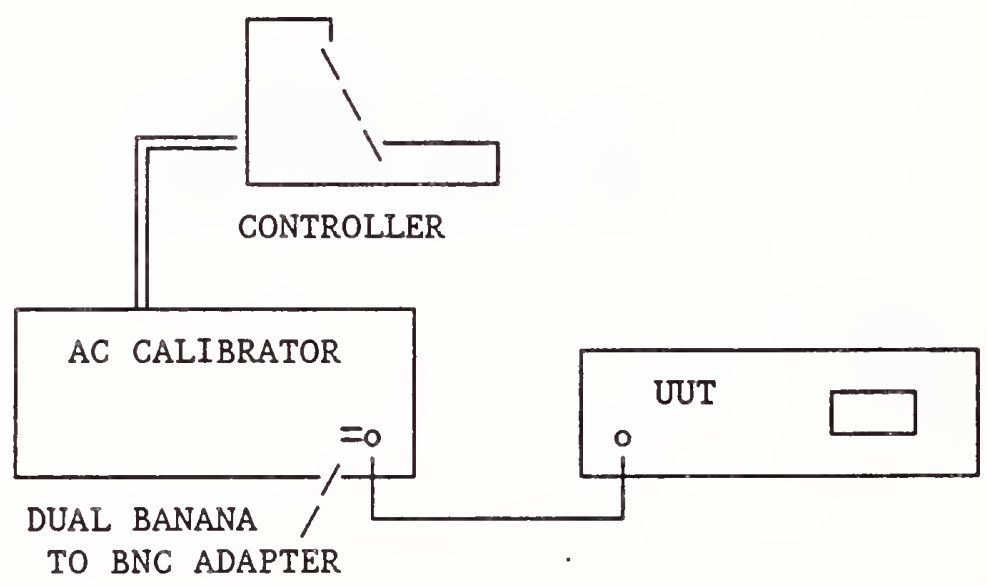

Fig. 10.6.3 Set-Up for the Accuracy Test with the Calibrator 


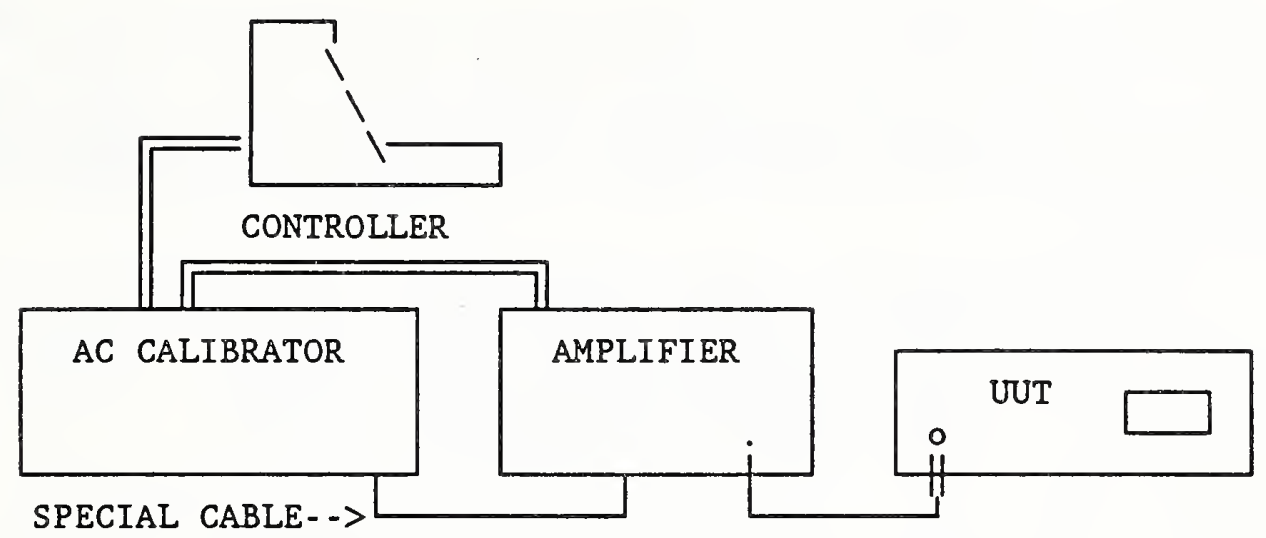

Fig. 10.6.4 Set-Up for the Accuracy Test with the Calibrator and Amplifier

2. Insert the $51 / 4$ in. floppy disk labelled "TMDE4A" into the right-hand disk drive of the computer (controller). The program requires that HPBasic 2.1 and AP 2.1 (or later versions) are first loaded into the computer.

3. Type LOAD "MENU" on the computer keyboard.

4. Press EXECUTE.

5. Press RUN and follow directions shown on the computer display.

6. Enter the results of the measurement shown on the printout into the data sheet, Table $10.6 \mathrm{~b}$. 
Accuracy for frequencies from $100 \mathrm{kHz}$ to $999.9 \mathrm{kHz}$ for all input levels from 100 microvolts to $1 \times 10^{8}$ volt-hertz.

\section{Specification:}

Shall be within $\pm 5 \%$ of true input level.

Test Point: $\quad 100.0 \mathrm{~V}$ rms at $999.9 \mathrm{kHz}$

Equipment:

\section{Items}

AC Calibrator

Function Generator

Power Amplifier

28-volt dc power supply

Output Transformer

100-volt thermal converter

DC millivoltmeter

Oscilloscope

Thermal converter output

cable

Cable with BNC connectors

RG $214 / 0$ cable with type "N"

connectors ( 3 required)

Type " $\mathrm{N}$ " tee (2 required)

BNC (male) to "N" (female)

(4 required)

Dual banana to " $\mathrm{N}$ " adapter

Coaxial relay

Relay control box

\section{Model}

Fluke $5200 \mathrm{~A}$ or equivalent

Hewlett-Packard 3325A or equivalent ENI A300-40PA (modified)

Kepco JQE 25-10M or equivalent

ENI AM-5B Serial No. 103

Ballantine 1394A-100 (modified)

Fluke $8506 \mathrm{~A}$ or equivalent

Tektronix 465 or equivalent

Type MS connector MS3102A-10SL-3P (3-pin male) to dual Banana plug

3 feet or less, each.

Hewlett-Packard 8761A

Special part 


\section{Procedure:}

It is important to read the entire procedure before beginning the test. All equipment should be warmed up following the manufacturers' specification before any measurements are made.

WARNING: Thermoelements are easily damaged

by even moderate over-voltage.

Do not leave connected except when

actually carrying out test.

1. Connect the equipment as shown in figure 10.6.5. Attach the BNC (male) to $\mathrm{N}$ (female) adapter to a type "N" (male) to "N" (male) adapter and then to a type "N" tee, and connect the combination to the input of the UUT.

2. Attach the coaxial relay to the thermal converter and port 1 of the coaxial relay to the type "N" tee.

3. Attach a BNC (male) to "N" (female) adapter to both input and output terminals of the output transformer.

4. Make sure the amplifier power supply is turned off. Then use a RG $214 / \mathrm{U}$ cable to connect the output of the power amplifier to the input of the transformer and another RG $214 / \mathrm{U}$ cable to connect the transformer to the tee leading to the UUT and thermal converter.

5. Make sure that the output voltage from the ac calibrator is zero. Then connect the output of the ac calibrator to port 2 of the coaxial switch using the dual banana to "N" adapter and a RG $214 / \mathrm{U}$ cable.

6. Connect the output of the 100-volt thermal converter to the dc millivoltmeter using a thermal converter output cable. Set the millivoltmeter to the 1-volt range. Set the coaxial switch to "Port 2" by momentarily depressing button No. 2 on the switch control box.

7. Set the frequency of the ac calibrator to $1 \mathrm{kHz}$, and bring the output voltage up slowly to 100 volts rms while observing the dc millivoltmeter reading and making sure the reading does not exceed 8 millivolts.

8. With the ac calibrator set to $100.0 \mathrm{~V}$ and when the reading on the dc 


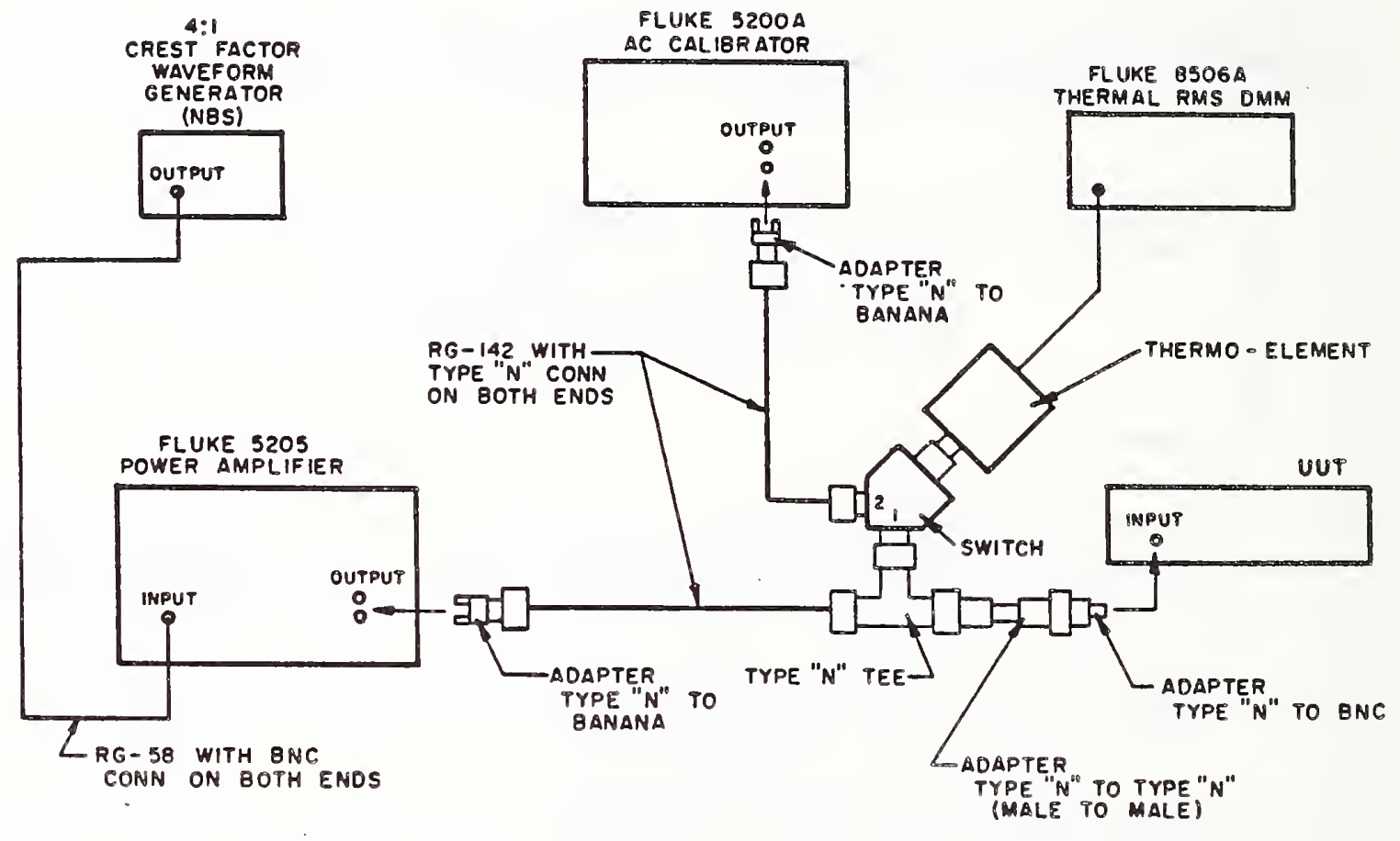

Fig. 10.6.5 Set-Up for the 100-volt Accuracy Test using a Thermal Convertex 
millivoltmeter has settled (about 5 to 10 minutes after setting frequency and amplitude; step 7), note and record the millivoltmeter reading on the data sheet, Table 10.6.c.

9. Turn on the power supply to the rf power amplifier and adjust it to 28 volts dc. The quiescent current should be approximately 6.5 amperes. Note warning!

WARNING: Do not turn on the rf power amplifier

if the cooling fan is not operating.

Do not obstruct air flow to the heat

sink. After switching off the power

supply, leave fan on until the heat

sink is at room temperature.

11. Set the frequency of the function generator to $999.9 \mathrm{kHz}$ and the amplitude to $1 \mathrm{mV}$ rms. Increase the output voltage until the UUT reads approximately $100.0 \mathrm{~V}$ rms.

12. Set the increment control on the function generator so that the least significant digit can be incremented $(0.001 \mathrm{mV})$.

13. Set the coaxial switch to "Port $1 "$ and, using the increment or decrement control (up or down arrows) of the function generator, slowly adjust the output voltage until the dc millivoltmeter reading settles to the same voltage as that obtained when using the $1 \mathrm{kHz}$ signal from the ac calibrator. The dc voltage reading will take 20 to 30 seconds to settle, and it may not be possible to get exactly the same reading as before because of limited resolution in the adjustment of the function generator. Generally, the dc millivolt readings should agree within $\pm 0.002 \mathrm{mV}$.

14. When the millivoltmeter reading agrees within the tolerance with the reading obtained when measuring the $1-\mathrm{kHz}$ reference signal, note and record on the data sheet, Table $10.6 \mathrm{c}$, the reading on the UUT (including the units) as well as the millivoltmeter reading.

15. Set the coaxial switch back to "Port 2," and check whether the reading has changed. If the reading has changed by more than $0.002 \mathrm{mV}$, repeat steps 11 to 13 . If it has not changed, the test is completed.

16. Set the function generator voltage to 0.4 millivolts (it cannot be set to zero) to power down the equipment, and set the ac calibrator to zero output. Turn off the power amplifier. 
Accuracy for frequencies from $1 \mathrm{MHz}$ to $9.99 \mathrm{MHz}$ for all input levels from 100 microvolts to $1 \times 10^{8}$ volt-hertz.

\section{Specification:}

Shall be within $\pm 10 \%$ of true input level.

Test Point: $\quad 10.00 \mathrm{~V}$ rms at $9.99 \mathrm{MHz}$

Equipment:

Items

AC Calibrator

Function Generator

Power Amplifier

28-volt dc power supply

10-volt thermal converter

DC millivoltmeter

Oscilloscope

Thermal converter output

cable

Cable with BNC connectors

RG 214/U cable with type "N"

connectors ( 3 required)

Type "N" tee (2 required)

50-ohm "N" adapter

BNC (male) to "N" (female)

(2 required)

Dual banana to "N" adapter

Coaxial relay

Relay control box
Mode 1

Fluke 5200A or equivalent

Hewlett-Packard 3325A or equivalent

ENI A300-40PA (modified)

Kepco JQE 25-10M or equivalent

Ballantine 1394A-10 or equivalent

Fluke $8506 \mathrm{~A}$ or equivalent

Tektronix 465 or equivalent

Type MS connector MS3102A-10SL-3P (3pin male) to dual Banana plug

3 feet or less, each.

Special part

Hewlett-Packard $8761 \mathrm{~A}$

Special part

\section{Procedure:}

It is important to read the entire procedure before beginning the test. All equipment should be warmed up following the manufacturers' specification before any measurements are made. 
WARNING: Thermoelements are easily damaged

by even moderate over-voltage.

Do not leave connected except when

actually carrying out test.

1. Connect the equipment as shown in figure 10.6.6. Attach the BNC (male) to $\mathrm{N}$ (female) adapter to the $50-\mathrm{ohm}$ " $\mathrm{N}-\mathrm{N}$ " adapter, then to a type "N" tee, and connect the combination to the input of the UUT.

2. Attach the coaxial relay to the thermal converter and port 1 of the coaxial relay to the type "N" tee.

3. Attach a BNC (male) to "N" (female) adapter to a type "N" tee, and connect the combination to one of the inputs of the oscilloscope.

4. Make sure the amplifier power supply is turned off. Then use a RG $214 / 0$ cable to connect the output of the power amplifier to the tee at the oscilloscope and another RG $214 / \mathrm{U}$ cable to connect the oscilloscope to the tee leading to the UUT and thermal converter.

5. Make sure that the output voltage from the ac calibrator is zero. Then connect the output of the ac calibrator to port 2 of the coaxial switch using a dual banana to "N" adapter and a RG $214 / 0$ cable.

6. Connect the output of the thermal converter to the dc millivoltmeter using a thermal converter output cable. Set the millivoltmeter to the 1-volt range. Set the coaxial switch to "Port 2" by momentarily depressing button No. 2 on the switch control box.

7. Set the frequency of the ac calibrator to $1 \mathrm{kHz}$, and bring the output voltage up slowly to 10 volts rms while observing the dc millivoltmeter reading and making sure the reading does not exceed 8 millivolts.

8. Turn on the oscilloscope and set it to display a 10-volt, 10-MHz signal ( 5 volts/div; 0.2 microsecond/div, 10x magnification, dc coupled). 


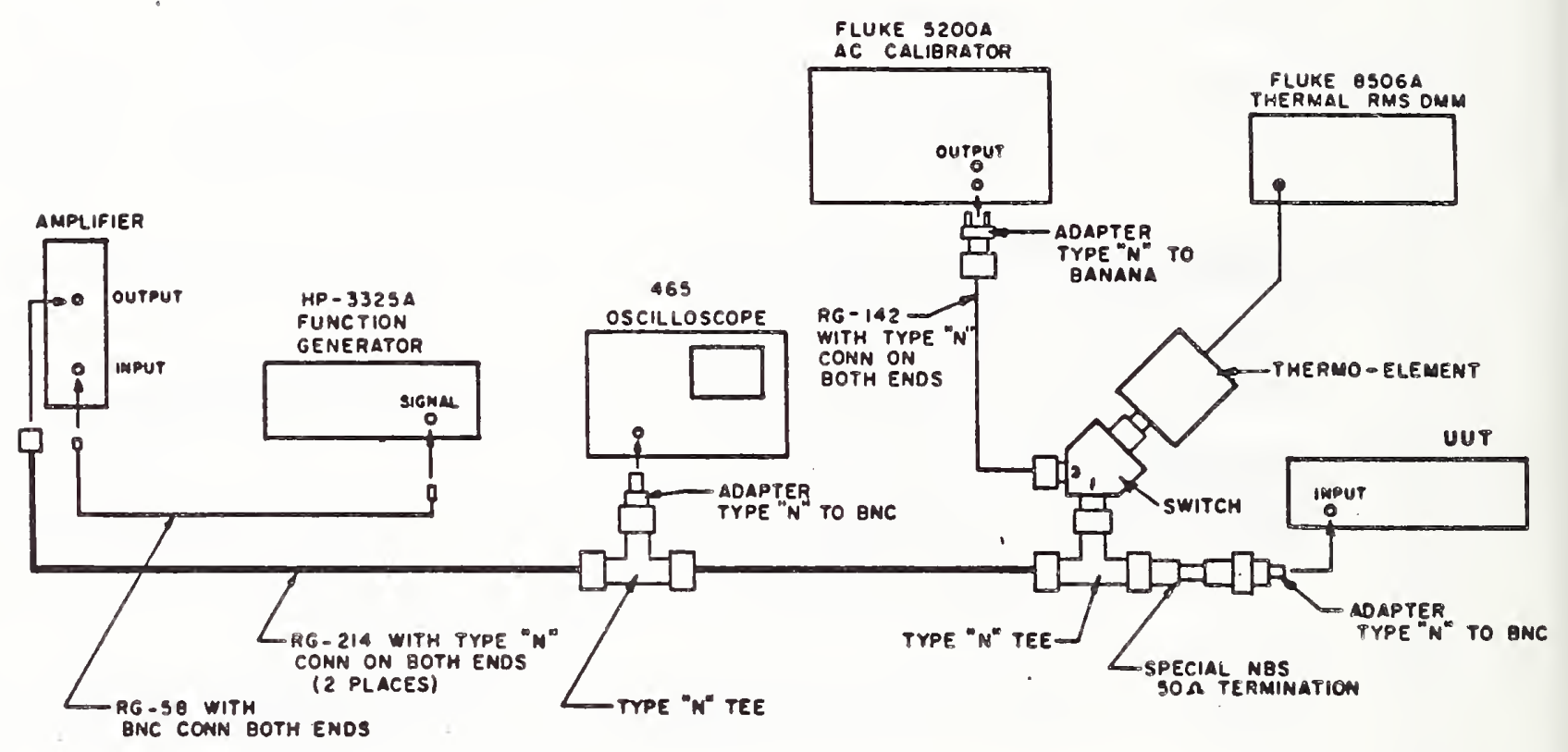

Fig. 10.6.6 Set-Up for Low-Voltage Accuracy Test using a Thermal Converter 
TEST PROCEDURES FOR ME-545()/G TRUE-RMS VOLTMETER

9. Turn on the power supply to the rf power amplifier and adjust it to 28 volts dc. The quiescent current should be approximately 6.5 amperes. Note warning!

WARNING: Do not turn on the rf power amplifier

if the cooling fan is not operating.

Do not obstruct air flow to the heat

sink. After switching off the power

supply, leave fan on until the heat

sink is at room temperature.

10. Set the frequency of the function generator to $9.99 \mathrm{MHz}$ and the amplitude to $1 \mathrm{mV}$ rms. Increase the output voltage until the UUT reads approximately $10.0 \mathrm{~V}$ rms .

11. Observe the amplifier output waveform on the oscilloscope for parasitic oscillations, clipping, or other distortion. If distortion or oscillation is observed, shut off the amplifier immediately and investigate the cause.

12. Set the increment control on the function generator so that the least significant digit can be incremented ( $0.001 \mathrm{mV})$.

13. With the ac calibrator set to $10.000 \mathrm{~V}$, and when the reading on the dc millivoltmeter has settled (about 5 to 10 minutes after setting frequency and amplitude; step 7), note and record the millivoltmeter reading on the data sheet.

14. Set the coaxial switch to "Port 1" and, using the increment or decrement control (up or down arrows) of the function generator, slowly adjust the output voltage until the dc millivoltmeter reading settles to the same voltage as that obtained when using the $1 \mathrm{kHz}$ signal from the ac calibrator. The dc voltage reading will take 20 to 30 seconds to settle, and it may not be possible to get exactly the same reading as before because of limited resolution in the adjustment of the function generator. Generally, the dc millivolt readings should agree within $\pm 0.002 \mathrm{mV}$.

15. When the millivoltmeter reading agrees within the tolerance with the reading obtained when measuring the $1-\mathrm{kHz}$ reference signal, note and record on. the data sheet, Table $10.6 \mathrm{c}$, the reading on the UUT (including the units) as well as the millivoltmeter reading.

16. Set the coaxial switch back to "Port 2," and check whether the reading has changed. If the reading is unchanged, the test is completed. If the reading has changed by more than $0.002 \mathrm{mV}$, repeat steps 11 to 16 and revise the reading on the data sheet, Table $10.6 \mathrm{c}$. 
TEST PROCEDURES FOR ME-545()/G TRUE-RMS VOLTMETER

17. Set the function generator voltage to 0.4 millivolts (it cannot be set to zero) to power down the equipment, and set the ac calibrator to zero output. 
Accuracy for frequencies from $10 \mathrm{MHz}$ to $19.99 \mathrm{MHz}$ for all input levels from 100 microvolts to $1 \times 10^{8}$ volt-hertz.

Specification:

Shall be within $\pm 15 \%$ of true input level.

Test Point: $5.00 \mathrm{~V}$ rms at $19.99 \mathrm{MHz}$

Equipment:

Items

AC Calibrator

Function Generator

Power Amplifier

28-volt dc power supply

5-volt thermal converter

DC millivoltmeter

Oscilloscope

Thermal converter output cable

Cable with BNC connectors

RG $214 / \mathrm{U}$ cable with type "N"

connectors ( 3 required)

Type " $N$ " tee (2 required)

$50-0 h m$ " $N$ " adapter

$\mathrm{BNC}$ (male) to "N" (female)

(2 required)

Dual banana to "N" adapter

Coaxial relay

Relay control box
Model

Fluke $5200 \mathrm{~A}$ or equivalent

Hewlett-Packard $3325 \mathrm{~A}$ or equivalent

ENI A300-40PA (modified)

Kepco JQE 25-10M or equivalent

Ballantine 1394A-5 (modified)

Fluke $8506 \mathrm{~A}$ or equivalent

Tektronix 465 or equivalent

Type MS connector MS3102A-10SL-3P (3-pin

male) to dual Banana plug

3 feet or less, each.

Special part

Hewlett-Packard 8761A

Special part 


\section{Procedure:}

It is important to read the entire procedure before beginning the test. All equipment should be warmed up following the manufacturers' specification before any measurements are made.

WARNING: Thermoelements are easily damaged

by even moderate over-voltage.

Do not leave connected except when

actually carrying out test.

1. Connect the equipment as shown in figure 10.6.6. Attach the BNC (male) to $\mathrm{N}$ (female) adapter to the $50-\mathrm{ohm}$ "N-N" adapter, then to a type "N" tee, and connect the combination to the input of the UUT.

2. Attach the coaxial relay to the thermal converter and port 1 of the coaxial relay to the type "N" tee.

3. Attach a BNC (male) to "N" (female) adapter to a type "N" tee, and connect the combination to one of the inputs of the oscilloscope.

4. Make sure the amplifier power supply is turned off. Then use a RG $214 / \mathrm{U}$ cable to connect the output of the power amplifier to the tee at the oscilloscope and another RG $214 / \mathrm{U}$ cable to connect the oscilloscope to the tee leading to the UUT and thermal converter.

5. Make sure that the output voltage from the ac calibrator is zero. Then connect the output of the ac calibrator to port 2 of the coaxial switch using a dual banana to " $N$ " adapter and a RG $214 / \mathrm{U}$ cable.

6. Connect the output of the 5-volt thermal converter to the dc millivoltmeter using a thermal converter output cable. Set the millivoltmeter to the 1 -volt range. (10 $\mathrm{mV}$ will then be displayed as $0.010000 \mathrm{~V})$. Set the coaxial switch to "Port 2" by momentarily depressing button No. 2 on the switch control box.

7. Set the frequency of the ac calibrator to $1 \mathrm{kHz}$, and bring the output voltage up slowly to 5 volts rms while observing the dc millivoltmeter reading and making sure the reading does not exceed 8 millivolts.

8. Turn on the oscilloscope and set it to display a 5-volt, 20-MHz signal (2 volts/div; 0.1 microsecond/div, 10x magnification, dc coupled).

9. Turn on the power supply to the rf power amplifier and adjust it to 28 volts dc. The quiescent current should be approximately 6.5 amperes. Note warning! 
WARNING: Do not turn on the rf power amplifier

if the cooling fan is not operating.

Do not obstruct air flow to the heat

sink. After switching off the power

supply, leave fan on until the heat

sink is at room temperature.

10. Set the frequency of the function generator to $19.99 \mathrm{MHz}$ and the amplitude to $1 \mathrm{mV} \mathrm{rms}$. Increase the output voltage until the UUT reads approximately $5.0 \mathrm{~V}$ rms.

11. Observe the amplifier output waveform on the oscilloscope for parasitic oscillations, clipping, or other distortion. If distortion or oscillation is observed, shut off the amplifier immediately and investigate the cause.

12. Set the increment control on the function generator so that the least significant digit can be incremented $(0.001 \mathrm{mV})$.

13. With the ac calibrator set to $5.000 \mathrm{~V}$, and when the reading on the dc millivoltmeter has settled (about 5 to 10 minutes after setting frequency and amplitude; step 7), note and record the millivoltmeter reading on the data sheet, Table $10.6 \mathrm{c}$.

14. Set the coaxial switch to "Port $1^{n}$ and, using the increment or decrement control (up or down arrows) of the function generator, slowly adjust the output voltage until the dc millivoltmeter reading settles to the same voltage as that obtained when using the $1 \mathrm{kHz}$ signal from the ac calibrator. The dc voltage reading will take 20 to 30 seconds to settle, and it may not be possible to get exactly the same reading as before because of limited resolution in the adjustment of the function generator. Generally, the dc millivolt readings should agree within $\pm 0.002 \mathrm{mV}$.

15. When the millivoltmeter reading agrees within the tolerance with the reading obtained when measuring the $1-\mathrm{kHz}$ reference signal, note and record on the data sheet the reading on the UUT (including the units) as well as the millivoltmeter reading.

16. Set the coaxial switch back to "Port 2," and check whether the reading has changed. If the reading is unchanged, the test is completed. If the reading has changed by more than $0.002 \mathrm{mV}$, repeat steps 11 to 16 and revise the reading on the data sheet, Table $10.6 \mathrm{c}$.

17. Set the function generator voltage to 0.4 millivolts (it cannot be set to zero) to power down the equipment, and set the ac calibrator to zero output. 
TEST PROCEDURES FOR ME-545()/G TRUE-RMS VOLTMETER

Table 10.6a Accuracy Test, Data Sheet, Micropotentiometer Measurements.

\begin{tabular}{|c|c|c|c|c|c|}
\hline Test Point & $\begin{array}{l}\text { Measurement Data } \\
\text { Num. Value |Units }\end{array}$ & $\begin{array}{l}\text { Estimated } \\
\text { Uncertainty } \\
\text { Measurement }\end{array}$ & $\begin{array}{r}\text { Specific } \\
\text { Min. }\end{array}$ & $\begin{array}{l}\text { on Limits } \\
\text { Max. }\end{array}$ & $\begin{array}{c}\text { Calibr. } \\
\text { mV } \\
\text { Value }\end{array}$ \\
\hline $\begin{array}{c}+100 \mu \mathrm{V} \\
\mathrm{dc}\end{array}$ & & $\pm 0.8 \mu \mathrm{V}$ & $* x * x * x$ & $\star * * * * * *$ & $* *$ \\
\hline $\begin{array}{c}-100 \mu \mathrm{V} \\
\mathrm{dc}\end{array}$ & & $\pm 0.8 \mu \mathrm{V}$ & $* * * * * x$ & $\star * * * * * *$ & \\
\hline $\begin{array}{l}100 \mu \mathrm{V} \\
10.00 \mathrm{~Hz}\end{array}$ & & $\pm 3 \mu \mathrm{V}$ & $95 \mu$ & $105 \mu \mathrm{V}$ & \\
\hline $\begin{array}{l}100 \mu \mathrm{V} \\
10.00 \mathrm{kHz}\end{array}$ & & $\pm 3 \mu \mathrm{V}$ & $95 \mu \mathrm{r}$ & $105 \mu \mathrm{V}$ & \\
\hline $\begin{array}{l}100 \mu \mathrm{V} \\
999.9 \mathrm{kHz}\end{array}$ & & $\pm 3 \mu \mathrm{V}$ & $95 \mu T$ & $105 \mu \mathrm{V}$ & \\
\hline $\begin{array}{l}100 \mu \mathrm{V} \\
9.99 \mathrm{MHz}\end{array}$ & & $\pm .3 \mu \mathrm{V}$ & $90 \mu v$ & $110 \mu \mathrm{V}$ & \\
\hline $\begin{array}{r}100 \mu \mathrm{V} \\
19.99 \mathrm{MHz}\end{array}$ & & \pm 3 & $85 \mu \mathrm{V}$ & $115 \mu \mathrm{V}$ & \\
\hline
\end{tabular}


TEST PROCEDURES FOR ME-545()/G TRUE-RMS VOLTMETER

Table 10.6b Accuracy Test, Data Sheet, Calibrator.

\begin{tabular}{|c|c|c|c|c|c|}
\hline Test Point & $\begin{array}{l}\text { Measurement } \\
\text { Num. Value }\end{array}$ & $\begin{array}{l}\text { Data } \\
\text { Units }\end{array}$ & $\begin{array}{l}\text { Estimated } \\
\text { Measurement } \\
\text { Uncertainty }\end{array}$ & $\begin{array}{c}\text { Specificati } \\
\text { Min. }\end{array}$ & $\begin{array}{l}\text { Max. } \\
\text { Maxits }\end{array}$ \\
\hline $\begin{array}{l}1.00 \mathrm{mV} \\
10.00 \mathrm{~Hz}\end{array}$ & & & $\pm 0.0002 \mathrm{mV}$ & $1.05 \mathrm{mV}$ & $0.95 \mathrm{mV}$ \\
\hline $\begin{array}{l}300.0 \mathrm{~V} \\
10.00 \mathrm{~Hz}\end{array}$ & & & $\pm 0.06 \quad \mathrm{~V}$ & $315 \mathrm{~V}$ & $285 \mathrm{~V}$ \\
\hline $\begin{array}{l}1.00 \mathrm{mV} \\
50.00 \mathrm{~Hz}\end{array}$ & & & $\pm 0.0002 \mathrm{mV}$ & $1.03 \mathrm{mV}$ & $0.97 \mathrm{mV}$ \\
\hline $\begin{array}{l}300.0 \mathrm{~V} \\
50.00 \mathrm{~Hz}\end{array}$ & & & $\pm 0.06 \quad \mathrm{~V}$ & $309 \mathrm{~V}$ & $291 \mathrm{~V}$ \\
\hline $\begin{array}{l}1.00 \mathrm{mV} \\
10.0 \mathrm{kHz}\end{array}$ & & & $\pm 0.0002 \mathrm{mV}$ & $1.03 \mathrm{mV}$ & $0.97 \mathrm{mV}$ \\
\hline $\begin{array}{l}10.0 \mathrm{mV} \\
10.0 \mathrm{kHz}\end{array}$ & & & $\pm 0.002 \mathrm{mV}$ & $10.3 \mathrm{mV}$ & $9.7 \mathrm{mV}$ \\
\hline $\begin{array}{l}100.0 \mathrm{mV} \\
10.0 \mathrm{kHz}\end{array}$ & & & $\pm 0.02 \mathrm{mV}$ & $103 \mathrm{mV}$ & $97 \mathrm{mV}$ \\
\hline $\begin{array}{l}1.00 \mathrm{~V} \\
10.0 \mathrm{kHz}\end{array}$ & & & $\pm 0.0002 \mathrm{~V}$ & $1.03 \mathrm{~V}$ & $0.97 \mathrm{~V}$ \\
\hline $\begin{array}{l}10.0 \mathrm{~V} \\
10.0 \mathrm{kHz}\end{array}$ & & & \pm 0.002 & $10.3 \mathrm{~V}$ & $9.7 \mathrm{~V}$ \\
\hline $\begin{array}{l}300.0 \mathrm{~V} \\
10.0 \mathrm{kHz}\end{array}$ & & & \pm 0.06 & $309 \mathrm{~V}$ & $291 \mathrm{~V}$ \\
\hline $\begin{array}{l}1.00 \mathrm{mV} \\
99.9 \mathrm{kHz}\end{array}$ & & & $\pm 0.0002 \mathrm{mV}$ & $1.03 \mathrm{mV}$ & $0.97 \mathrm{mV}$ \\
\hline $\begin{aligned} 200.0 \mathrm{~V} \\
99.9 \mathrm{kHz}\end{aligned}$ & & & \pm 0.04 & $206 \mathrm{~V}$ & $194 \mathrm{~V}$ \\
\hline
\end{tabular}


TEST PROCEDURES FOR ME-545()/G TRUE-RMS VOLTMETER

Table 10.6c Accuracy Test, Data Sheet, Thermal Converter.

\begin{tabular}{|c|c|c|c|c|c|}
\hline Test Point & $\begin{array}{l}\text { Measurement } \\
\text { Num. Value }\end{array}$ & $\begin{array}{l}\text { Data } \\
\text { Units }\end{array}$ & $\begin{array}{l}\text { Estimated } \\
\text { Measurement } \\
\text { Uncertainty }\end{array}$ & $\begin{array}{l}\text { Specification } \\
\text { Limits } \\
\text { Min. Max. }\end{array}$ & $\begin{array}{l}\text { Millivolt- } \\
\text { meter } \\
\text { Reading }\end{array}$ \\
\hline $\begin{array}{c}100.0 \mathrm{~V} \\
1 \mathrm{kHz}\end{array}$ & $* * * * * * * * * * * *$ & $* * *$ & $( \pm 0.18)$ & $* * * * * * * * * * * *$ & \\
\hline $\begin{array}{l}100.0 \mathrm{~V} \\
999.9 \mathrm{kHz}\end{array}$ & & & \pm 0.2 & $95 \mathrm{~V} \quad 105 \mathrm{~V}$ & \\
\hline $\begin{array}{l}10.00 \mathrm{~V} \\
1 \mathrm{kHz}\end{array}$ & $* * * * * * * * * * *$ & $* * *$ & $( \pm 0.18)$ & $* * * * * * * * * * *$ & \\
\hline $\begin{array}{l}10.00 \mathrm{~V} \\
9.99 \mathrm{MHz}\end{array}$ & & & $\pm 0.03 \mathrm{~V}$ & $9 \mathrm{~V} 11 \mathrm{~V}$ & \\
\hline $\begin{array}{l}5.00 \mathrm{~V} \\
1 \mathrm{kHz}\end{array}$ & $* * * * * * * * * * *$ & $* * *$ & $( \pm 0.18)$ & $* * * * * * * * * * * *$ & \\
\hline $\begin{array}{l}5.00 \mathrm{~V} \\
19.99 \mathrm{MHz}\end{array}$ & & & \pm 0.02 & $4.25 \mathrm{~V} 5.75 \mathrm{~V}$ & \\
\hline
\end{tabular}




\subsection{Response Time}

Shall be 3 seconds or less to rated accuracy.

Specification:

Shall be within \pm 38 of true input level.

Test Points: $\quad 100.0 \mathrm{mV}$ rms at $1.00 \mathrm{kHz}$

$1.0 \mathrm{~V}$ rms at $1.00 \mathrm{kHz}$

$10.0 \mathrm{~V}$ rms at $1.00 \mathrm{kHz}$

$100.0 \mathrm{~V}$ rms at $1.00 \mathrm{kHz}$

Equipment:

Items

AC calibrator

Instrument Controller

(IEEE-488 Bus)

IEEE-488 cable

Dual banana to BNC adapter

Cable with BNC connectors
Model

Fluke $5101 B$ or equivalent

Hewlett-Packard 9836 or equivalent

WARNING: This procedure uses lethal voltages during the test

Care should be taken to avoid injury or shock.

1. Connect the calibrator to the to the input of the UUT using the cable with BNC connectors and the dual-banana adapter, as shown in figure 10.7.1. Link the instrument controller (computer) to the calibrator using the IEEE-488 cable. 


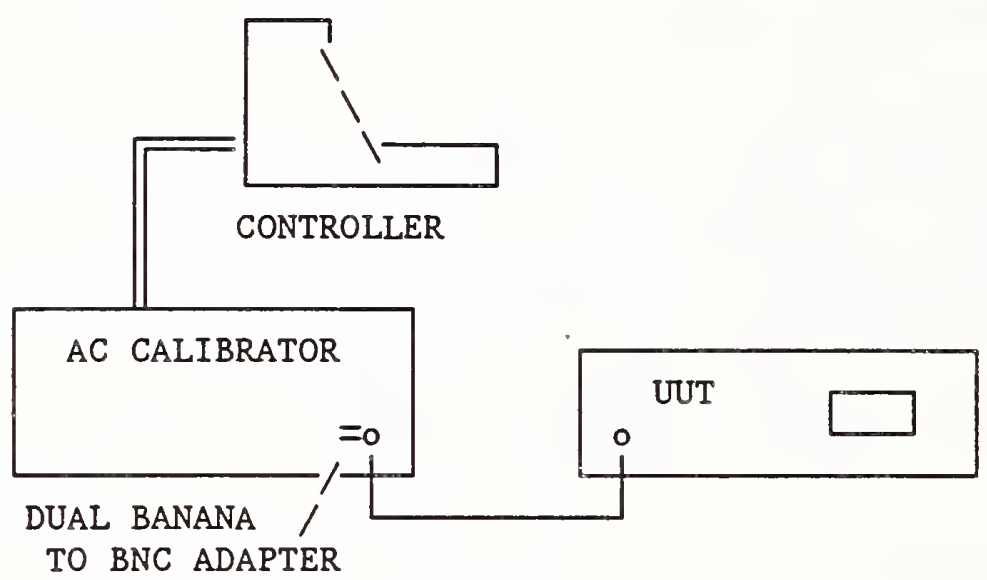

Fig. 10.7.1 Set-Up for Response Time Test

2. Insert the $51 / 4$ in. floppy disk labelled "TMDE4A" into the right-hand disk drive of the computer (controller). The program requires that HPBasic 2.1 and AP 2.1 (or later versions) are first loaded into the computer.

3. Type LOAD "MENU" on the keyboard of the computer.

4. Press EXECUTE.

5. Press RUN and follow directions shown on the computer display.

6. Record the results shown on the printout into the data sheet, Table 10.7 
TEST PROCEDURES FOR ME-545()/G TRUE-RMS VOLTMETER

Table 10.7 Response Time, Data Sheet, ( 3 Seconds)

\begin{tabular}{|c|c|c|c|c|c|}
\hline Test Point & $\begin{array}{l}\text { Measurement } \\
\text { Num. Value }\end{array}$ & $\begin{array}{l}\text { Data } \\
\text { Units }\end{array}$ & $\begin{array}{l}\text { Estimated } \\
\text { Measurement } \\
\text { Uncertainty }\end{array}$ & $\begin{array}{c}\text { Specificat } \\
\text { Min. }\end{array}$ & $\begin{array}{l}\text { Mimits } \\
\text { Max. }\end{array}$ \\
\hline $\begin{array}{l}100.0 \mathrm{mV} \\
1.00 \mathrm{kHz}\end{array}$ & & & $\pm 0.2 \mathrm{~s}^{*}$ & $103 \mathrm{mV}$ & $97 \mathrm{mV}$ \\
\hline $\begin{array}{l}1.00 \mathrm{~V} \\
1.00 \mathrm{kHz}\end{array}$ & & & $\pm 0.2 \mathrm{~s}^{*}$ & $1.03 \mathrm{~V}$ & $0.97 \mathrm{~V}$ \\
\hline $\begin{array}{l}10.0 \mathrm{~V} \\
1.00 \mathrm{kHz}\end{array}$ & & & $\pm 0.2 \mathrm{~s}^{*}$ & $10.3 \mathrm{~V}$ & $9.7 \mathrm{~V}$ \\
\hline $\begin{array}{r}100.0 \mathrm{~V} \\
1.00 \mathrm{kHz}\end{array}$ & & & $\pm 0.2 s^{*}$ & $103 \mathrm{~V}$ & $97 \mathrm{~V}$ \\
\hline
\end{tabular}

* Estimate in the uncertainty of the time interval is based on spread of results obtained by a skilled observer. 
10.8 Crest Factor

\section{Specification:}

Meter shall handle crest factors of 4:1 for all input levels below 100 volts, increasing for downscale measurements.

Test Point: $\quad 90.0 \mathrm{~V}$ rms at $60 \mathrm{kHz}$ (nominal)

Equipment:

\section{Items}

\section{AC Calibrator}

Power Amplifier

100 -volt thermal converter

DC millivoltmeter

Thermal converter output

cable

Cable with BNC connectors

$$
\text { (2 required) }
$$

RG 142/U cable with type "N" connectors (2 required)

Type "N" tee

BNC (male) to "N" (female)

Dual banana to " $\mathrm{N}$ " adapters

$$
\text { (2 required) }
$$

"N" to "N" adapter (male)

Coaxial relay

Relay control box

4:1 Crest Factor Waveform

Generator

\section{Mode I}

Fluke 5200A or equivalent

Fluke 5205 or equivalent

Ballantine 1394A-100 (modified)

Fluke $8506 \mathrm{~A}$ or equivalent

Type MS connector MS3102A-10SL-3P (3-pin male) to dual Banana plug

3 feet or less, each.

Hewlett-Packard 8761A

Special part (NBS design)

Special part (NBS design) 


\section{Procedure:}

It is important to read the entire procedure before beginning the test. All equipment should be warmed up following the manufacturers' specification before any measurements are made.

WARNING: Thermoelements are easily damaged

by even moderate over-voltage.

Do not leave connected except when

actually carrying out test.

1. Connect the equipment as shown in figure 10.8. Attach the BNC (male) to $\mathrm{N}$ (female) adapter to a type "N" (male) to "N" (male) adapter and then to a type "N" tee, and connect the combination to the input of the UUT.

2. Attach the coaxial relay to the thermal converter and port 1 of the coaxial relay to the type "N" tee.

3. Attach dual banana plug to " $N$ " adapters to one end of each of the two RG-142 cables. Connect the other end of one of the cables to the "tee", and connect the free end of the other cable to port 2 of the coaxial relay.

4. Make sure that the output voltage from the power amplifier is zero, then plug the cable from the "tee" into the output terminal of the power amplifier.

5. Connect the output of the 100-volt thermal converter to the dc millivoltmeter using a thermal converter output cable. Set the millivoltmeter to the 1-volt range. Set the coaxial switch to "Port 1" by momentarily depressing button No. 1 on the switch control box.

6. Make sure that the output voltage from the ac calibrator is zero. Then connect the output of the ac calibrator to port 2 of the coaxial switch using the dual banana to " $\mathrm{N}$ " adapter and a RG $142 / \mathrm{U}$ cable.

7. Set the instrument under test to the manual range mode. Then, set the UUT to a range that has a full scale value of 100 volts rms. If the UUT does not have a manual range setting with a full scale value of 100 volts rms, see the note on page 65 .

8. Connect the special crest factor waveform generator to the input of the power amplifier, and observe the millivoltmeter reading. The reading should not exceed 8 millivolts. When the reading has settled, record the UUT reading and the millivoltmeter reading on the first line of the data sheet, Table 10.8 . 
9. Set the coaxial switch to "Port $2^{n}$ by momentarily depressing button No. 2 on the switch control box.

10. Set the frequency of the ac calibrator to $60 \mathrm{kHz}$, and bring the output voltage up slowly while observing the dc millivoltmeter reading and making sure the reading does not exceed 8 millivolts. When the millivoltmeter reading approaches the reading determined in step 8 , wait and let the reading settle.

11. Adjust the calibrator voltage until the dc millivoltmeter reading settles to the same voltage as that obtained when using the crest factor generator and amplifier (step 8 ). The dc voltage reading may take 20 to 30 seconds to settle, and it may not be possible to get exactly the same reading as before because of limited resolution in the adjustment of the calibrator. Generally, the dc millivolt readings should agree within $\pm 0.002 \mathrm{mV}$.

12. When the millivoltmeter reading has settled and agrees to within the tolerance with the reading obtained in step 8 , enter the calibrator voltage and the new millivoltmeter reading in the second line of the data sheet, Table 10.8 .

13. Set the coaxial switch back to "Port 1," and check whether the millivoltmeter reading has changed. If the reading has changed by more than $0.002 \mathrm{mV}$, repeat steps 11 to 13 . If it has not changed, the test is completed. The test is successful if the difference between the UUT UTT reading and the calibrator voltage does not exceed the stated tolerance.

Note:

Although the crest factor test can be performed with the UUT in the autorange mode, operation in this mode does not insure that the applied voltage will be near the full-scale value. The test is more meaningful if the rms amplitude of the crest factor signal applied to the UUT is at, or just below, the full-scale voltage of the measuring range.

If the UUT does not have a range with a full-scale value of 100 volts rms, set the meter to its next lower range and reduce the output voltage of the crest-factor waveform generator so that the rms output from the power amplifier is about $10 \%$ below the nominal value of the range selected. To reduce the output voltage of the crest-factor waveform generator, an attenuator is inserted between the output terminals of the waveform generator and the input terminals of the power amplifier. In its simplest form, the attenuator can be constructed using two resistors with resistances of the order of $1 \mathrm{k} \Omega$ to $10 \mathrm{k} \Omega$. Adjustment and verification of the desired output voltage level can be obtained using the Fluke 8506 Digital Multimeter. 


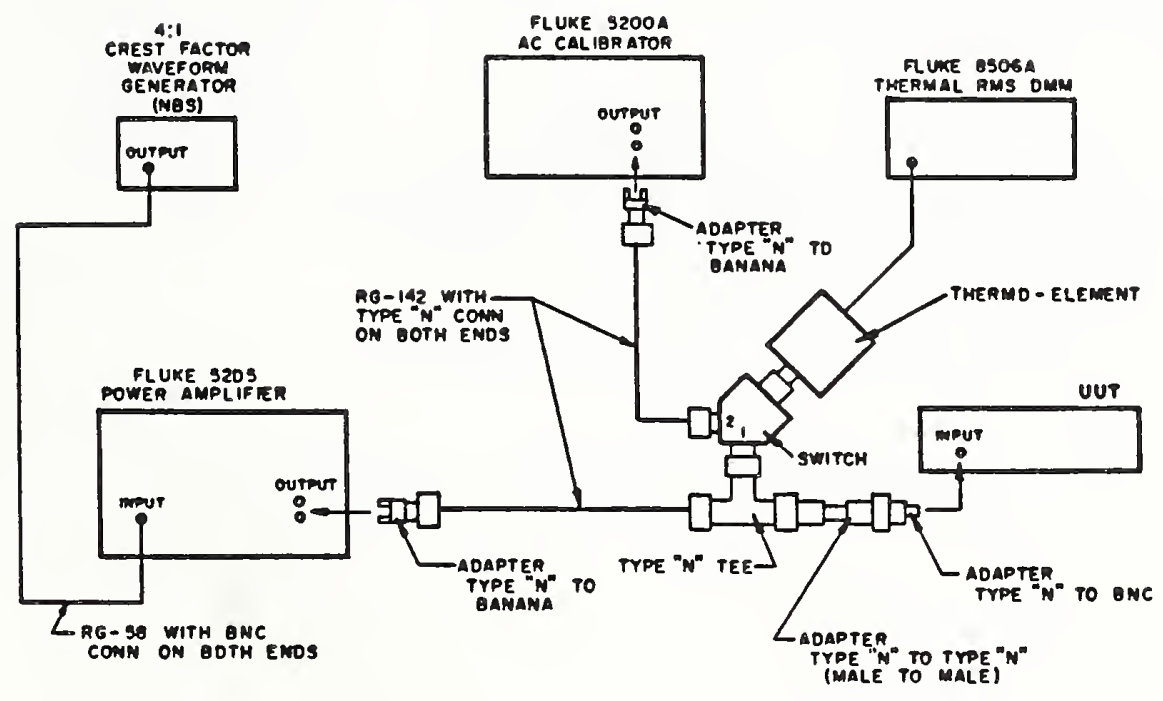

Fig. 10.8 Set-Up for the Crest Factor Test 
TEST PROCEDURES FOR ME-545()/G TRUE-RMS VOLTMETER

Table 10.8 Crest Factor.

\begin{tabular}{|c|c|c|c|c|c|c|}
\hline Test Point & \multicolumn{2}{|c|}{$\begin{array}{c}\text { Calibrator Voltage } \\
\text { Num. Value Units }\end{array}$} & $\begin{array}{c}\text { U T } \\
\text { Reading }\end{array}$ & $\begin{array}{c}\text { Estim. } \\
\text { Meas. } \\
\text { Uncert. }\end{array}$ & $\begin{array}{c}\text { Specification } \\
\text { Limits } \\
\text { Min. Max. }\end{array}$ & $\begin{array}{c}\text { Milivolt- } \\
\text { meter } \\
\text { Reading }\end{array}$ \\
\hline \hline $\begin{array}{r}90.0 \mathrm{~V}^{*} \\
60 \mathrm{kHz}\end{array}$ & $* * * * * * * * * *$ & $* * *$ & & & \pm 38 of Cali- & \\
\hline $60 \mathrm{kHz}$ & & & $* * * * * * * * * *$ & \pm 0.18 & $* * * * * * * * * * *$ & \\
\hline \hline
\end{tabular}

* See Note if attenuator is used. 
10.9 Input Connector

Specification:

Input connector of meter shall be selectable by a front panel switch, allowing the outer connector to be floating from chassis ground or to be connected to chassis ground. Connector type shall be BNC type female.

\section{Procedure:}

1. The existance of the input connector is to be determined by inspection.

2. Connect an ohmmeter between the BNC outer shell and a grounded point on the chassis.

3. Switch the front panel switch to the grounded position. Read and record the resistance.

4. Switch the front panel switch to the ungrounded position. Read and record the resistance. 
TEST PROCEDURES FOR ME-545()/G TRUE-RMS VOLTMETER

Table 10.9 Input Connector

\begin{tabular}{|l|c|c|c|c|c|}
\hline $\begin{array}{l}\text { Measurement } \\
\text { Description }\end{array}$ & $\begin{array}{c}\text { Measurement } \\
\text { Data }\end{array}$ & $\begin{array}{c}\text { Estimated } \\
\text { Measurement } \\
\text { Uncertainty }\end{array}$ & $\begin{array}{c}\text { Specification Limits } \\
\text { Min. }\end{array}$ & Units \\
\hline $\begin{array}{l}\text { Connector } \\
\text { of BNC type }\end{array}$ & & N/A & Yes & & ohms \\
\hline $\begin{array}{l}\text { Resistance } \\
\text { grounded }\end{array}$ & & N/A & & & ohms \\
\hline $\begin{array}{l}\text { Resistance } \\
\text { floating }\end{array}$ & & N/A & & & \\
\hline
\end{tabular}




\subsection{AC Common Mode Rejection}

\section{Specification:}

Shall be greater than $60 \mathrm{~dB}$ up to $400 \mathrm{~Hz}$.

Equipment:

Items

Model

AC Calibrator

Fluke $5200 \mathrm{~A}$ or equivalent

\section{Procedure:}

1. Connect the equipment as shown below.

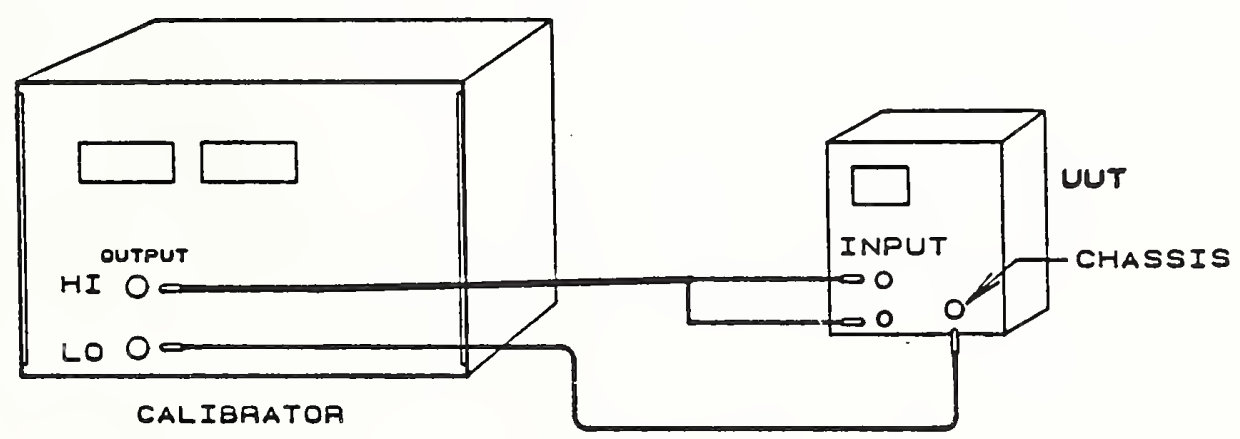

Fig. 10.11.1 Test setup for measuring the common mode rejection.

2. Initially, set the UUT controls as follows:

Function: $\quad$ AC VOLTAGE

Range Mode: MANUAL - most sensitive range

3. Set the output level of the calibrator to $0.100 \mathrm{mV}$ rms and $400 \mathrm{~Hz}$.

4. Set the calibrator to OPERATE position. Read and record the value displayed on the UUT as $V_{1}$.

NOTE: If the UUT indicates underrange, enter zero for $V_{1}$.

5. Set the output level of the calibrator to $0.420 \mathrm{~V}$ rms and $400 \mathrm{~Hz}$. Set the calibrator to OPERATE and record the value displayed by the UUT on the data sheet as $V_{2}$.

NOTE: If the UUT indicates an overrrange, set the range switch to its next highest position and repeat steps 4 and 5 . 
TEST PROCEDURES FOR ME-545()/G TRUE-RMS VOLTMETER

6. Calculate the common mode rejection (CMR) according to the formula $\operatorname{CMR}=20 \log _{10} \frac{\left(V_{2}^{2}-V_{1}^{2}\right)^{\frac{1}{2}}}{0.42}$

and record this value on the data sheet, Table 10.11.

NOTE: Assure that the units in the above equation are consistent. 
TEST PROCEDURES FOR ME-545()/G TRUE-RMS VOLTMETER

Table 10.11 Common Mode Rejection

\begin{tabular}{|l|c|c|c|c|c|}
\hline $\begin{array}{l}\text { Measurement } \\
\text { Description }\end{array}$ & $\begin{array}{c}\text { Measurement } \\
\text { Data }\end{array}$ & $\begin{array}{c}\text { Estimated } \\
\text { Measurement } \\
\text { Uncertainty }\end{array}$ & $\begin{array}{c}\text { Specification Limits } \\
\text { Min. }\end{array}$ & Units \\
\hline$V_{1}$ & & N/A & & \\
\hline$V_{2}$ & & N/A & & & V \\
\hline CMR & & & & & \\
\hline
\end{tabular}




\subsection{Maximum Input Protection}

Specification:

Shall be at least 420 volts peak ( 300 volts RMS) on all ranges, and shall be at least $1 \times 10^{8}$ volt-hertz on all ranges above 1 volt.

Equipment:

I tems

Meter Calibrator

Wall Clock
Model

Fluke $5101 \mathrm{~B}$ or equivalent Commercial item

\section{Procedure:}

WARNING: This procedure uses lethal voltages during the rest. Care should be taken to avoid injury or shock.

1. Connect the equipment as shown below.

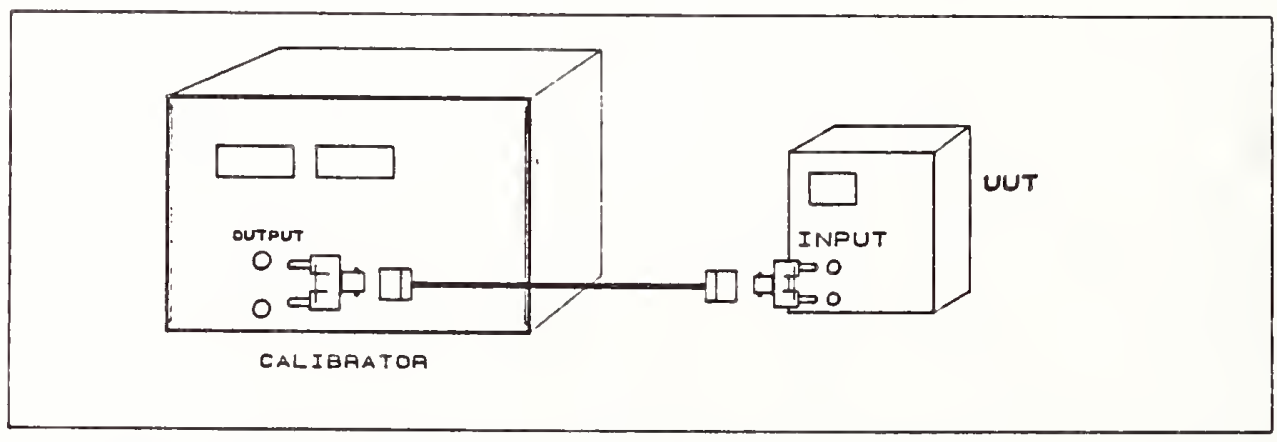

Fig. 10.12 Test setup for measuring maximum input protection.

2. Set the UUT controls as follows:

Function: $\quad$ AC VOLTAGE

Range Mode: MANUAL

3. Apply 300 volts ac at $1 \mathrm{kHz}$ from the meter calibrator to the input of the UUT. Note the time on the wall clock.

4. After 2 minutes has elapsed, note any evidence of smoking, arcing, or 


\subsection{Input Impedance}

\section{Specification:}

Input impedance shall be 1 megohm or greater, shunted by 50 picofarads capacitance or less.

\section{Equipment:}

Items

Digital LCR meter

Isolation Transformer
Model

Hewlett-Packard 4262A or equivalent

Topaz $91002-22$ or equivalent

Three-wire-female to two-wire-male adapter Order by description

\section{Procedure:}

1. Connect the equipment as shown below.

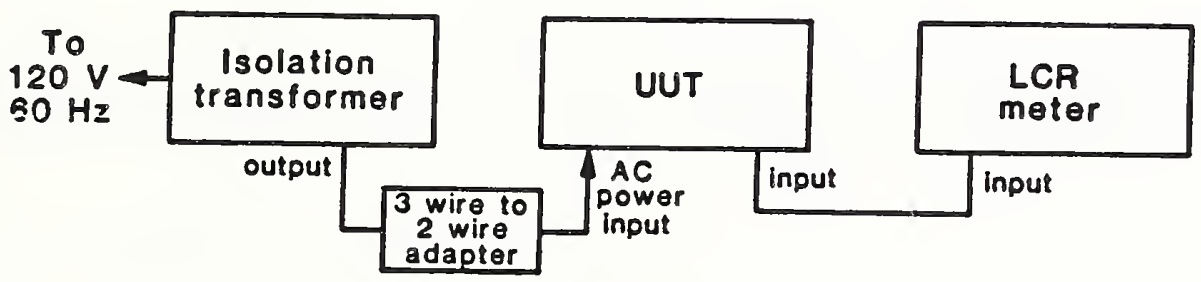

Fig. 10.13 Test setup for measuring input impedance.

Note: This procedure requires that the chassis of the UUT be ungrounded with respect to earth ground. Assure that adequate safety precautions are observed.

2. Set the UUT controls as follows:
Function: $\quad$ AC VOLTAGE
Range Mode: AUTORANGE 
3. Set the controls on the LCR meter as follows:

DC Bias OFF

Circuit Mode PRL

Function $C$

Test Signal $1 \mathrm{kHz}$

LCR Range AUTO

DQ Range AUTO

Trigger INT

4. Disconnect the cable to the input of the UUT.

5. Read and record on the data sheet the value of the cable capacitance as indicated by the LCR meter.

6. Reconnect the cable to the input of the UUT.

7. Read and record on the data sheet the value of the sum of the cable and input capacitance as indicated by the LCR meter.

8. Subtract the value of the capacitance obtained in step 5 from the value of the capacitance obtained in step 7. Record this difference on the data sheet.

9. Press the R/ESR button on the LCR meter.

10. Read and record on the data sheet the value of the input resistance indicated on the LCR display. 
TEST PROCEDURES FOR ME-545()/G TRUE-RMS VOLTMETER

Table 10.13 Input Impedance

\begin{tabular}{|l|c|c|c|c|c|}
\hline $\begin{array}{l}\text { Measurement } \\
\text { Description }\end{array}$ & $\begin{array}{c}\text { Measurement } \\
\text { Data }\end{array}$ & $\begin{array}{c}\text { Estimated } \\
\text { Measurement } \\
\text { Uncertainty }\end{array}$ & $\begin{array}{c}\text { Specification Limits } \\
\text { Min. }\end{array}$ & Units \\
\hline Cable Cap. & & \pm 0.2 & & & $\mathrm{pF}$ \\
\hline Cable + Input & & \pm 0.2 & & & $\mathrm{pF}$ \\
\hline Input Cap. & & \pm 0.2 & 0 & 50 & $\mathrm{pF}$ \\
\hline Input Resist. & & \pm 0.004 & 1 & & $\mathrm{M} \Omega$ \\
\hline
\end{tabular}


TEST PROCEDURES FOR ME-545()/G TRUE-RMS VOLTMETER

10.14 DC Output

Specification:

The meter shall have rear panel dc output. Output connector shall be BNC type Eemale or dual banana female.

Procedure:

1. The existance of the dc output connector is to be determined by inspection. 
TEST PROCEDURES FOR ME-545()/G TRUE-RMS VOLTMETER

Table 10.14 DC Output

\begin{tabular}{|l|c|c|c|c|c|}
\hline $\begin{array}{l}\text { Measurement } \\
\text { Description }\end{array}$ & $\begin{array}{c}\text { Measurement } \\
\text { Data }\end{array}$ & $\begin{array}{r}\text { Estimated } \\
\text { Measurement } \\
\text { Uncertainty }\end{array}$ & $\begin{array}{c}\text { Specification Limits } \\
\text { Min. }\end{array}$ & Units \\
\hline $\begin{array}{l}\text { Connector } \\
\text { on rear pnl. }\end{array}$ & & N/A & Yes & & \\
\hline $\begin{array}{l}\text { Connector } \\
\text { proper type }\end{array}$ & & N/A & Yes & & \\
\hline
\end{tabular}



TEST PROCEDURES FOR ME-545()/G TRUE-RMS VOLTMETER

\section{APPENDIX C}

SOFTWARE FOR THE AUTOMATIC TESTS FOR

THE ME-545()/G TRUE-RMS VOLTMETER

$$
C \cdot 1
$$




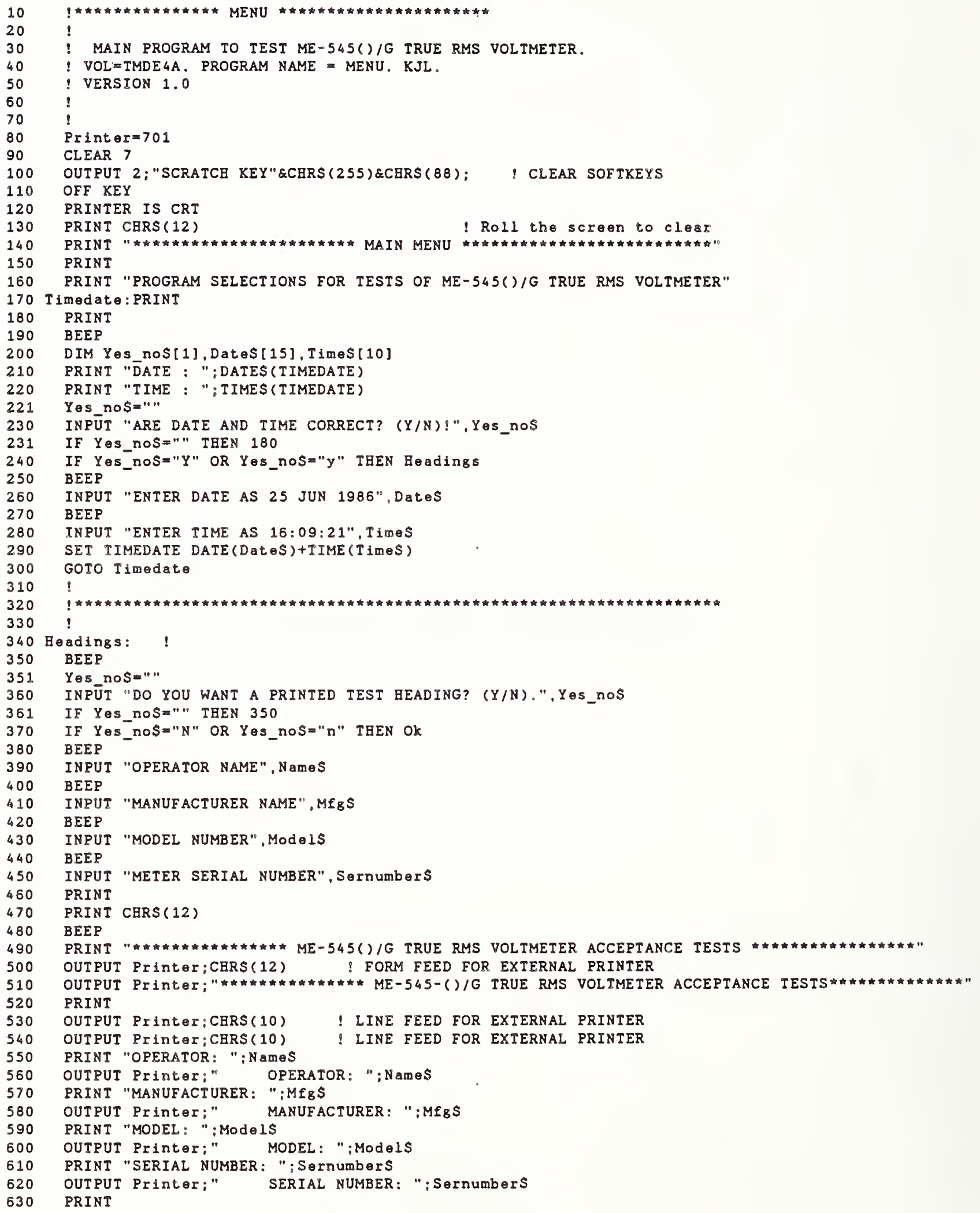


PRINT DATES(TIMEDATE)\&" "ETIMES(IIMEDATE)

OUTPUT Printer;" "EDATES(TIMEDATE)\&" "\&TIMES(TIMEDATE)

PRINT

OUTPUT Printer;CERS(10) ! LINE FEED FOR EXTERNAL PRINTER

PRINTER IS CRT

PRINT "PAUSED. PRESS <CONTINUE> WBEN READY."

PAUSE

$!$

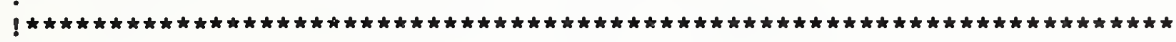

$!$

Ok:PRINT CHR\$(12)

!

1

BEEP

PRINT " Run the test for :"

PRINT

PRINT

PRINT " 1. AC VOLTAGE (5200A/5205A) "

PRINT

PRINT "

2. RESPONSE TIME (5101B) "

PRINT

PRINT

PRINT " ENTER THE NUMBER OF CBOICE

INPUT Choice

!

PRINT

PRINT " WAIT -- Loading program number ";Choice

IF Choice<0 TEEN PRINT " Improper Choice"

IF Cholce<0 TEEN WAIT 2.0

IF ChOice<0 THEN GOTO Ok

IF ChOICe=1 TEEN LOAD "VOLTS"

IF Choice=2 THEN LOAD "RESP"

IF Choice=0 TBEN OK

IF ChOICe>2 THEN PRINT "

IF ChOICe>2 TEEN WAIT 2.0

Improper cholce"

IF Choice>2 IBEN GOTO OK

1000 END

10

20

30

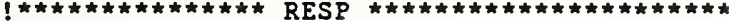

$!$

! Program to test AC response time for meters in the voltage mode.

PROGRAM $=$ RESP. VOL=TMDE4A. VERSION 1.1

! KJL.

$!$

!

110 Start: Addr $=702$

120 DIM Pass $\$ 1]$

130 Printer $=701$

140 PRINTER IS CRT

150 PRINT CERS(12) ! Roll the screen to clear it

160 BEEP 170 PRINT

170 PRINT " "Enter the type of test desired:"

190 PRINT " $\quad$ (1) AC VOLTAGE RESPONSE TIME"

200 PRINT " $\quad$ (2) RETURN TO MAIN MENU."

INPUT Cholce

IF Chol $C \theta=1$ IBEN 330

IF Choice=2 TEEN LOAD "MENU"

PRINT

PRINT " IMPROPER CEOICE 11

BEEP

Try Again "

WAIT 2.0

GOTO Start 
Appendix C - Software Listing for True-RMS Voltmeter (ME-545()/G)

1

!

!

OUTPUT Addr;"CC"

PRINT CBRS(12)

!

TIMe=3.0 ! RESPONSE TIME INTERVAL IN SECONDS

Numberoftests $=4 \quad$ ! Number of tests to be performed $!$

RESTORE 420 ! DATA=VOLTAGES $81 \mathrm{kBz}$. TO BE USED IN TBE TEST

DATA $0.10,1.0,10.0,100$.

!

FOR N=1 TO Numberoftests ! Loop each test

READ $D(N)$

! Read output level

NEXT N

BEEP $3000, .6$

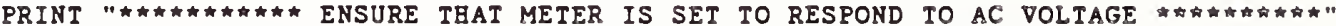

PRINT

PRINT

PRINT " CONNECT METER TO FLUKE 5101B CALIBRATOR!!!!!"

PRINT

PRINI

PRINT " At the sound of the tone, mentally note the voltage reading on the meter."

PRINT

PRINT " This test will consist of" ; Numberoftests;"tests."

PRINT

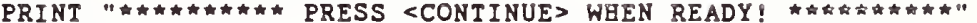

PRINT

PAUSE

PRINT CBRS(12)

FOR Test $=1$ TO Numberoftests

If Test=1 TEEN OUTPUT Printer;"

AC VOLTAGE RESPONSE TIME TESTS"

Ac volts: OUTPUT Addr; $D(T e s t) ; " V "$

OUTPUT Addr;","

OUTPUT Addr;"1000日," ！ TEST FREQUENCY = $1 \mathrm{kBZ}$

PRINT CBRS(12)

PRINT

PRINT

PRINT

BEEP

PRINI *

PRINI

PRINT "

PRINT

PRINT "

INPUT AS

! IEST FREQUENCY $=1 \mathrm{kBZ}$.

PRINT

PRINT "

OUTPUT Addr;"N"

WAIT TIme

Enter_acvolts : BEEP $3000, \ldots 15$

PRINT

Meter_reading $\$="$ "

PRINT "ENTER THE OBSERVED READING AT TEE TIME OF TBE TONE"

INPUT Meter_readingS

IF Meter_readings=" THEN Enter_acvolts

PRINT

PRINT " READING ENTERED " "Meter_reading\$

PRINT

BEEP

Yes_noS=" "

PRINT "IS THE READING ENTERED CORRECTLY? (Y/N)"

INPUT Yes_noS

IF YeS_nO $\bar{S}=\cdots$ THEN 900

IF Yes_nOS="N" OR Yes_nOS="מ" THEN Enter_acvolts 


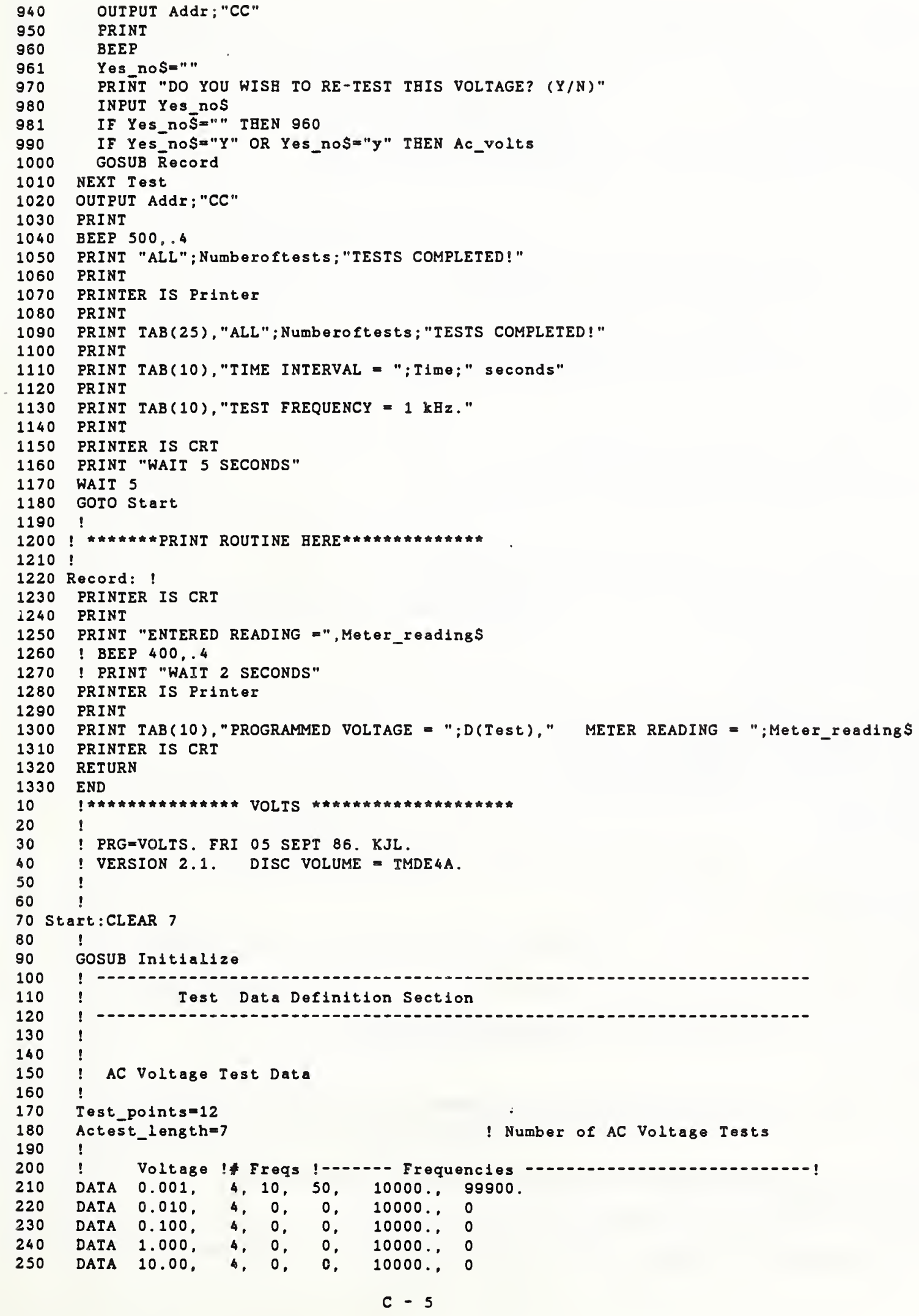




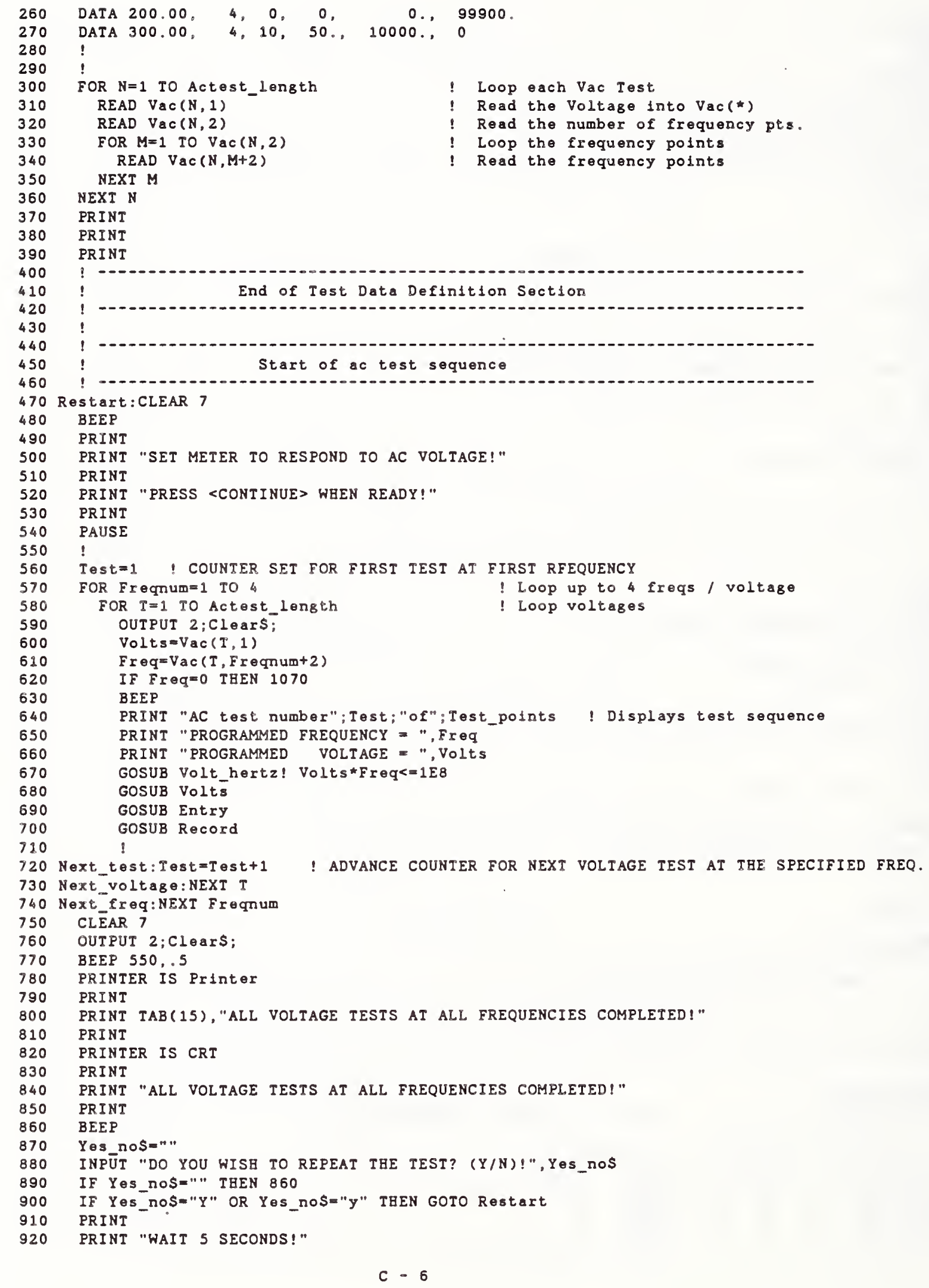


WAIT 5

LOAD "MENU"

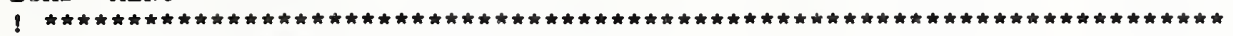

!

Start of Subroutines

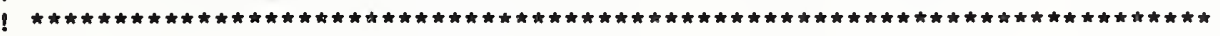

Volts: !

Checkout $=1$

!

Addr $=$ Add $r+0$

! Get HP address from IEEE address

$$
\text { C }-7
$$




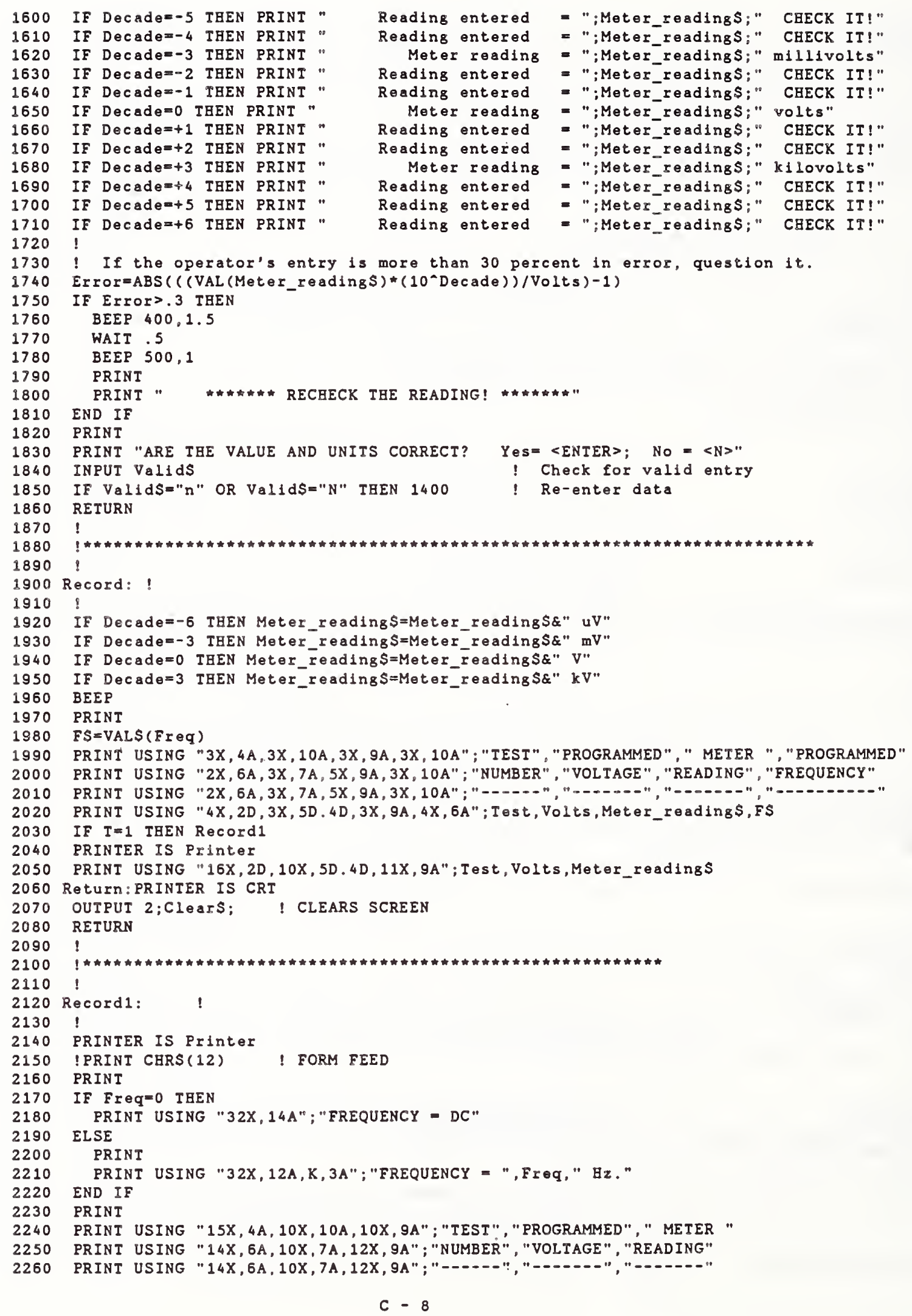




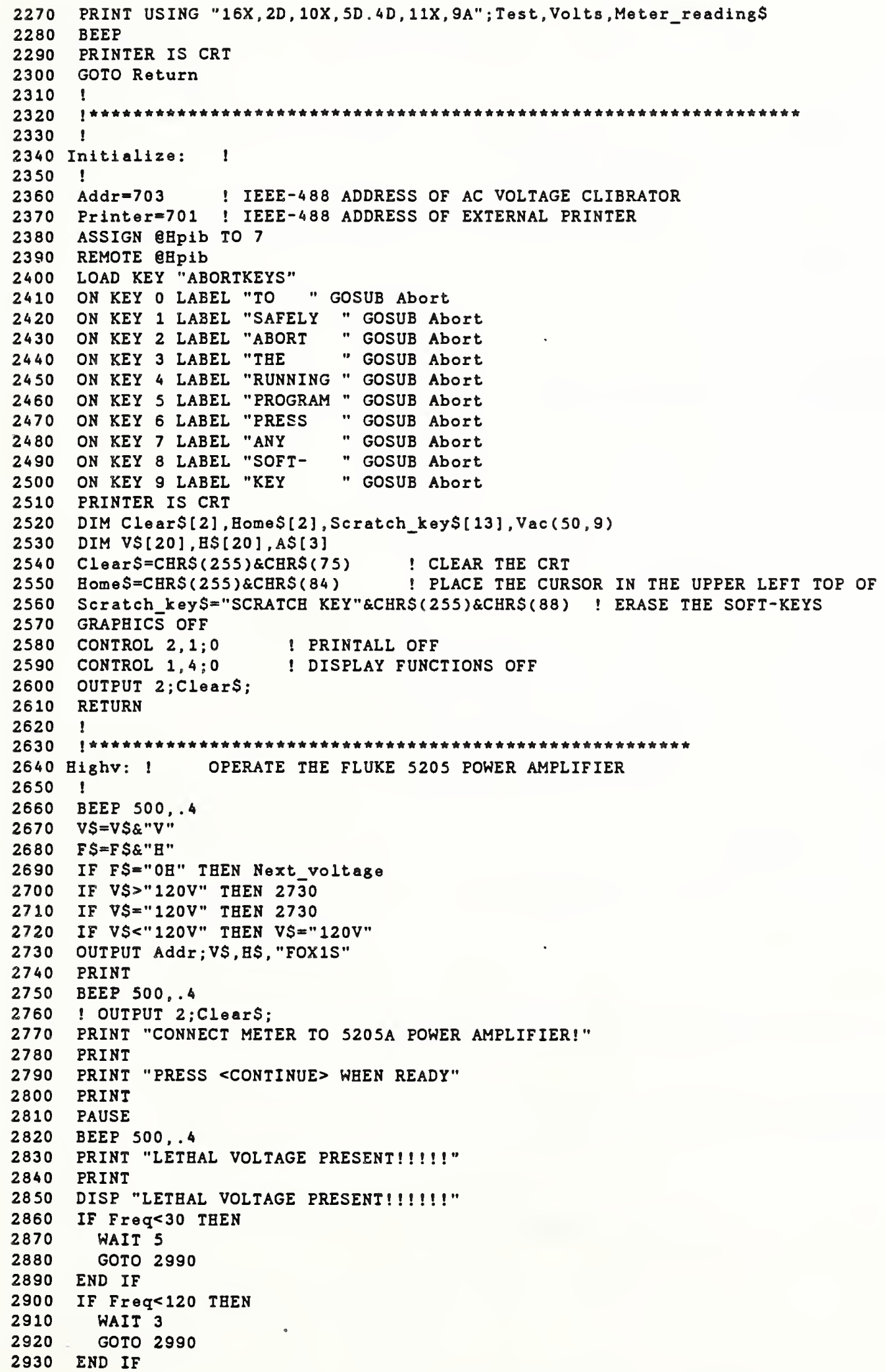




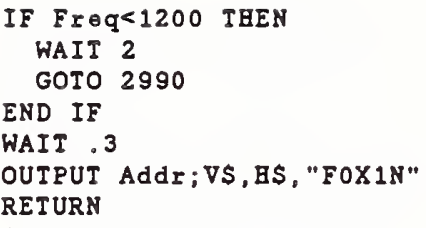


Appendix C - Software Listing for True-RMS Voltmeter (ME-545()/G)

3610 PRINT "ALL AC VOLTAGE TESTS COMPLETED! WAIT."

3620 WAIT 5

3630 LOAD "MENU"

3640 BEEP $500, \ldots$

3650 END 

APPENDIX D

LIST OF SPECIAL PARTS

$$
\text { D }-1
$$




\section{List of special parts}

\section{4:1 Crest Factor Waveform Generator}

A circuit designed at NBS which generates a waveform for the crest-factor test with a fundamental of $\approx 31 \mathrm{kHz}$ and significant harmonic components limited to $\simeq 1 \mathrm{MHz}$. The circuit is shown in fig. D-1, and the spectrum generated is shown in fig. D-2. [Fabricated at NBS]

$50-\mathrm{ohm}$ "N" adapter

A modified set of commercial $\mathrm{N}$-type male and female connectors attached to the ends of a short tube containing a disk-type, 50-ohm shunt resistor. [Fabricated at NBS]

Cable with dual Banana plug

A special cable supplied by the manufacturer (Fluke) with output and sensing leads for a voltage standard. [Manufactured by Fluke]

Relay control box

A metal enclosure containing a 9 -volt battery and two double-pole, double-throw momentary push-button switches intended to control the operation of the Hewlett-Packard co-axial relay. The circuit is shown in fig. D-3. [Fabricated at NBS]

Resistor Junction Box

An enclosure containing two 3-kilohm tin-oxide resistors in series. The two ends of the resistor chain and the center tap are brought out to the center pins of three female BNC-type connectors. [Fabricated at NBS]

Step-up (output) transformer

A commercial signal transformer designed for use with the high-frequency amplifier to step up the output voltage. [ENI Model AM5-5B] 


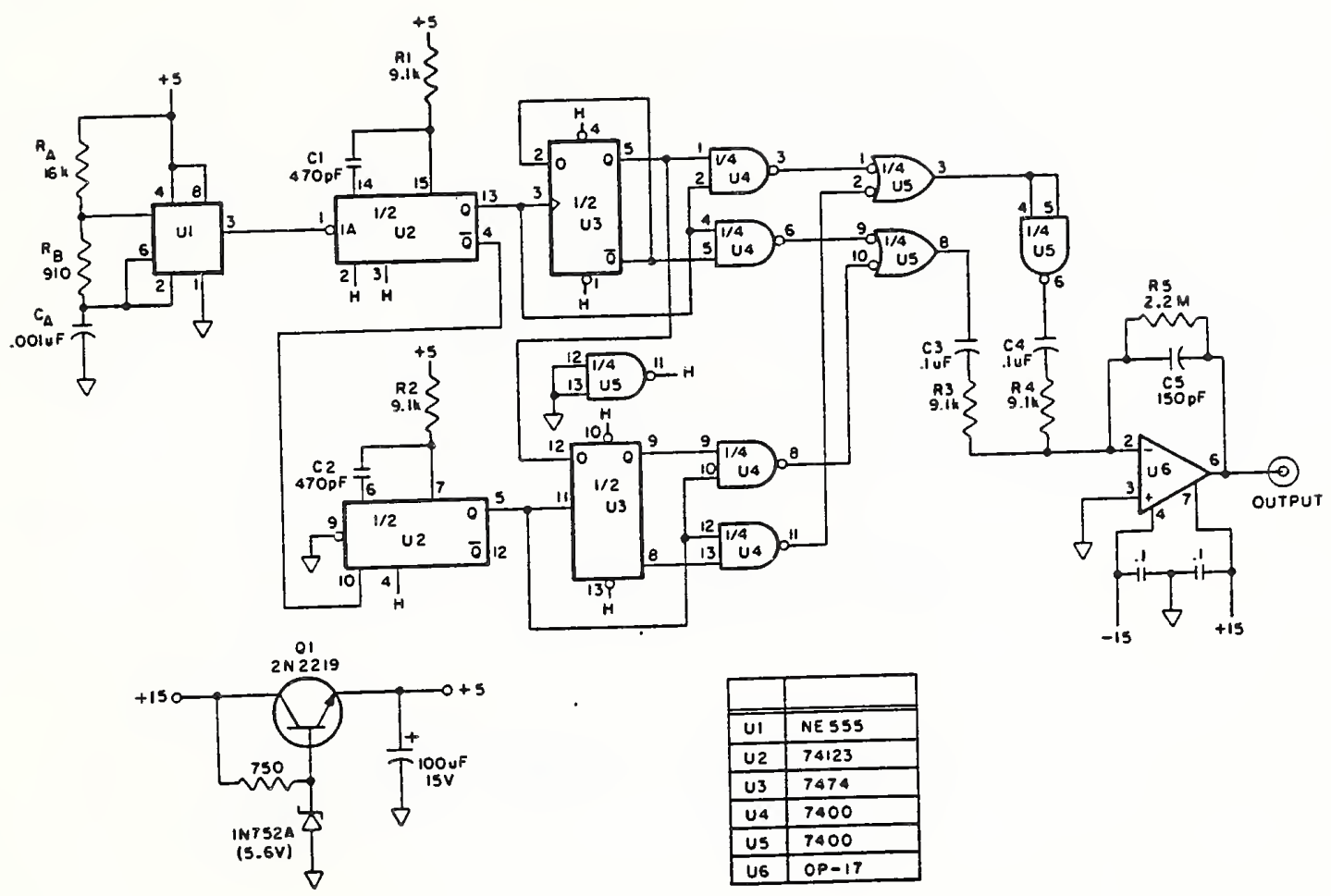

Fig. D-1, Circuit Diagram of Crest Factor Test Signal Generator

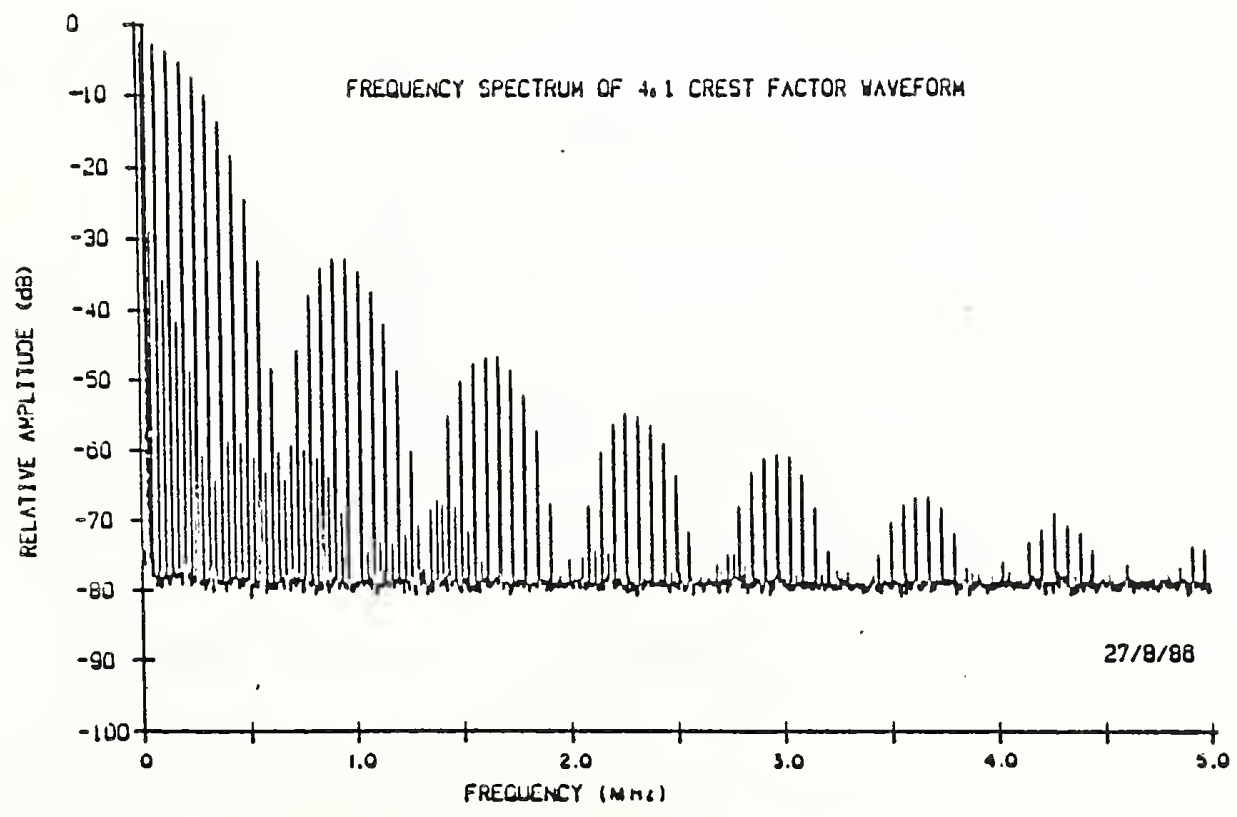

Fig. D-2, Frequency Spectrum of Crest Factor Test Signal 


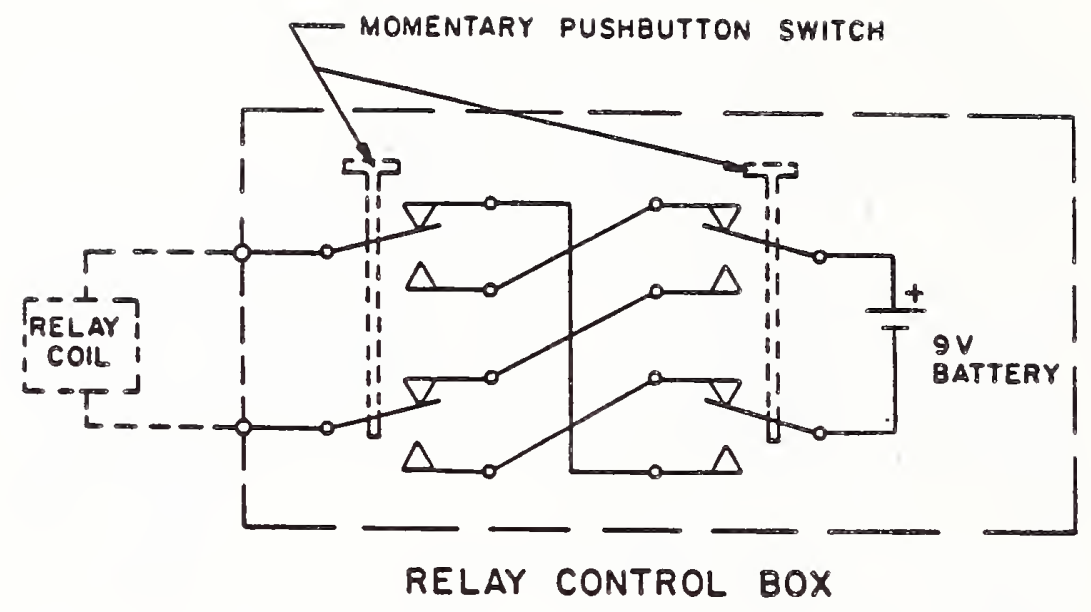

Fig. D-3, Circuit Dlagram of Relay Control Box

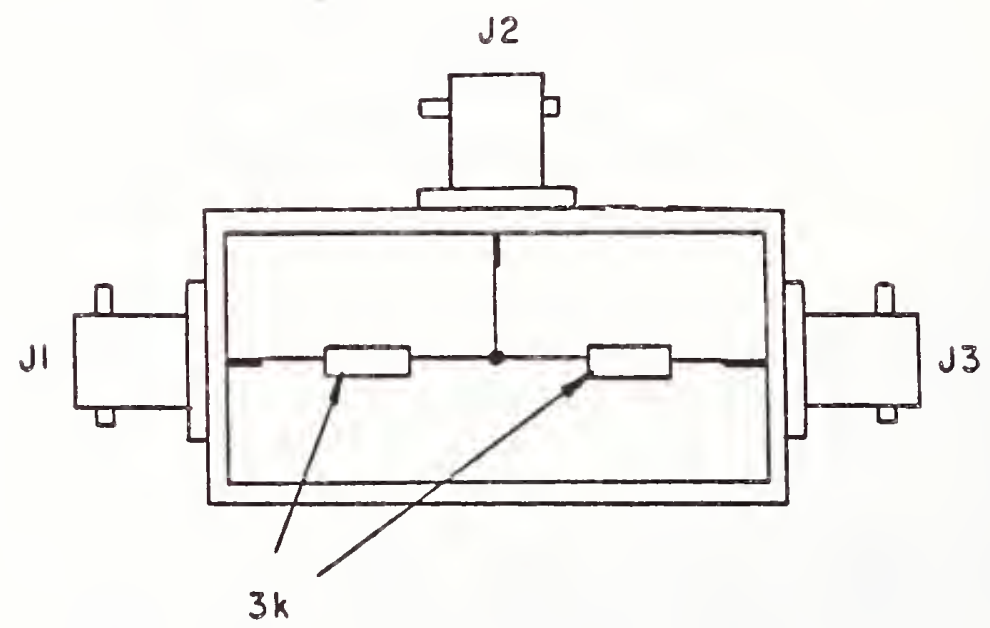

Fig. D-4, Resistor Junction Box, $3 \mathrm{k} \Omega$, Assembly Drawing 
APPENDIX E

EQUIPMENT LIST FOR RMS VOLTMETER TESTS

E - 1 


\section{EQUIPMENT LIST for RMS VOLTMETER TESTS ${ }^{3}$}

Function Generator

Wall Clock, commercial item
Hewlett-Packard $3325 \mathrm{~A}$ or equival

To describe the system discussed adequately, commercial equipment and parts are identified by the manufacturer's name and model number. In no case does such identification imply a recommendation or endorsement by the National Bureau of Standards, nor does it imply that the material or equipment identified is necessarily the best available for the purpose. 
1. For an interesting discussion of analog meters, see Soisson, Harold E., Electronic Measuring Systems, McGraw-Hill Book Company, Inc., New York, 1961, pp. 182-188.

2. B. Gilbert, "A precise four-quadrant multiplier with subnanosecond response," IEEE J. Solid-State Circuits, Vol. SC-3, pp. 365-373, December 1968 .

3. S. K. Ammann, Integrating Analog-to-Digital Converter, U. S. Patent No. 3,316,547, April 25, 1967.

4. R. C. Kime, Jr., The Charge-Balancing A-D Converter: An Alternative To Dual-Slope Integration, Electronics, May 24, 1973.

5. G. Grandbois, T. Pickerell, Quantized feedback takes its place in analogto-digital conversion, Electronics, pp. 103-107, October 13, 1977.

6. E. R. Hnatek, A User's Handbook of $D / A$ and $A / D$ Converters, John Wile \& Sons, New York, 1976.

7. L. Mattera, Converter Stresses Stability, Electronics, p. 139-140, February 19, 1976.

8. L. T. Jones, J. J. Ressmeyer, C. A. Clark, Precision DVM Has Wide Dynamic Range and High System Speed, Hewlett-Packard Journal, Vol. 32, No. 4, pp. 23-31, April 1981.

9. Requirements for Electrical Analog Indicating Instruments, ANSI C39.1. 1981 ; superceded by:

Direct Acting Indicating Analogue Electrical Measuring Instruments and their Accessories, IEC Publication $51-1984$

10. F. L. Hermach, "AC-DC Comparators for Audio-Frequency Current and Voltage Measurements of High Accuracy," IEEE Trans. on Instrum. \& Meas., Vol. IM-25, No. 4, pp.489-494, December 1976. 
NBS-114A (REV. 2-BC)

U.S. DEPT. OF COMM.

BIBLIOGRAPHIC DATA

SHEET (See in structions)

1. PUBLICATION OR REPORT NO.

NBSIR 88-3736
2. Performing Organ. Report Nof 3. Publication Date

722

MARCII 1988

4. TITLE AND SUBTITLE

Electrical Performance Tests for True-RMS Voltmeters

5. AUTHOR(S)

R.S. Turge T, O.B. Laug, T.E. Leedy

6. PERFORMING ORGANIZATION (If joint or other thon NBS, see instructions)

7. Contract/Grant No.

NATIONAL BUREAU OF STANDARDS

U.S. DEPARTMENT OF COMMERCE

8. Type of Report \& Period Covered GAITHERSBURG, MD 20899

9. SPONSORING ORGANIZATION NANAE ANO COMPLETE ADORESS (StreCt. CItY. StOte, ZIP)

U.S. Army Communications Electronics Command

Fort Monmouth, New Jersey 07703

10. SUPPLEMENTARY NOTES

Document describes a computer program; SF-185, FIPS Software Summary, is attached.

11. ABSTRACT (A 200-word or less factual summary of most significant information. If document includes a significant bibliography or literoture survey, mention it here)

Electrical performance test procedures for a true rms voltmeter were developed by the National Bureau of Standards for the U.S. Army Communications-Electronics Command. The report provided detailed, step-by-step test procedures that are based on the specifications supplied by the Army for the purpose of evaluating the bid samples of this type of instrument. Examples are provided of the data sheets and tables for recording of interim data and the final results.

This report discusses the philosophy underlying each of the measurement procedures from a point of view of the basic metrology required to perform the measurements. In addition, the sources of measurement error are discussed.

12. KEY WORDS (Six to twelve entries; alphabetical order: capitalize only proper names; and separate key wards by semicolons) Army specifications; rf voltmeter; test procedures; true rms voltmeter; voltmeter

13. AVAILABILITY

KX Unlimited

For Official Distribution. Do Not Release to NTIS

Order From Superintendent of Documents, U.S. Government Printing Office, Washington, D.C. 20402.

Forder From National Technical Information Service (NTIS), Springfield, VA. 22161
14. NO. OF

PRINTED PAGES

129.

15. Price

$\$ 18.95$ 


IR 88-3737

\section{CANCELLED}

\section{UNAVAILABLE FOR BINDING}





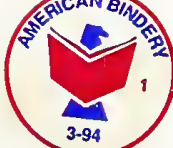


